The University of North Carolina at Greensboro

\title{
JACKSON LIBRARY
}

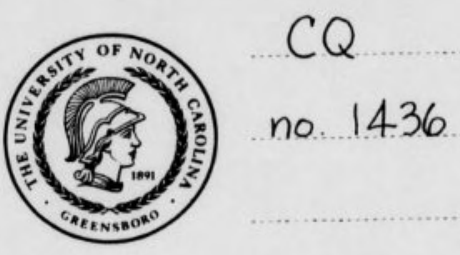

UNIVERSITY ARCHIVES 


\section{AESTRACT}

GUANCI, JOSEFH J. Applications of Ion-Selective Electrodes: (1) Development of a Thiamine Ion-Selective Electrode. of the Ion-Selective Electrode Apparatus. (1976) Directed by: Dr. Harvey B. Herman. Pp. 112.

The development of a thiamine ( $v$ itamin $B_{1}$ ) ion-selective electrode has been investigated. The perticular type of electrode employed was a liquid membrane electrode composed of an 1on-exchanger solution consisting of thiamine-bramothymol blue acid dye salt in a water imiscible solvent one-half octanol-l, one-half chlorof orm. Several properties of the thiamine liquid membrane electrode were studied: response, reproducibility, and $\mathrm{pH}$ dependence. The primary purpose of the thiamine electrode was to determine the concentration of thiamine commonly found in commercially avallable multi-vitamin preparations. The thiamine electrode was tested in the presence of diverse substances normally found in these vitamin preparations. These interference substances were vitamin $\mathrm{B}_{6}$ (pyridoxine monohydrochloride), vitamin $\mathrm{E}_{2}$ (riboflavin), vitamin C (ascorbic acid), vitamin $B_{3}$ (nicotinamide), and vitamin $B_{5}$ (d-calcium pantothenate). Because of the large number of standard rout ine samples needed to be analyzed when determining the potential response of lon-selective electrodes, a hard-wire autanatic solution addition instrument has been developed which handles addition of a stock solution to desired volumes either by manual control or by an automatic control. In conjunction with this unit, a data recording system was devised to store the electrical potential readings of the electrode cell for the different concentration ranges studied. 


\title{
APPLICATIONS OF ION-SELECT TVE \\ ELACTRODES
}

\author{
by \\ Joseph James Guanc1, Jr.
}

A Thesis Submitted to

the Faculty of the Graduate School at

The Untversity of North Carolina at Greensboro

in Partial Fulfillment

of the Requirements for the Degree

Master of Selence

\section{Greensboro} August, 1976

Approved by

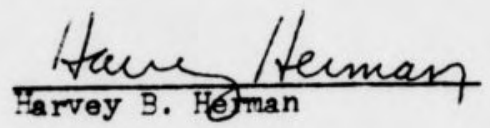


This thesis has been approved by the following committee of the Faculty of the Graduate School at the University of North Carolina at Greensboro.

Thesis Adviser Itany B. Herman

Committee Members

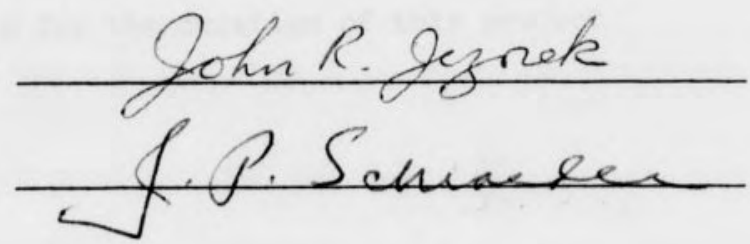

August 5, 1976

Date of Oral Examination 


\section{ACKNOWLEDGEMENTS}

The author wishes to thank Dr. H. B. Herman for his guidance and encouragement during this project and in the preparation of this thesis. The author woild also like to express appreciation to the entire staff of the Chemistry Department at the University of North Carolina at Greensboro. To Joy Lent and Susan Hardaway, the author expresses gratitude for their perseverance and technical aid in the typing of this thesis.

The author also wishes to acknowledge the financial ald offered by the University of North Carolina at Greensboro in the form of a graduate assistantship for the duration of this project. 
TABIE OF CONTENTS

Fage

ACKNOWLEDGEMENTS

IIST OF TABLES .

v1

LIST OF FIGURES

vi1

PAPT I DEVELOPMENT OF A THIAMINE ION-SELECTIVE ELECTPODE

CHAPTER

I. INTRODUCTION $\ldots \ldots \ldots \ldots \ldots \ldots \ldots \ldots \ldots \ldots \ldots \ldots \ldots, \ldots \ldots \ldots$,

II. THEORY OF ION-SELECTTVE EIECTPODES $\ldots \ldots \ldots \ldots \ldots \ldots, 3$

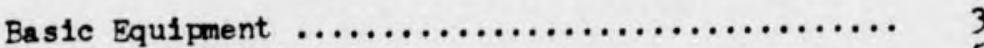

The Nernst Equation $\ldots \ldots \ldots \ldots \ldots \ldots \ldots \ldots \ldots \ldots, 5$

Methods of Analysis $\ldots \ldots \ldots \ldots \ldots \ldots \ldots \ldots \ldots \ldots$, ,

III. BASIC MEMBRANE SENSORS EMPLOYED IN ION-SELECTIVE

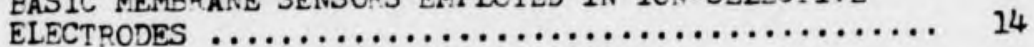

Glass Membrane Electrodes ................. 14

Crystal Nembrane Electrodes .................. 16

Liquid Membrane Electrodes ................... 18

IV. APPLICATIONS OF ICN-SELECTIVE EIECTPCDES $\ldots \ldots \ldots \ldots, 25$

Modifled Membrane Electrodes ................ 25

Blological and Clinfeal Uses of Membrane
Electrodes $\ldots \ldots \ldots \ldots \ldots \ldots \ldots \ldots \ldots \ldots \ldots \ldots \ldots \ldots \ldots \ldots \ldots$

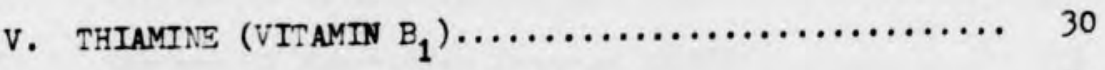

Physical Properties ....................... 30

Biologieal Importance $\ldots \ldots \ldots \ldots \ldots \ldots \ldots \ldots \ldots \ldots, 31$

VI. DEVELOPNENT OF A THIAMINE LIQUID MEMPPANE

ELECTRODE $\ldots \ldots \ldots \ldots \ldots \ldots \ldots \ldots \ldots \ldots \ldots \ldots \ldots \ldots \ldots \ldots, 33$

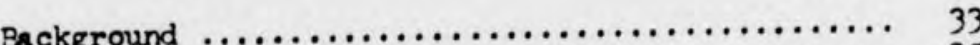

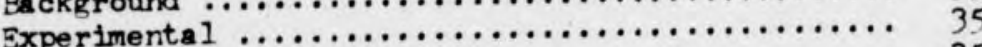

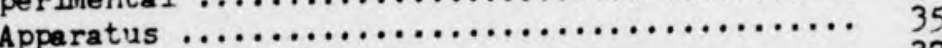

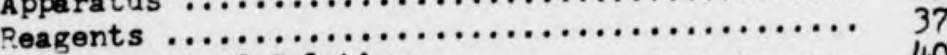

Freperation of Solutions .................. 40

Ion-exchanger Solutions .................. 40

Euffer Solutions ...................... 46

Thiamine Hydrochloride Solutions ......... 47 
lquid Membrane Electrode's Internal irence Solution ..................... 49

- Solutions ......................... 49

The Thlamine Stock Solution .............. 52

Methods of Ana lysis .................... 53

The General Procedure for an Experiment

Employling a Liquid Membrane Electrode Cell .. 55

The Progressive Procedure for Determining the

Most Suitable Iiquid Membrane Electrode for

Thlamine Ana lysis ...................... 58

The 1:l Chlorof orm-0ctanol-1 Liquid Membrane

Electrode

VII. DISCUSSION AND CONCLUSIONS $\ldots \ldots \ldots \ldots \ldots \ldots \ldots \ldots, 73$

PART II AUTOMATION OF THE ION-SELECTIVE ELECTRODE APPARATUS

CHAPTER

I. INTRODUCTION $\ldots \ldots \ldots \ldots \ldots \ldots \ldots \ldots \ldots \ldots \ldots \ldots \ldots \ldots \ldots \ldots \ldots \ldots, 78$

II. CIPCUIT DESIGN AND CPEPATION $\ldots \ldots \ldots \ldots \ldots \ldots \ldots \ldots, 80$

III. RESUITS AND DISCUSSION $\ldots \ldots \ldots \ldots \ldots \ldots \ldots \ldots \ldots \ldots, \ldots \ldots \ldots$

Sunmary $\ldots \ldots \ldots \ldots \ldots \ldots \ldots \ldots \ldots \ldots \ldots \ldots \ldots \ldots, 9,9$

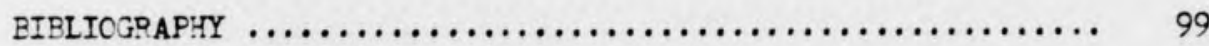

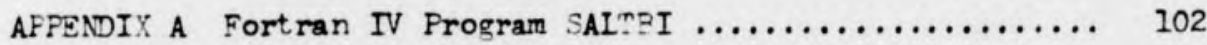

APPENDIX \& Fortran IV Program SALTIV $\ldots \ldots \ldots \ldots \ldots \ldots \ldots \ldots \ldots \ldots$

APPGNDIX C Fortran IV Subroutine Frogram FREE $\ldots \ldots \ldots \ldots \ldots .108$

APPENDIX D Fortran IV Subrout 1ne Program LINFTT $\ldots \ldots \ldots \ldots \ldots$ ill 
The Iiquid Membrane Electrode's Internal

Reference Solution ..................... 49

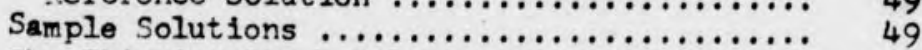

The Thiamine Stock Solution ............... 52

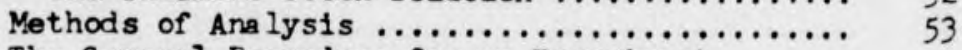

The General Procedure for an Experiment

Employing a Ifquid Membrane Electrode Cell .. 55

The Progressive Procedure for Determining the

Most Suitable Iiquid Membrane Electrode for

Thiamine Analysis ...................... 58

The 1:1 Chlorof orm-0ctanol-1 Liquid Membrane

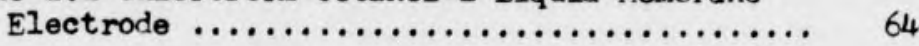

VII. DISCUSSION AND CONCLUSIONS $\ldots \ldots \ldots \ldots \ldots \ldots \ldots \ldots, 73$

PAPT II AUTOMATION OF THE ION-SELECTIVE ELECTRODE APPARATUS

CHAPTER

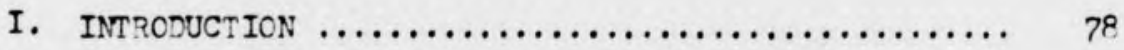

II. CIPCUIT DESIGN AND CPEPATION $\ldots \ldots \ldots \ldots \ldots \ldots \ldots \ldots, 80$

III. RESUITS AND DISCUSSION $\ldots \ldots \ldots \ldots \ldots \ldots \ldots \ldots \ldots \ldots \ldots \ldots \ldots \ldots, q_{4}$

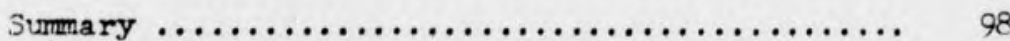

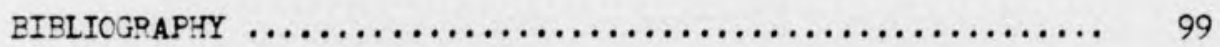

AFPENDIX A Fortran IV Frogram SAI'PI $\ldots \ldots \ldots \ldots \ldots \ldots \ldots \ldots, 102$

APPENDIX \& Fortran IV Frogram SALTIV $\ldots \ldots \ldots \ldots \ldots \ldots \ldots \ldots \ldots \ldots \ldots$

APPSNDIX C Fortran IV Subroutine Frogram FREE $\ldots \ldots \ldots \ldots \ldots, 108$

APPENDIX D Fortran IV Subrout 1ne Program IINFIT $\ldots \ldots \ldots \ldots \ldots$ 111 
1. Determining Factors to Calculate Ionic Strength

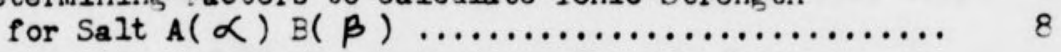

2. $\mathrm{pH}$ Dependence of the 1,2-dichloroethane Iiquid Membrane Electrode ........................... 59

3. Results for Various Liquid Membrane Electrodes

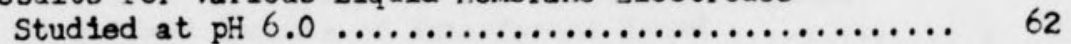

4. Symbol Designations for Figures 13 and $14 \ldots \ldots \ldots \ldots .68$

5. Analysis of Strip-Chart Pecomier Plot of Potential versus Fluoride Ion Concentration ............... 95 
Fage

1. Schematic Dlagram of an Ion-Selective slectrode Cell ....

2. Illustration of Electrode Response Towards Primary Ion $\mathrm{N}^{+2}$ and Interferent Ion $\mathrm{B}^{+2}$ Using Seperate

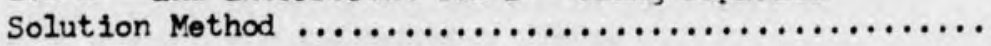

3. Illustration of Primary Ion $M+2$ Electrode ?esponse Using Fixed Amounts of Interferent Iont2 ............ 13

4. Diagram of a Glass Membrane Electrode $\ldots \ldots \ldots \ldots \ldots \ldots . . \ldots$

5. Diagram of a Crystal Membrane Electrode $\ldots \ldots \ldots \ldots \ldots \ldots .17$

6. Diagram of a Liquid Membrane Electrode ............... 19

7. Diagram of Ion-exchange Equilibrium Across the Iiquid Membrane Interface Eetween the Aqueous Fhase and the Organic Phase................................ 22

8. Schemat1c Diagram of an Automatic Analysis System ....... 28

9. Diagram of Molecular Structures for:

(A) Eramothymol Blue Dye Salt

(B) Riboflavin

(C) d-pantothenic acid

(D) Fyridoxtine Monohydrochloride

(E) Ascorbic Acid

(F) Nicotinamide

10. pH Dependence of the 1:1 Chloroform-Cetanol-1 IIquid

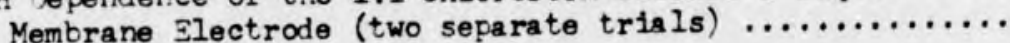

11. A working curve illustrating the response and reproduclbility of the $1: 1$ chloroform-octanol-1 11quid membrane elect-ode towards different thiamine concentrations

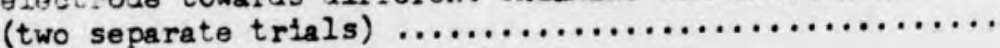

12. A working curve 1llustrating the response of the $1: 1$ chloroforn-octanol-1 liquid membrane electrode towards thiamine with and without sodium lon interference and towards sodium ion without thamine....

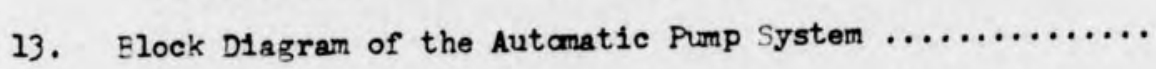


14. Schematic Diagram of the Circuit Design for the

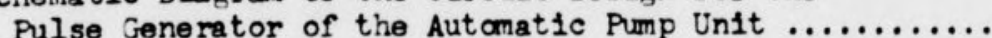

15. Schematic Diagram of the C1rcuit Design for the

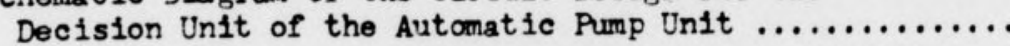

16. Ilustration of a strip-chart recorder scan of fluoride elect rode response towards five different fluoride concentrations using the automatic pump unit working

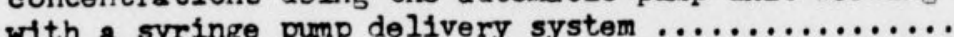


PART I

DEVELOFMENT OF A THIAMINE

ION-SELECTIVE ELDCTRODE 


\section{CHAPTER ONE}

\section{INTRODUCTION}

During the past years, a considerable amount of progress has been achieved in analytical potentiometry through the development and Introduction of lon-selective electrodes. These electrodes are not only employed in routine chemical analysis but, due to imaginative development, now have applicability to the analysis of biological and clintcal samples.

Scme advantages of lon-selective electrodes over alternate conventional analytical techniques are the selective rapidity of response towards the Ion or constituent of interest, its non-destructive character towards the semple being analyzed, the small quantity of sample needed for analysis, and, in most cases, the analysis of a sample without pretreatment. This last factor eliminates time consuming separations and chemical preparations. A very important a spect of the employment of lon-selective electrodes is the low initial cost and the easy avallability of the equipment required for elect rode systems.

Some disadvantages of Ion-selective electrodes are the frequency of the calibrations of electrodes and the temperature dependence. Also, in the Nernst equation there is the increasing uncertainty of the activity of an Ion as the charge on the ion increases and the uncertainty of the activity term due to the presence of foreign complexes and Ion-pairs.

Ion-selective electrodes have proved recently that they can be useful as probes for clinicel analysis, bicmedical monitoring, and 
micro-biological processes. ${ }^{1}$ These electrodes, in combination with biological materials, can form new sensors that selectively measure non-1onic, blological species in body fluids or living tissue. Miniaturized electrodes are highly userul for constant monitoring of blological fluids in vivo making them an important clinical tool, especisily in emergency situations. 


\section{CHAPTER TWO \\ THEORY OF ION-SELECTIVE ELDCTRODES}

\section{Essic Equipment}

As previously stated, the equipment needed for lon-selective electrode analysis is relatively inexpensive, easily available in chemical laboratories, and simple to assemble. The apperatus used for electrode mes surement consists of a voltmeter, an external reference electrode, and the Ion-selective electrode. Figure 1 depicts such an apperatus. The potential of the lon-selective electrode cell is measured by making electrical contact to the lon-selective eletrode and to the reference electrode which is in contact with the sample solution vis a selt bridge. The voltmeter connected across the two electrodes meesures the potential of the entire cell.

A simple voltmeter cannot be used because it draws a senell current from the cell which changes the cell potential being measured. A potenticmeter must be utilized to deteet the cell potent1al under zero current conditions. Alternately, comerelal high-input-impedance voltmeters using operational amplifiers which draw negligible current from the cell are capable of measuring cell potential accurately.

The reference electrode is assumed to be of fixed potential with no change of 11quid function potential during the course of an analysis. The reference electrode is a very important part of the complete cell and requires special care. In most cases, the lon-selective electrode cells consist of two reference electrodes; an intermal one within the ion-selective electrode that is in contact with a solution containing the lon to be detected and a salt suitable for the particular reference 


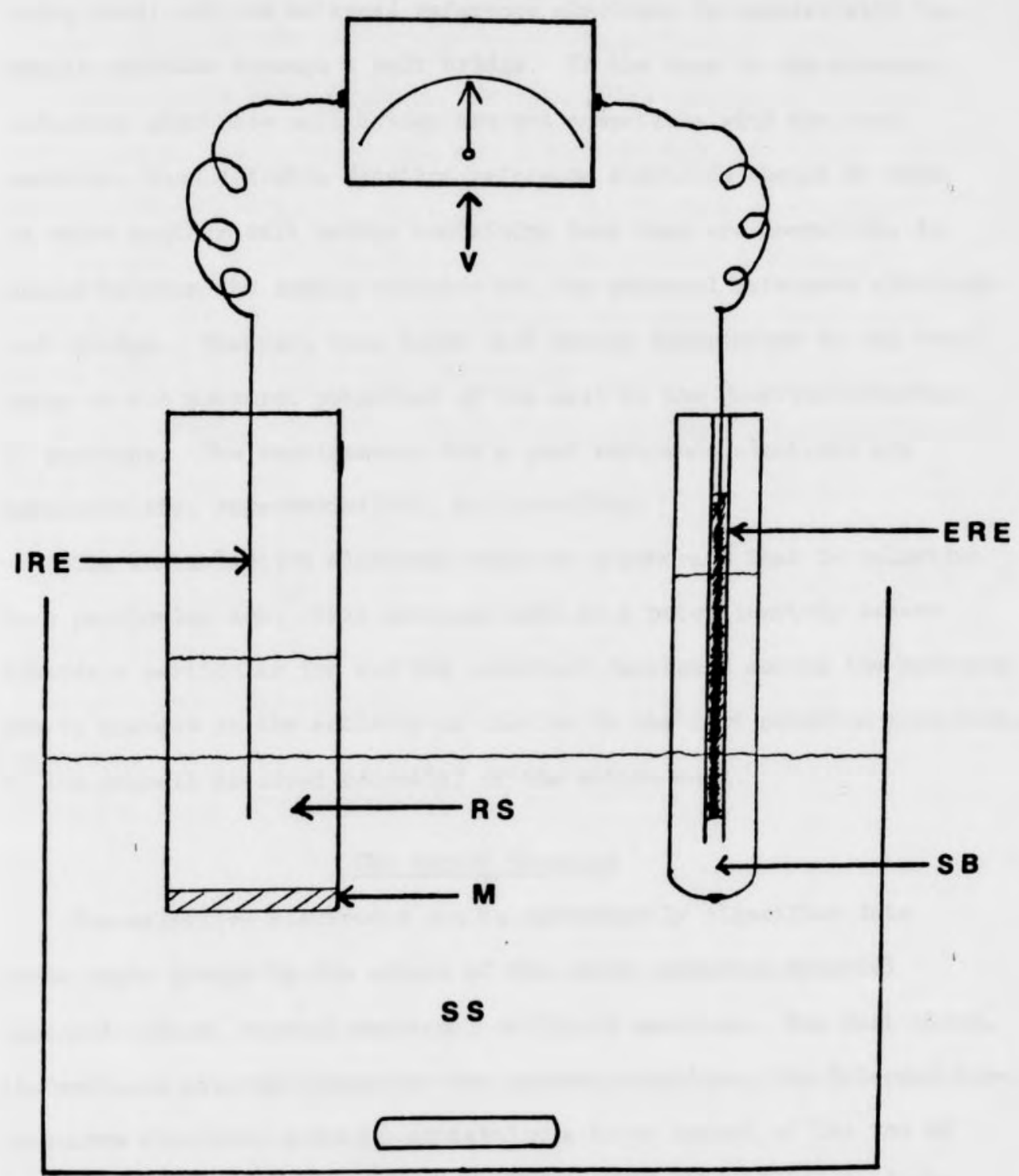

Figure 1. Schematic Diagram of an Ion-Selective Electrode Cell

IRE, internal reference electrode; $B R E$, external reference electrode; RS, Internal reference solution; $M$, membrane sensor; $S B$, selt bridge; SS, semple solution; V, voltmeter. 
being used, and one extermal reference electrode in contact with the sample solution through a salt bridge. If the fons in the external reference electrode salt bridge are not competible with the test solution, then a double junction reference electrode should be used In which another salt bridge containing lons that are compatible is placed between the sample solution and the external reference electrode salt bridge. However, this added selt bridge contributes to the total value of the mesured potential of the cell by the function potential it produces. The requirements for a good reference electrode are reversibility, reproducibility, and stability.

The inn-selective electrode contains a membrane that is selective to a particular 1on. This membrane acts as a potentiometric sensor towards a particular ion and the potential developed across the membrane due to changes in the activity of the Ion in the test solution contributes to the overall measured potential of the entire cell.

\section{The Nernst Equation}

Ion-selective electrodes can be conveniently classified into three basic groups by the nature of the active membrane materis employed: glass, crystal membrane, or liquid membrane. For most cases, the membrane material separates two aqueous solutions, the internal ionselective electrode solution containing a known amount of the fon of Interest and the sample solution containing an unknown amount of the Ion to be detected. The membrane is constructed to be as selective as possible to one particular 1on. All three types of membrane electrodes measure the activity of the desired lons in various sample solutions. When a membrane electrode is immersed in a sample solution, there is a 
momentary movement of lons across the membrane towards the solution containing the lower activity of the mobile lon. Because the lons have a charge, there is a point across this membrane where the fons cease to migrate due to an electrical potential which forms due to the transfer of the mobile lons and, eventually, an equilibrim results in which the potential across the membrane now contributes to the total potential of the entire cell.

When operating properly, the membrane electrodes obey the modified Nernst equation:

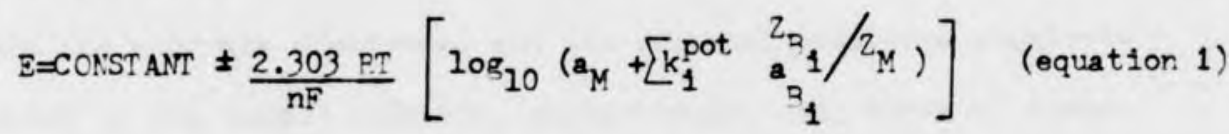

where:

$E=$ measured potential in millivolts

$R=$ gas constant

$\mathrm{T}=\mathbf{a b s o l u t e}$ temperature

$F=$ Faraday

$n=10 n i c$ charge of the ion to be measured

$a_{N}=$ activity of the ion to be measured in the sample solution

$a_{B_{1}}=$ activity of the interfering ions in the sample solution

$Z_{M}$ and $Z_{B_{1}}=$ ionic charges of the fon $M$ and interfering lons $B_{1}$, respectively $k_{1}^{\text {pot }}=$ selectivity constant

CONSTANT = potential of the reference electrodes and all junctions in the cell

Before the second tern of the right side of the Nernst equation the plus sign is used when considering the detection of cations and the minus sign is used when considering the detection of antons. Assuming 
there is an internal reference electrode in the membrane electrode, the total measured potential can also be represented by:

$$
\Delta E_{\text {mes sured }}=\Delta E_{\text {membrane }}+\sum E_{j}+E \text { (Int. ref.) }-\underbrace{}_{\text {(equation 2) }} \text { (ext. ref.) }
$$

where $\Delta E_{\text {membrane }}$ is the potential across the membrane due to the migration of the specific lon towards the solution of lower activity. $\Delta \mathrm{E}_{\text {membrane }}$ is related to the last term on the right hand side of equation 1. $\Sigma E_{j}, E$ (int. ref.), and $E$ (ext. ref.) refer to the potentisl due to all the functions in the cell, the internsl reference electrode within the membrane electrode, and the external reference electrode immersed in the semple solution, respectively. All three of these terrus are assumed to remain constant during the analysis of samples and, therefore, are represented as the "CONSTANT" in equation 1. $\frac{2.303 \mathrm{RT}}{\mathrm{F}}$ is the Nernst factor and depends on the temperature. The concentration of the lons is in terms of activity, which contains corrections for the interionic forces of all the lons in the sample solution.

The activity is determined by the equation:

$$
a_{M}=\gamma\left(c_{M}\right)
$$

where:

$a_{M}=$ activity of the ion $M$ being detected in the semple

$\gamma=$ activity coefficient of the Ion $M$ in the sample

$C_{M}=$ concentration of the fon $M$

The activity and concentrations are in terms of moles per liter.

To determine the activity coefficient, the best and the simplest

equation derived was from C. W. Davies ${ }^{2}$ : 


$$
-\log _{10} \gamma=\mathrm{Az}_{\mathrm{M}}^{2}\left(\frac{\sqrt{\mathrm{I}}}{1+\sqrt{\mathrm{I}}}-0.3 \mathrm{I}\right) \quad \text { (equation 4) }
$$

where:

$A=$ constant depending on temperature and solvent $(A=0.5115$ for water at $25^{\circ} \mathrm{C}$ )

$z=$ Ionic charge of the fon $M$ In the sample

$I=10 n i c$ strength of the solution represented by the term:

$$
I=\frac{i}{2} \sum_{1}^{1} c_{1} z_{1}^{2}
$$

where:

$c_{1}=$ concentration of every ion in the solution

$z_{1}=$ ionic charge of every ion in the solution

There is another more simple approach to determine I using a table derived from equation 5. The method uses factors multiplied to the salt concentration of the solution for each lonized salt in the solution to obtain the lonic st rength value. For example, use salt $A(\alpha) B(\beta)$ where $A$ and $B$ are the lonic parts of the salt with their lonic charge represented by $\alpha$ and $\beta$. The results are quite simple as shown in Table 1.

\section{$\underline{\text { Table } 1}$}

Deternining Factors to Calculate Tonic Strength for Salt $A(\alpha) E(\beta)$
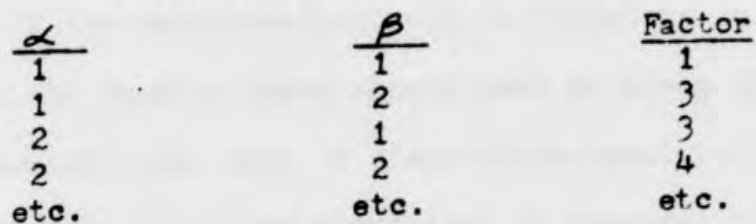

Once the factor is determined for each soluble salt in the sample solution, the ionic strength for the particular salt is then determined by multiplying its factor by the concentration (in molarity) of the salt. The total ionic strength of a sample solution is then calculated by 
suming all of the Individual lonic strengths of the constituent salts.

The selectivity term in the Nernst equation, $k^{\text {pot }}$, is a weighting factor related to the selectivity of the membrane electrode towards the fon of interest and an interfering ion. $k^{\text {pot }}$ is a combination of parameters! the lon-exhange equilibrium constant between the aqueous solutions and membrane, the mobilities of the lons, and the activity coefficients within the membrane phase. The selectivity constant Indicates the extent to which an interfering fon will alter the response of the membrane electrode. The lower the value of $k^{\text {pot }}$, the better the response of the electrode towards the Ion of interest. The selectivity constent is only an approximate value, but it allows some prediction of the kfind and the amount of interference that can be tolerated. The mathematical method for determining $k^{\text {pot }}$ will be discussed later.

\section{Methods of Analysis}

When using an Ion-selective electrode cell, it is necessary to calibrate the electrode system with standard solutions of know ton activity. A plot of mesured potential versus $\log _{10}$ of the activity of the specific ion for a range of different activities can then be used as a working curve to determine the unknown lon activity in sample solutions. If the membrane electrode is operating in an ideal Nernstian manner, then the working curve should have an array of data points forming straight line with a slope value equal to $\frac{2.303 \mathrm{PT}}{\mathrm{nF}}$ and an Intercept value equal to the "CONSTANT" of equation 1 . The slope and intercept values are calculated using a lineer regression approach where it is assumed that all error is in the $Y$ values, in this case the 
potential readings. Each $Y$ value error is weighted the same and it is assumed there is no error in the $X$ values, in this case $\log _{10}$ ectivity of the specific Ion. Depending upon the charge of the lon beling detected by the membrane electrode, the slope of the curve will be positive if the ion is a cation or negative if the ion is an anton.

There are two besic approaches to determine the selectivity constant used in the Nernst equation, the separate solution method and the mixed solution method. ${ }^{3}$ For the separate solution method, the potent is (m1llivolts) is plotted versus the $\log _{10}$ of the activity of the Ian of interest $M$, sometimes called the primary lon, and then the potential is separately plotted versus the $\log _{10}$ of the activity of the interfering Ion B. A plot for divalent cations is given in F1gure 2.4 There are two ways to use this method. The first is to choose the same activity values for both the $M^{+2}$ and $E^{+2}$ lons and determine the seloctivity constant $k_{M B}^{\text {pot }}$ by the equation 5

$$
\frac{E_{2}-E_{1}}{2.303 \mathrm{RT} / 2 \mathrm{~F}}=\log _{10} \mathrm{k}_{\mathrm{MB}}^{\text {pot }}
$$

where $E_{1}$ and $E_{2}$ are the potent1als due to the primary divalent ion $\mathrm{M}^{+2}$ and the interfering 10n $\mathrm{B}^{+2}$, spectively, at the log activity value chosen for both. The second way is to choose the same potential for both $\mathrm{M}^{+2}$ and $\mathrm{B}^{+2}$ lons, locate their log activities at this potential, and determine the selectivity constant by the equation ${ }^{5}$

$$
\frac{a_{M}}{a_{B}}=k_{M B}^{\text {pot }} \quad \text { (equation 7) }
$$

If the interfering lon has a charge $\mathrm{nt}$, then equation? becomes 


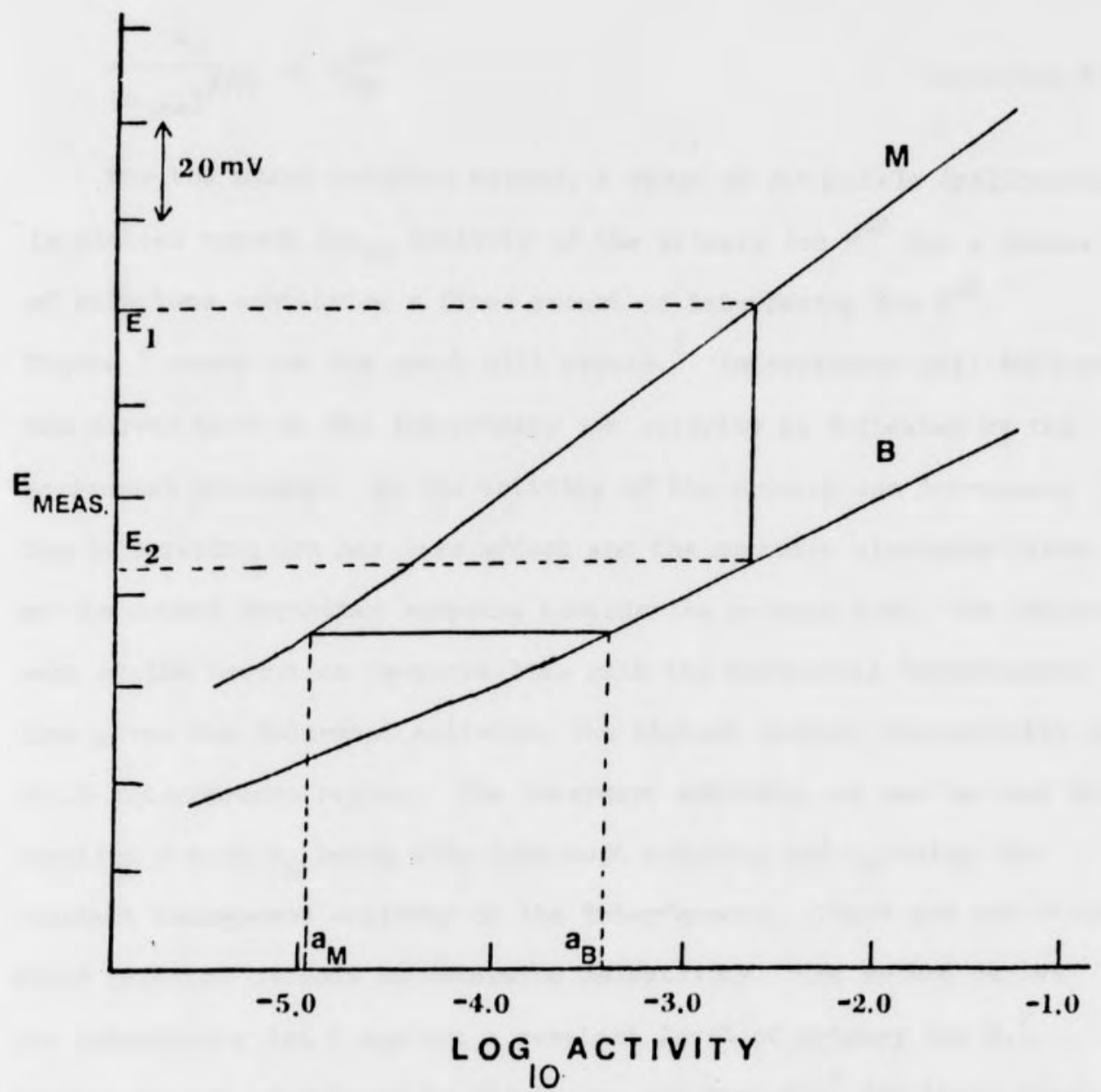

Figure 2. Illustration of Electrode Zesponse Towards Primary Ion $\mathrm{M}+2$ and Interferent Ion $\mathrm{E}^{+2}$ Using Separate Solution Nethod

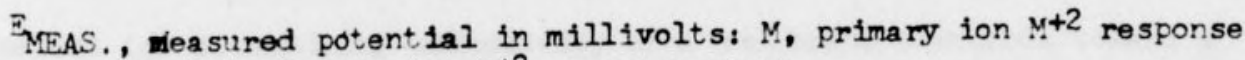
curve; $B$, interferent ion $\Xi^{+2}$ response curve. 


$$
\frac{a_{M}}{\left(a_{B^{n+}}\right)^{2 / n}}=k_{M B}^{\text {pot }}
$$

For the mixed solution method, ange of potentis is (millivolts) is plotted versus $\log _{10}$ activity of the primary ion $M^{+2}$ for a number of solutions containing a fixed amount of interfering ion $B^{+2}$. Figure 3 shows how the graph will appear. ${ }^{6}$ Interference will influence the curves more at the low primary lon activity as indicated by the horizontal plateaus. As the activity of the primary ion increases, the interfering Ion has less effect and the membrane electrode takes on its normal Nernstian response towards the primary lon. The intercept of the Nernstien response Ine with the horlzontal interference Iine gives the intercept activity, the highest primary ion activity at which interference begins. The intercept activity now can be used in equation? with $a_{M}$ being this intercept activity and $a_{B}$ being the constant background activity of the interference. There are two other mixed solution methods to determine selectivity. One method varies the interfering 1on $B$ against a constent level of primary lon $M .^{\text {? }}$ Another method, developed by Srinivasan and pechnitz ${ }^{8}$ for their treatment of mixed solution potential data using an anion liquid membrane electrode, included two equations derived for high and low selectivities.

When comparing the separate solution method to the mixed solution method for determining selectivity of a mem brane electrode toward a primary ion over an interfering one, the latter is preferred since it represents a more realistic approach in which the primary ion is in the same solution as the interfering lon. 


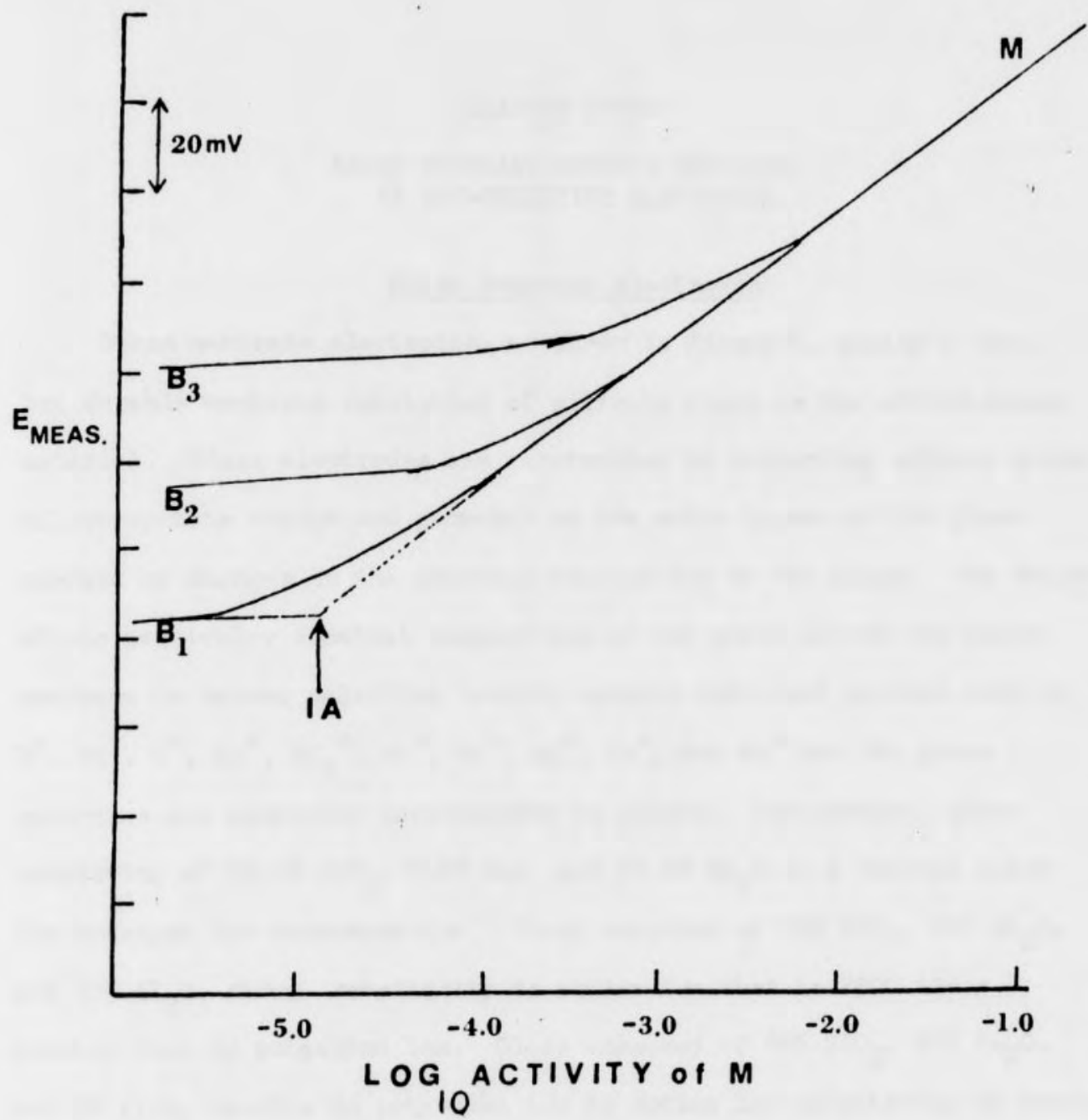

Figure 3. Illustration of Frimary Ion $\mathrm{v}+2$ Electrode Pesponse Using Fixed Amounts of Interferent Ion $\mathrm{B}^{+2}$

EIEAS., measured potential in millivolts; $M$, response of primary ion $\mathrm{N}+2$ at fixed concentrations of interferent ion $3+2$ where the concentrations are $B_{3}>B_{2}>B_{1} ; I_{A}$, intercept activity of $\mathrm{N}+2$. 


\section{CHAPTER. THREE}

\section{BASIC MEMBRANE SENSORS EMPLCYED \\ IN ION-SELDCTIVE ELECTRODES}

\section{Gless Membrane Electrodes}

Glass membrane electrodes, as shown in Figure 4, employ a thin but durable membrane consisting of silicate glass as the active sensor material. Glass electrodes are constructed by implanting anionic sites of appropriate charge and geometry on the outer layers of the glass surface by changes in the chemical composition of the glass. The choice of the perticular chemical composition of the glass allows the glass membrane to becone selective towards certain univalent cations such as $\mathrm{H}^{+}, \mathrm{Na}^{+}, \mathrm{K}^{+}, \mathrm{LI}^{+}, \mathrm{NH}_{4}^{+}, \mathrm{Rb}^{+}, \mathrm{Cs}^{+}, \mathrm{Ag}^{+}, \mathrm{Tl}^{+}$, and $\mathrm{Cu}^{+}$but the $\mathrm{glass}$ membranes are generally unresponsive to antons. For example, glass consisting of $72.26 \mathrm{StO}_{2}, 6.44 \mathrm{CaO}_{\text {, and }} 21.44 \mathrm{Na}_{2} \mathrm{O}$ is a typical glass for hydrogen ton determination. Glass composed of $718 \mathrm{S1O}_{2}, 117 \mathrm{Na}_{2} \mathrm{O}$, and $18 \mathrm{Al}_{2} \mathrm{O}_{3}$ shows sensitivity to sodium ion that is 2500 times greater than to potassium Ion. Glass composed of $68 \% \mathrm{S1O}_{2}, 278 \mathrm{Na}_{2} \mathrm{O}$, and $5 . \mathrm{Al}_{2} \mathrm{O}_{3}$ results in potassium ion to sodium ion selectivity of twenty to one. The explanation for the glass electrode response and selectivity is complicated but it involves surface ton exchange and ion diffusion principles. It should be noted that the lons do not migrate campletely across the membrane in glass electrodes. Pather, the fons in the internal reference solution of the glass membrane electrode and the sample solution approsche the center of the membrane, but do not migrate through a central dry glass layer. 


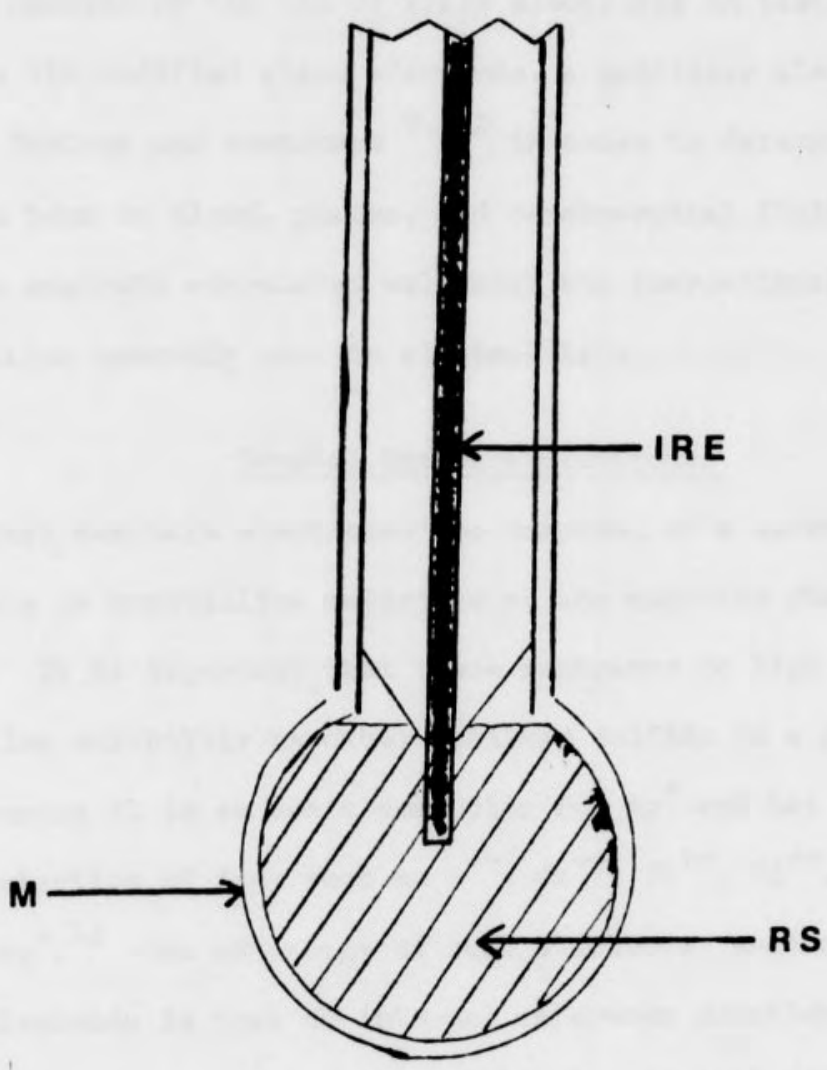

Figure 4. Diagram of a Glass Membrane Electrode

IRE, internal reference electrode $(\mathrm{Ag} / \mathrm{AgCl})$; $\mathrm{S}$, internel reference solution; $\mathrm{M}$, glass membrane. 
One example of the use of glass electrodes in testing biological fluids is the modified glass electrode, a capillery electrode, mede by H. D. Portnoy and coworkers 9,10 in order to determine sodium and potassium 1ons in blood, plasma, and cerebrospinal fluid. Their electrode anelysis correlated well with the conventional flame photometry determination commonly used in clinical labs.

\section{Crystal Membrane Electrodes}

Crystal membrane electrodes are camposed of a sensor made of solid-state or crystalline materials as the membrane phase as shown in Figure 5. It is important that these membranes be high ionic conductors and have low solubility in water. Silver sulfide is a good crystal matrix because it is an lonle conductor for $\mathrm{Ag}^{+}$and has been developed for the detection of lons such as $\mathrm{S}^{--}, \mathrm{Cu}^{++}, \mathrm{Pb}^{++}, \mathrm{Cd}^{++}, \mathrm{I}^{-}, \mathrm{Br}^{-}, \mathrm{Cl}^{-}$. $\mathrm{CN}^{-}$, and $\mathrm{Ag}^{+} .11$ One advantage of such electrodes such as the silver sulfide electrode is that no internal reference solution is needed if a metallic lead is connected directly to the crystal membrane. An excellent example of a crystal membrane electrode is the lanthanum fuoride electrode whose sensor is developed fran a single erystal of this salt doped with rare earth material to increse its electrical conductivity. ${ }^{12}$ Lanthanum fluoride conducts pluoride lons and its high selectivity towns fluoride is due to the size of the crystal lattice into which other lons cannot enter.

The lanthenum fluoride electrode has had considerable use in clinical analysis for determination of fluoride in blood serum in conjunction with a standard fluoride chemical test using morin-thortum 


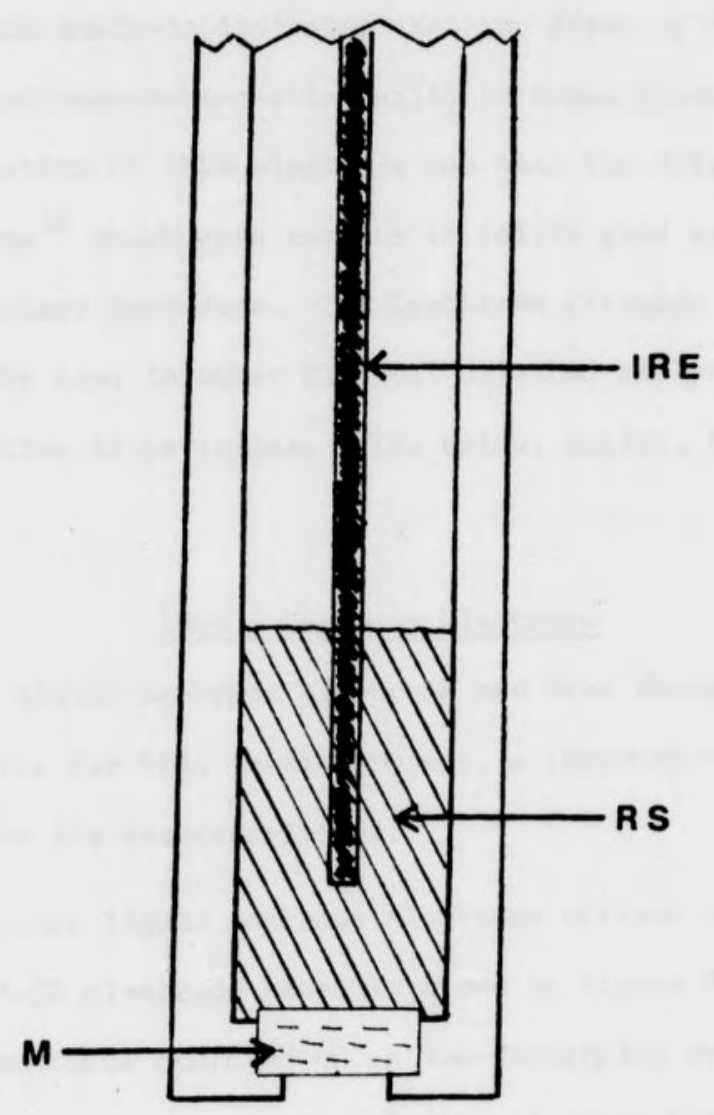

F1gure 5. Diagram of a Crystal Membrane Electrode

IRE, Internal reference electrode ( $A g / A g C 1) ; R S$, internal reference solution; $M$, crystal membrane. 
reagent. ${ }^{13}$ This analysis indicated that two forms of fluoride, exchangeable and non-exchangeable, extst in human blood serum. Another application of this electrode has been the determination of fluoride in bone ${ }^{14}$ which gave results in falrly good agreement with a clinical standard procedure. The lanthanum fluoride electrode has been extensively used in other clintcal orlented analyses such as fluortde detection in beverages, milk, urine, saliva, toothpaste, etc. .

\section{Ilquid Membrane Electrode}

Since the liquid membrane electrode has been chosen as the thiamine detector for this thesis project, a thorough description will be given of its characteristics.

A very popular liquid membrane electrode of fered commercially is the Orion 92-32 electrode assembly shown in Figure 6. This electrode consists of a membrane camposed of an lon-exchanging or carrying material dissolved in a water immiscible liquid phase that is held in an inert porous support membrane. By choosing an appropriate ionexchenging site and liquid phase, the liquid membrane can selectively respond to practically any destred ion. Because mobility of a desired Ion is the essential principle of forming a membrane potential, the liquid membrane offers a fine medium for this ion mobllity by providing a phase for lon diffusion.

As demonstrated in Figure 6, the membrane containing the active Ifquid phase is placed between two aqueous phases; the Internal reference solution in which the $\mathrm{Ag} / \mathrm{AgCl}$ reference electrode is immersed 


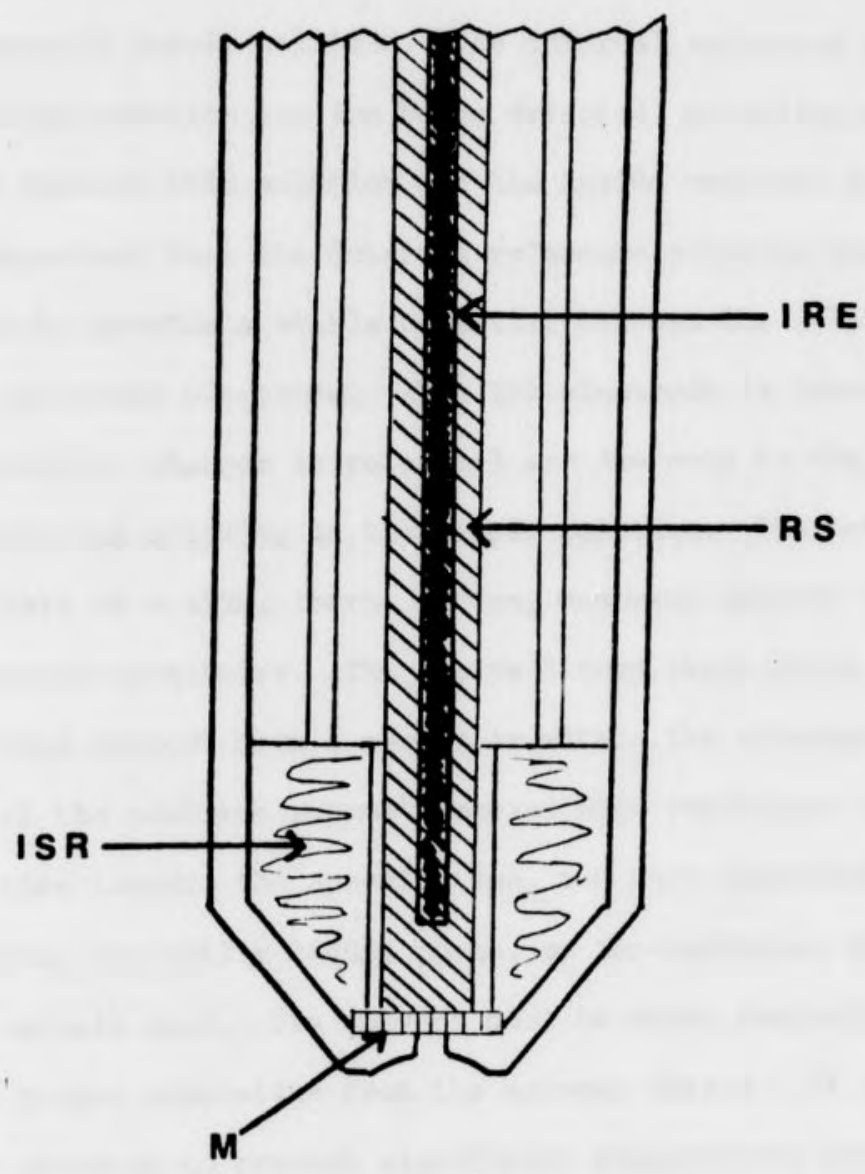

Figure 6. Diagram of a Liquid Membrane Electrode

IRE, internal reference electrode ( $\mathrm{Ag} / \mathrm{AgCl}$ ); $\mathrm{M}$, liquid membrane; ISR, 1on-exchanger solution reservolr; RS, internal reference solution. 
and the aqueous sample solution. The internal reference solution of the electrode contains the fon being detected, providing stable potential between this solution and the inside membrane surface. It is also important that the internal reference solution has chloride Ions so as to provide a stable potential between the solution and the internal reference electrode. When the electrode is immersed in the sample solution, changes in potential are due only to the changes in the specific ion activity in the sample solution. The active liquid phase is held in a thin, inert, porous, membrane support that usually has hydrophobic qualities. The active liquid phase wicks into the pores of this support fram a reservolr within the electrode body. The thinness of the membrane support removes high resistance and shortens response time towards the specific ion, two very important features.

Choosing the active liquid phase, or lon-axchanger solution, requires certain care. The solvent must be water immiscible in order to insure proper separation from the aqueous phases. It must have a low vapor pressure to prevent significant evaporation; heve a high viscosity to hinder rapid loss by outward flow across the membrane, a design that prevents contamination of the 1on-exchanger solution by sample material; and have good stability for a reasonable period of time. Usually, a low dielectric constant, organic solvent provides a good active liquid phase medium. In order for the desired ion to move across the membrane, a charged "site" of opposite charge or a neutral "site" that can trap the fon must exist in the membrane solvent phese. The fon and the site became neutral, undissocisted 
selt molecules in the solvent. This ion-site must have a relatively large non-polar area to prevent solubility in the adjacent aqueous loyers and to insure solubility in the organic, low dielectric constant, solvent phase. When the active liquid phase is in contact with the adjacent aqueous phases, an exchange equilibrium exists across the membrane interface between the lons of the aqueous phase and the lons of the ion-site molecule in the organic phase. This ion exchanging is depicted in Figure?. The ions move through the membrane towards the solution of lower activity by driving the equilibrium at the membrane interfaces to the right. Available sites keep "latching on" to other Ions of interest and contime to drive the reaction to the right until the potential across the membrane which opposes this reaction reaches a point where no further migration across the membrane is possible. The selectivity of the electrode depends upon choosing an appropriate site group that exchanges more readily with the desired ion in the presence of possible interfering lons in the sample. Also, cholce of the "site" depends upon how quickly lon-exchange equilibrium can occur with the ion of interest.

In the course of using a liquid membrane electrode, it is usually best to make the desired ion concentration of the internal reference solution approximately the same as that to be analyzed in the sample solution. This prevents a large concentration gradient between sample and internal ion solutions. Also, because of the outward flow of the active liquid phase, some slight drifting of potential is usually observed. If drifting is still excessive after proper conditioning of the electrode, there could be a defect in the electrode assembly or the 

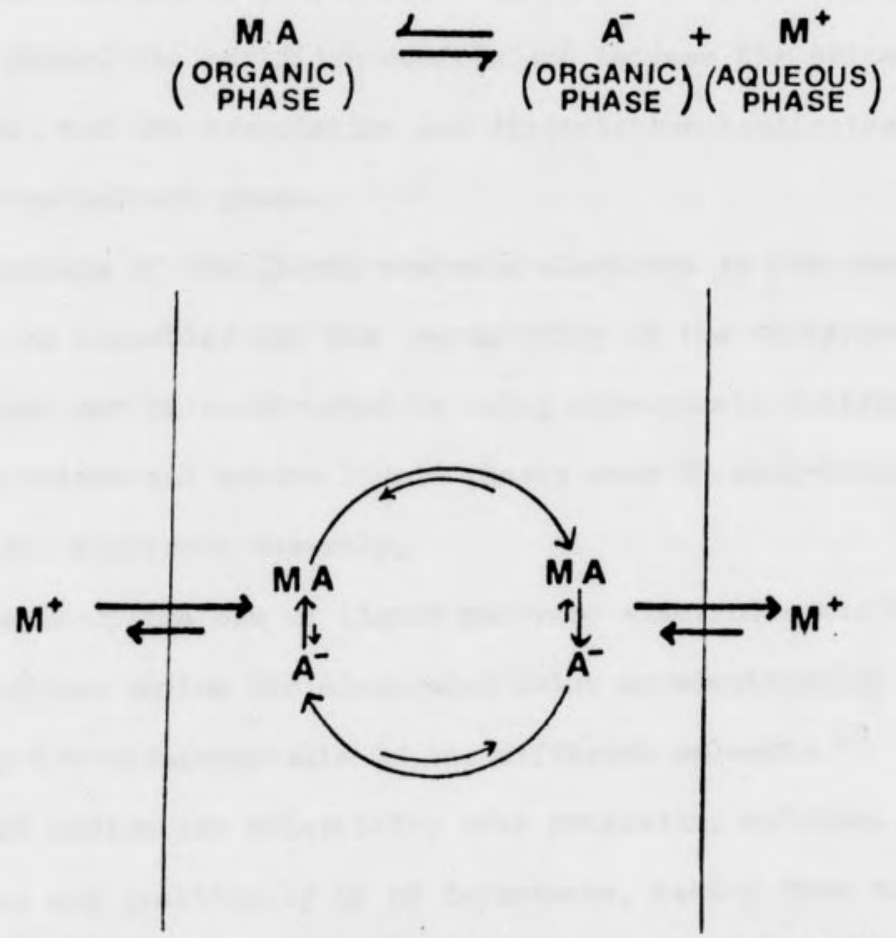

HIGH M ${ }^{+}$ACTIVITY

SOLUTION
MEMBRANE SOLUTION
LOW $\mathrm{M}^{+}$ACTIVITY SOLUTION

\section{Figure 7. Disgram of Ion-exchange Equilibrium Across the Ifquid Membrane Interface Between the Aqueous Phase and the Organ 1c Phase}

$\mathrm{M}^{+}$, specific mobile Ion (In this case anivalent cation); $\mathrm{A}^{-}$, Ionexchanger site. 
organic solvent used in the active liquid phase may not have the proper characteristics. It should be noted that the choice of solvent for the active 1iquid phase also determines selectivity of the liquid membrene electrode due to properties such as mobility of the lons in the solvent phase, the partition coefficlent between the solvent and aqueous phase, and the association and dissociation tendencles of the lons within the solvent phase.

The advantage of the liquid membrane electrode is the ease of which it can be assembled and the versatility of the different electrodes that can be constructed by using appropriste internal reference solutions and active liquid phases even if restricted to hering only one electrode assembly.

One example of the use of liquid membrane electrodes was the development of two sodium ion electrodes using an electrically neutral Iigand as the Ion-exchanger site In two different solvents. ${ }^{15}$ Eoth electrodes had sodium ton selectivity over potassium, calctum, and magnestum ions and practically no pH dependence, making them suttable for messurements in blood serum. A potassium ion electrode was developed using valinomycin as the fon-exchanger site giving an electrode with a high selectivity for potassium over sodium ion and diavalent cations. ${ }^{16}$ It was used for the direct determination of potassium ion in human serum and no significant complexing of potassium Ion appeared to occur in the serum. Rechn1tz and Herman ${ }^{17}, 18$ developed a carbonate liquid membrane electrode with high selectivity towards carbonate ton activity for the direct determination of the carbon dioxide content in human serum samples. 
A slight alteration of the liquid membrane electrode which employs an active IIquid phase has been the development of a dry membrane composed of the lon-exchanger material imbedded in a polymeric film. This is sealed to an electrode body containing an internal reference solution similar to the 11quid membrane electrode. Sametimes the lonexchanger solution functions as a plasticizer for the polymeric film or an additional plesticizer such as di(2-ethyl hexyl)-2-ethylhexylphosphonate (DOOP) or d1-n-decyl phthalate (DDP) is used. As a result, a complete ionexchanger membrane is formed from a polyweric film containing the lonexchanger and plasticizer in molecular dispersion with the advantages over the conventional liquid membrane electrode of having no gradual loss of the fon-exchanger solution, using only a small amount of the ionexchanger solution for the membrane construction, and the easy replacement of an old membrane with a new one. A short review by Koryta ${ }^{19}$ of this type of lon-exchanger membrane has recently appeared. 
CHAPTER FOUR

\section{APPLICATIONS OF ION-SELECTIVE ELDCTRODES}

\section{Modified Membrane Electrodes}

Many types of electrodes for clinteal and biological analysis have been developed using one of the three besic lon-selective electrode sensors in combination with other analytical and elinical construction techniques. Scme examples of these modifled electrodes are gas-sensing electrodes, b1oprobes which use biological substrates in conjunction with membrane electrodes, and microelectrodes.

The gas-sensing electrodes are camprised of a conventional membrane electrode, contacted by a solution conteining lons the membrane electrode can selectively detect, which is then completely surrounded by a gas permeable, hydrophobic membrane. When the ent1re gas electrode is immersed in a sample solution, the gas permeeble membrane allows only the free passage of the dissolved gas from the sample into the inner solution layer surrounding the membrane electrode, shifting the equilibrium of this inner solution which is detected by the membrane electrode. One example described in the literature is the determination of $\mathrm{pCO}_{2}$ by direct measurement with a carbon dioxide gas-sensing electrode. 20

A fairly new area that is under investigation is the bloprobe that uses a conventional membrane electrode surrounded by specific biological materials, such as enzymes or proteins, to produce sensors that selectively detect blological species in body fluids and living tissue. Cne bloprobe is the urea enzyme electrode in which the urease enzyme is Imoblized 
around an armonis membrane glass electrode. 1 The urease hydrolyzes the urea in a biological sample to form carbonate and ammonium lons. The ammonium Ions are detected by the membrane electrode and thus the cell potential is related to the uree activity in the sample. There are many other examples of these bloprobes using vartous cambinations of blological materials and membrane electrodes. A short review of these bioprobes has been organized by G. A. Rechnitz ${ }^{1}$ discussing the construction and use of bioprobes.

A relatively new development hes occurred for lon-selective electrodes by the construction of microelectrodes. ${ }^{1}$ These microelectrodes should respond no differently from their larger models except very speciel care must bo taken in the englneering design. Two types of microolectrodes doveloped so far are the open-t1p micropipet electrode and the closed-tip microelectrode. The open-t1p micropipet electrode cantains an active liquid lon-exchanger solution in which the membrane surface has been reduced to a single pore epproximately 0.5 to $1 \mu$ in in diameter. The closed-t1p microelectrode uses a glass sensor as the membrane surface and this electrode has a size range of 100 to $500 \mu \mathrm{m}$. This small size allows the closed-tip microelectrode to be instelled in a hypodermic syringe needle along with an external reference electrode.

\section{Blologicel and Clinical Uses of Membrane Electrodes}

Today instrumentation has become an integral pert of blological. clinical, and blanedical analysis. Many different analytical techniques are used to determine constituents in blological and medical samples. 
A large portion of these analyses are carried out by automatic systems. Two advantages of using automated analysis equipment are reliability of the anaiysis results and the ability to analyze a large number of samples quickly. For most instrumental anslyses, pretreatment of samples is necessary. The time used in this process can vary, depending upon the method chosen for analysis. Using 1onselective electrodes has many benefits. Being highly selective, they may need very little pretreatment of sample or none at all. They offer a relatively inexpensive analytical mothod that can give reproducible results comparable to conventional clinical methods that may be slower or require more care and maintenance. Also, membrane electrodes supply quick sample results, making them Ideal to be employed in automated systems where large number of samples have to be analyzed.

One autcated electrode sampler system is shown in Figure $8 .{ }^{21}$ The sampler contains a number of samples to be analyzed. A proportioning pump pulls the sample and any other needed components simultaneously towards the electrodes. The sample solution flows through a mixing co1l, a drop chamber disconnector which debubbles the sample and reduces olectrical noise, and finally enters the membrane electrode and reforence electrode through flow caps which have a reservolr where the sample is in contact with the electrode sensors. The sample enters and leaves by means of inlot and outlot tubing and is discarded after analysis. The system can be autcomatically washed to be used again for the next semple. Compentes 11ke Ortion Research and Technicon have developed autcatic electrode analyzers that can determine more than one type of constituent from one sample and can analyze many samples within a short time. 


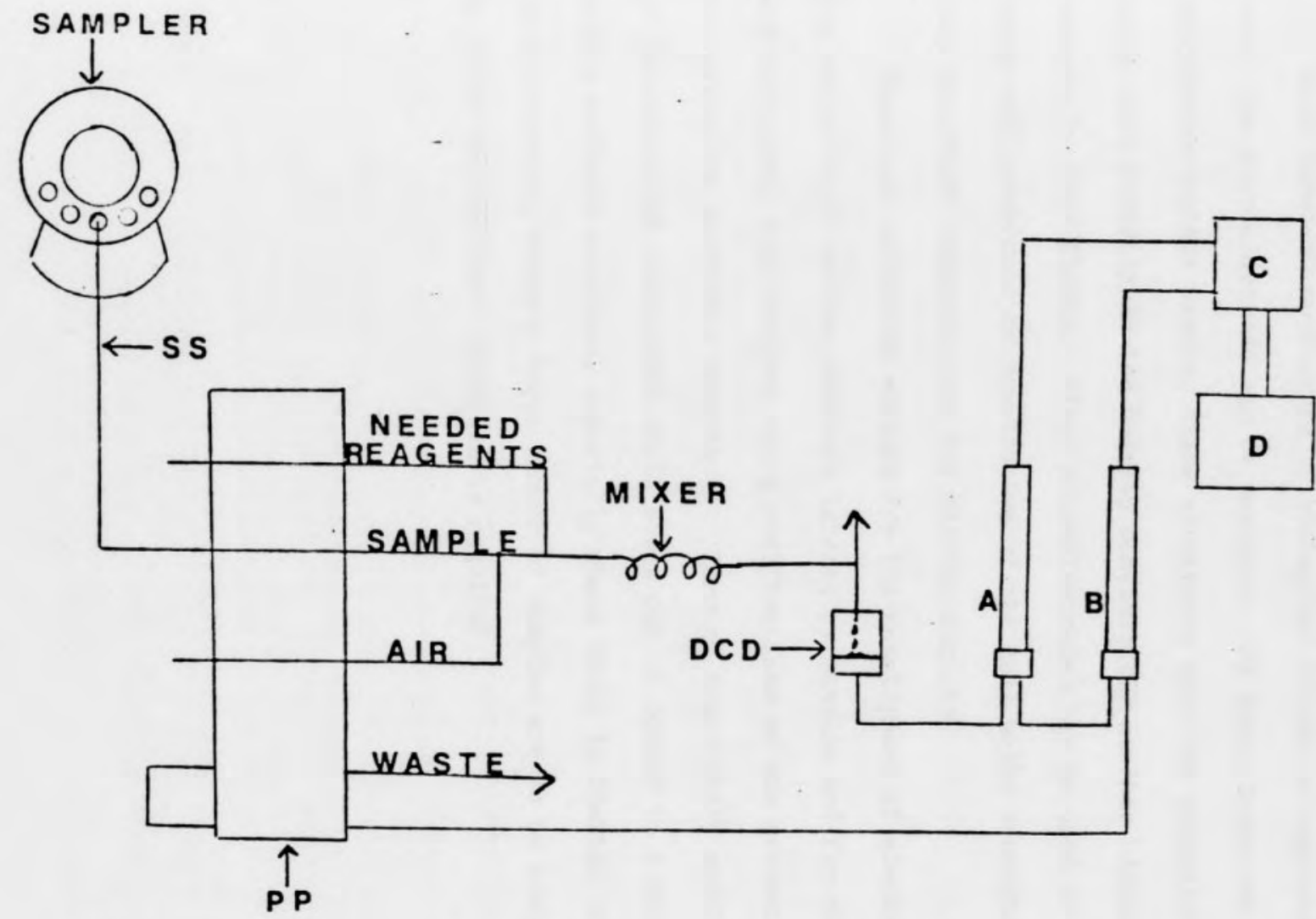

Figure 8. Schematic Diagram of an Automatic Analysis System

SS, sample solution; DCD, drop chamber disconnector; PP, proportioning pump;

$A$, ion-selective electrode; $B$, external reference electrode; $C$, voltmeter;

D, recorder. 
When constant monitoring of biological fluids is required in vivo, the microelectrode can be employed. By their insertion in a hypodernic syringe needle, these electrodes have the capability of being used directly in the body to continuously monitor blochemics l changes in body fluids. Also, microelectrodes can be used to directly study cell processes by penetration of the cell walls providing a very important research tool for microbiologists.

There are unlimited sources for the development of electrodes for analysis of routine chemical laboratory samples and for clinical and biological applications using modiffeations of the conventional 1on-selective electrode techniques. Through imaginative application of ion-selective electrodes whole areas can be opened to a means of quick, reliable analysis, especially where study is limited to small sample amounts, where a large number of samples are to be analyzed, or where "on-the-spot" analysis is required. 
CHAPTER FIVE

THIAMINE (VTTAMIN B $B_{1} 22,23,24$

\section{Physical Properties}

Thiamine can exist in the chloride hydrochloride form or the mononitrate form with the structure<smiles>Cc1ncc(CN=CCO)c(C)n1</smiles>

Thiamine hydrocholoride hes molecular weight of $337.28 \mathrm{~g}$ and Is formed as white crystals of monoclinic plates in rosette-like clusters with yeasty odor and bitter taste. Fractically all of the thiamine hydrochloride sold is synthetic. Thiamine hydrochloride is highly soluable in water in which one gram dissolves in about one milli1iter. It absorbs up to one mole of water in alr of average humidity. The wer can be removed by drying at $100^{\circ} \mathrm{C}$ or in a vacuum over sulfurte acid. In the dry form, thiemine hydrochloride is very stable and heating at $100^{\circ} \mathrm{C}$ for twenty-four hours does not cause decomposition nor aj.ter its potency. However, in aqueous solution, thiamine hydrochloride is sensitive to reduction and axidation. In neutral or alkaline solutions 1t is destroyed rapidly, but in acid solutions it can be sterilized by heating. Thismine hydrochloride occurs in natural foods and in animal 
tissue in the free form or in combined form. The acid dissociation constent of thiemine is $1.58 \times 10^{-5}$. It exists in various amounts in different sources. Yeast, cereal, grains, pork, and nuts are high in thianine hydrochloride.

Thiamine mononitrate has a molecular weight of 327.36 and is prectically nonhygroscopic. 2.7 grams dissolve in about $100 \mathrm{ml}$ of water at $25^{\circ} \mathrm{C}$. Aqueous solutions at a pH of 4.0 show greater stability than neutral solutions. Thiamine mononitrate is much more stable than the hydrochloride, making this thiamine form preferred and recommended for use in flour mixes and in preparation of vitamin capsules.

\section{Blological Importance}

In the human body free thiemine exists in the blood pla sma and cerebrospinal fluld in a concentration of about one microgram in one hundred milliliters. In the blood cells, the thiamine exists as the pyrophosphates in protein combination in a concentration of about six to twelve micrograms in one hundred milliliters. The body stores the thlamine it needs and excretes the excess. The stored thiamine is depleted in a short time and must be replaced by daily intake. Any excess thiamine is usually excreted in the urine, which contains only the free form. Normal urinal excretion of thiamine from an individual with adequate intake is at lesst fifty micrograms daily. Thiamine deficiency is characterized by loss of appetite and weight causing. in its advanced stages, the disease known as bertbert in which there is an incresse of pyruvate and lactate levels in the blood and possible degenerate changes of several peripheral nerves. 
Mumercus methods have been developed to test for thiamine incorporating animal assays and microblological, chamical and physical methods. Of the chemical methods, the preferred way at present to test for thiamine in body fluids and tissue is the oxidation of thiamine to thiochrome, which is a highly fluorescent species that can be easily measured using pluorometry. 25

A complete revilew of this thiochrome method and other thiamine analysis methods has been organized by K. A. Valsalan. 26 


\section{CHAPTER SIX}

\section{DEVELOPNENT OF A THIAMINE LIQUID MEMERANE ELECTRODE}

\section{Beckground}

The developnent of a thiamine liquid membrane electrode has been claimed by Ishibasht, Kine, and Maekawa. 27,28 Their thiamine electrode consists of an exchange site, tetraphenyl borate, in a 1,2-dichloroethane solvent. The response of the thismine electrode is Nernstian for a bivalent species. Selectivity is high for thiamine over sodium, potassium, and ammonium lons but is inadequate for the detection of mixtures containing pyridoxine monohydrochloride (vitamin $B_{6}$ ). Also, the description of the sample solution preparation is totally inadequate. The authors noted that thiamine is stable only at a low $\mathrm{pH}$ range but do not specify how the sample solution was pH controlled or if it was pH controlled at all.

A photometric method for the analysis of thiamine based on an extraction technique has been developed by Des Gupta and Cadwallader. ${ }^{29}$ The method employs the formation of the thiamine-branothymol blue salt and its extraction from an aqueous into an organic phase, the best solvent being chloroform. The reaction between the branothymol blue dye and the thiamine is considered to be a simple acid-base reaction where the dye is a strong acid and the thiamine is a bese. The site of reaction in thiamine may be either the amino group or the quaternary nitrogen with the sulfonic acid group of the dye. 29,30 The concentration 
of the thiamine in the aqueous solution is then determined photometrically by measuring the absorbance of the organtc solution. The thiaminebromothymol blue salt is more soluble in the organic solvent than the aqueous solution. This extraction process has been determined to be pH dependent with a $\mathrm{pH}$ of $6.6 \mathrm{giving}$ the optimum condition for extraction. Two mathematical approaches with supporting experimental data have been performed on the effect of $\mathrm{pH}$ and bramothymol blue dye concentretion on the extraction of the thiamine-bramothymol blue salt by an organic solvent. 30,31 An important feature of this mothod is the lack of interference from other vitamins, hormones, and other blological substances.

In the course of the development of a thiamine liquid membrane electrode, the thiamine electrode produced by IshibeshI, Kina, and Maekawa 27,28 and the extraction method of Des Gupta and Cadwallader 29 need to be considered. The liquid membrane electrode of Ishibeshi ot 21. hes low selectivity for thiarine over pyridoxine hydrochloride due possibly to the solvent used for the lon-exchanger solution. The lack of information concerning the $\mathrm{pH}$ dependence of the electrode's response towards thiamine concentration is a very importent factor if the electrode is to bo used effectively in practical analysis procedures.

For the thismine extraction method, pH dependence was noted for the extraction process of thiamine-branothymol blue salt with an organic solvent and lack of Interference from other common clinical substances was observed. Th1s extraction method offers an approach to a thiamine liquid membrane electrode by its use of an organic solvent (a plausible active IIquid phese), by the avallability of a possible ion exchenge site 
In the organic solvent (the thiamine-bromothymol blue salt), and, finally, by its high selectivity over the interfering substances commonly found in commercially prepared vitamin capsules.

\section{Experimental}

Apparatus.

The apparatus used for study of the thiamine liquid membrane electrode consists of a high impedance voltmeter, a commercially available liquid membrane electrode assembly, a double junction external reference electrode, a pH meter, a pH microelectrode, a constant temperature circulator, a jacketed beaker with a magnetic stirrer motor and stirring bar, a microplpet, and a ten milliliter full capacity buret.

The sample solution is contained in a jacketed beaker allowing a heat controlled transfer liquid to pass over the walls of the fonselective electrode cell and condition the sample solution to a desired temperature. The heat transfer liquid used is water and it is controlled and circulated using a Haake Constant emperature Circulator (Model FK). The semple is stirred by means of a magnetic stirrer motor and stirring bar.

The liquid membrane electrode is the Ionalyzer divalent cation electrode body, Model 92-32, developed by Orton Research Incorporated which uses thin porous membrane supports to hold the active liquid membrane phase. The external reference electrode is the 4857-H10 Double Junction Reference Electrode by Arthur H. Thomas Company. This contains a calomel element in an Inner section filled with saturated aqueous potassium chloride which is connected through a porous ceramic 
plug to the outer section containing a $1.0 \mathrm{M}$ aqueous sodium chloride solution. The junction with the sample is made through a porous ceramic plug in the t1p of the electrode. The liquid membrane electrode and external reference electrode are both positioned at an angle of $20^{\circ}$ with respect to the vertical by an Orion electrode holder in order to diminish the chance of alr bubbles getting trapped under the electrodes. Both electrodes are easily connected to the appropriate terminels in the voltmeter.

The voltmeter is an Orion Research Model 801 all-olectronic, highInput-impedance digitel $\mathrm{pH} / \mathrm{mv}$ meter that supplies a $\mathrm{pH}$ range from 0.000 to 13.999 in $0.001 \mathrm{pH}$ unit increments with apeatibility of \pm 0.001 pH unit. Also, when adjusted to the millivolt mode, the voltmeter supplies a range of +999.9 to -999.9 in 0.1 millivolt increments with a \pm 0.1 millivolt repeatibility. The date output is avilable as binarycoded decimals and the recorder output 1 s adjustable from 0 to 100 mill1volts for $\$ 1000$ millivolts or \pm ? $\mathrm{pH}$ units.

The pH electrode is a Fisher Scientific Microprobe Cambination Electrode, one fourth-1nch diameter version (Cat. No. 13-639-92) with the reference element solution being a $4 \underline{M}$ potassium chloride-saturated silver chloride aqueous solution. The $\mathrm{pH}$ meter used is a $\mathrm{pH} / \mathrm{pI}$. electrometer with dig1talizer/1ndicator (Models EU-200-30 and EU-200-62, respectively) produced by Heath Company. Some of its features are abllity to select cation, anion, or millivolt modes, automatic pH slope control, manual temperature control, or an opt1onal autcmatic temperature compensetion control. 
Minute volumes of solution are measured and dispensed using a Manostat D1g1-Pet ultra-micro pipet (Manostat Corp., Cat. No. 71-632-00) equipped with a $1.0 \mathrm{ml}$ full-capecity reservolr. This micropipet is able to dispense volumes of solutions down to to.0001 $\mathrm{ml}$ when using the $1.0 \mathrm{ml}$ reservolr. Dispensing of solutions by this micropipet should be done by 1mersing the capillary tip of the reservolr into the sample. The larger volumes of solution are measured using a $10.0 \mathrm{ml}$ capecity buret with a 0.02 milliliter gradient scale.

The entire sample solution is covered wth a layer of parafilm (American Can Company, Marathon Products, Neenah, W1s.), maleable plast1c wrapping $\mathrm{fllm}$, after the liquid membrane electrode, the external reference electrode, and the $\mathrm{pH}$ electrode are immersed in the sample solution. A small hole is bored through this parafilm layer to allow entry of the micropipet and buret tips into the sample solution.

\section{Reagents.}

The water used for all aqueous solution preparations was dist1lled In a Barnstead still (Model SM-10, Barnstead St1ll and Sterilizer Company, Inc., Forest H1lls, Eoston, Mass.). Th1s water was pased through a mixed bed of 1on-exchange column (Barnstead Hose Type Cartridge, Fisher Scientific Company) for removal of remeining inorganic impurities and later purified by a second distillation in a vented all-glass distillation apperatus for removal of organic impurities. The water was collected and stored in a closed Nalgene Container (Nalge Sybron Corporation) to prevent contamination from carbon dioxide.

The rater soluble bromothymol blue dye (Katheson Coleman and Sell), the polyvinyl chloride (Aldrich Chemical Company), and the 
d1-n-decyl phthalate (Eastman Corporation) were used without further purification. Sigma Chemical Corporation supplied the d-pantothenic acid (d-calcium pantothenate or vitemin $B_{5}$ ) stored desiccated at 0 to $0.5^{\circ} \mathrm{C}$, thiemine hydrochlorile (aneurine or vitamin $B_{1}$ ) stored in the dark, ntcotinamide (niacinamide or nicotinic acid amide), riboflavin (vitamin $B_{2}$ ) protected from 1ight, and pyridoxine monohydrochloride (vitamin $B_{6}$ ) stored in the dark and also desiceated. All S1gma Chemical Corporation products, unless specifically indicated, were not necessarily the anhydrous form. The ascorbic acid (vitamin C) was purchased from a local pharmacy (R1te-Ald Corp.) as commercial capsules. No 11st of other possible chemicals, such as binders or additives came with the capsules. The st ructures for the dye and the chemicals obteined from Sigma Corporation are given in figure 9. All other solid chemicals employed were either certified analytical reagents or certified A. C.S. chemicals of proper analytical grade.

The standard sodium hydroxide solutions and the standard hydroger chloride solutions were prepared using certified concentrated standard $10.000 \pm .005$ normal solution by Fisher Scientific Company. The solutions for the internal reference element of the $\mathrm{pH}$ electrode and double junction reference electrode were a $4 \underline{M}$ potassium chloride solution seturated with silver chloride (Corning Instruments, Inc.) and a saturated potassium chloride solution (Eeckman Instruments, Inc.), respectively. Nitrobenzene (Fisher Certifled Reagent, Fisher Sclentific Company) and the tetrahydrofuran (Matheson Coleman and Bell, classified as suitable for histological use) were used directly without further purification. Trifluoroacetyl-p-butylbenzene was prepared by Harvey B. 


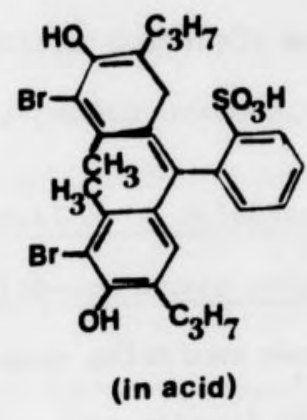

A

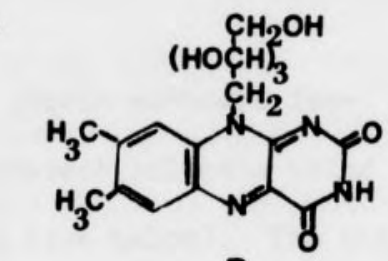

B<smiles>Cc1ncc(CO)c(CO)c1O</smiles>

D<smiles>NC(=O)c1cccnc1</smiles>

F

Figure 9. Diagram of Molecular Structures for Bromothymol Blue Dye Salt (A), Ribof lavin (B), d-pentothenic acid (C), Pyridoxine Monohydrochloride (D), Ascorbic Acid (E), and N1cotinamide (F). 
Herman. 17 Chloroform (F1sher Certified, Spectroanalyzed, Fisher Sclentific Company), and 1,2-dichloroethane (Matheson, Coleman, and Bell), purity unknown, were fractionally distilled before use.

\section{Preparation of Solutions.}

Ion-exchanger solutions. A number of 11quid membrane 1onexchenger solutions were prepered from different solvents using the thiamine-bromothymol blue extraction method (see below). The thiamine was always in excess as compared to the bromothymol blue dye and all 1on-axchanger solutions were stored in a freezer when not in use.

A 1,2-dichloroethane lon-exchanger solution was prepared by adding $0.16864 \mathrm{~g}$ of thiamine hydrochloride hydrate to $0.031220 \mathrm{~g}$ of bromothymol blue dye and diluting to $100 \mathrm{ml}$ with pH 6.6 phosphate buffer to make an fon-exchenger solution of $1 \times 10^{-3} \underline{M}$ thiamine-dye selt. $100 \mathrm{ml}$ of purifled 1,2-dichloroethene were added and stirred vigorously for one hour. Using a separatory funnel, the organic phase (bottom layer) was removed and the aqueous layer was extracted with an additional volume of $100 \mathrm{ml}$ of 1,2-dichloroethane with vigorous st1rring for forty-f1ve minutes and then separated. The organlc solvent extracts were collected, passed through a dry filter paper to remove any emulsifled aqueous phase, and evaporated in a fractional distillation apparatus to less than $50 \mathrm{ml}$. Th1s solution was then allowed to cool and was passed through another dry filter paper 1nto a $50 \mathrm{ml}$ volumetric plask where 1t was diluted to the mark with purifled organic solvent. A precipitate Indicated a saturated solution of the acid-dye salt. This ion-exchanger solution was centrifuged to remove the orange-red precipitate which was dried for infrared analysis. The lon-exchanger solution was yellow. An 
Infrared spectrum of the orange precipltate was determined and compered to the infrared spectra of the pure thiamine hydrochloride hydrate and the branothymol blue dye used for the lon-exchanger preparation.

The potassium bronide pellet technique was used for all three samples. By compering the three spectra, it was noted that the major Infrared peaks characterizing the thiamine hydrochloride hydrate and the bromothymol blue dye were also found in the orange precipitate spectrum indicating that it was the thiamine-bramothymol blue salt. The major peaks for the thianine hydrochloride hydrate sample were at 1655, 1610,1530 and $1045 \mathrm{~cm}^{-1}$. The major peaks for the bromothymol blue dye were at $3490,2960,1610,1090,1020$ and $620 \mathrm{~cm}^{-1}$.

The nitrobenzene lon-exchanger solution was propered by adding $0.17764 \mathrm{~g}$ of thiemine hydrochloride hydrate to $0.03122 \mathrm{~g}$ of bromothymol blue dye and diluting with $50 \mathrm{ml}$ of $\mathrm{pH} 6.6$ phosphate buffer to make en 1on-exchanger solution of $1 \times 10^{-3} \underline{M}$ thiemine-dye salt. $50 \mathrm{ml}$ of nitrobenzene were added to the aqueous solution and stirred vigorously for one and one-half hours. Using a seperatory funnel, the organic phase (bottow leyer) was removed and passed through a dry filter paper to remove any emulsified aqueous phase. The lon-exchanger solution was yellow.

The trifluoroecetyl-p-butylbenzene lon-exchanger solution was prepered fram $0.03553 \mathrm{~g}$ of thiemine hydrochloride hydrete to $0.00646 \mathrm{~g}$ of bramothymol blue dye and diluting these compounds in $10 \mathrm{ml}$ of $\mathrm{pH} 6.6$ phosphate buffer and $5 \mathrm{ml}$ of trifluoracetyl-p-butylbenzene solution to make an 1on-exchanger solution of $2 \times 10^{-3} \underline{M}$ thiamine-dyo salt. This mixture was stirred vigorously for five hours and allowed to stand 
overnight. Separation was not very complete. The solvent phase was emulsified with the aqueous phase and showed precipitate formation. The solvent phase was centrifuged and the organic phase was removed and passed through dry fllter peper. The pale yellow color of the lonexchanger solution indicated that extraction was incomplete.

The chloroform 1on-exchanger solution was prepared by adding $0.16864 \mathrm{~g}$ of th1amine hydrochloride hydrate to $0.03122 \mathrm{~g}$ of bromothymol blue dye and diluting to $100 \mathrm{ml}$ with $\mathrm{pH} 6.6$ phosphate buffer to make an lon-exchanger solution of $1 \times 10^{-3} \underline{\mathrm{M}}$ thlamine-dye salt. $100 \mathrm{ml}$ of purified chloroform were added to the aqueous solution and the mixture was stirred Flgorously for forty-five minutes. Using a separatory funnel, the aqueous phase (top layer) was removed, extracted with another $100 \mathrm{ml}$ of chloroform, and the mixture wes stirred Figorously for another forty-five minutes. The aqueous phese was aga in removed and extracted with an additional $100 \mathrm{ml}$ of chlorof orm with one hour of stirring. All three chloroform extracts were collected, pessed through a dry fliter peper, and evaporated using a fractional distillation apparatus until less than $50 \mathrm{ml}$ of solution remained in the reaction pot. Th1s was allowed to $\mathrm{cool}$ and was placed in a $50 \mathrm{ml}$ volumetric flask which siluted to the mark with purified chloroform. This 1on-exchanger solution was yellow.

The octanol-1 lon-oxchanger solution was propared from $0.17764 \mathrm{~g}$ of thiam ine hydrochloride hydrate, $0.03122 \mathrm{~g}$ of bromothymol blue dye, and $50 \mathrm{ml}$ of $\mathrm{pH} 6.6$ phosphate buffer to make an 1on-exchanger solution of $1 \times 10^{-3} \mathrm{M}$ thiemine-dye salt. $50 \mathrm{ml}$ of octanol-1 was added to this aqueous solution, the mixture was stirred vigorously for one hour, and 
the solution was placed in a seperatory funnel where extraction looked nearly complete since the aqueous phese (bottom layer) was very pele yellow while the organte phase had a clear, dark orange appearance. The organic phase was removed and passed through a dry fllter paper.

The following mixed lon-exchanger solutions were prepared by cambining the chloroform and octanol-1 lon-oxchenger solutions: $1: 1$. 2:1, and 4:1 chloroform/octanol-1 by volume. For all three preparations, cloudiness appeared for a brief time upon inftial mixing but disappeared after further mixing. When the fon-exchanger solutions were placed in a freezer, aqueous balls of blue color appeared in the organic ionexchanger solutions. The blue color was probably due to the dye in the solutions. In the chloroform-octanol-1 and in the octanol-1 lonexchanger solutions, the blue aqueous balls would periodically form while the solutions were stored in the freezer and had to be removed. All three chloroform-octanol-1 lon-exchange solutions should have been $1 \times 10^{-3} \underline{M}$ thiamine-branothymol blue selt if both the pure chloroform and octanol-1 1on-exchanger solutions were $1 \times 10^{-3} \mathrm{M}$.

The development of polymeric films as the membrane sensor for the liquid membrane electrode body was attempted. The gael of this construction was to produce a polymertc membrane that could be easily sealed in the Orion Pesearch 92-32 11quid membrane electrode body just as the conventional porous membrane supports were sealed. This polymeric film would need the characteristics of thinness, durability, and plasticity for forming good seals. A general procedure for forming 
polyvinyl chloride (PVC) membranes was developed with some small changes from reference methods. ${ }^{32}, 33,34,35 \mathrm{~mm}$ (1.d.) glass ring (10 ml volume capacity) and a $30 \mathrm{~mm}$ (1.d.) glass ring (4 ml volume capacity) were cut from glass test tubes. Two glass rings allowed the formation of PVC nembranes of different thickness. The edge of one side of the ring was smoothed with sandpaper and then sealed on a glass plate using a minimum amount of Non-Aq stopcock grease (Fisher Scientific Company), an organte insoluble grease. The entire edge of the glass ring in contact with the glass plate was coated with hot paraffin wax and allowed to cool in order to keep the glass ring in position on the glass plate. The stopcock grease was used to prevent the peraffin from dissolving in the organic solvent used for the PVC membrane construction. The PVC membrane solution prior to hardening contained various proportions of 1,2-d1chloroethane 1on-exchanger solution, FVC, and any needed plasticizer. All were dissolved in tetrahydrofuran (THF). THF was added to bring the entire membrane preparation into the liquid form. This final solution was then poured into the glass rings. Eech glass ring was covered with a layer of filter pepers (five to ten sheets) and weighted down with a heavy object so as to enable very slow evaporation of the THF. This solution was then allowed to sit undisturbed for at least forty-e1ght hours. The resulting solid PVC membrane was peeled from the glass and the underside of the membrane was allowed to dry thoroughly. The PVC membrane folls were made by cutting the lsige membrane with a cork borer to flt the diameter of a conventional Orion porous membrane electrode body. 
PVC membranes using the 1,2-dichloroethane 1on-exchanger solution as the plasticizer were prepared using the following amounts of materials. $32,33.34$ The first attempt used $0.66 \mathrm{~g}$ of the 1,2-dichloroethane 1on-exchanger solution and $0.28 \mathrm{~g}$ of PVC dissolved In $10.0 \mathrm{ml}$ of THF. $6.4 \mathrm{ml}$ of this mixture was poured into the $35 \mathrm{~mm}$ glass ring and the remaining $3.6 \mathrm{ml}$ into the $30 \mathrm{~mm}$ glass ring. The second attempt used $0.33 \mathrm{~g}$ of 1,2-dichloroethane lon-exchanger solution and $0.13 \mathrm{~g}$ of PVC dissolved in $8.3 \mathrm{ml}$ of ThF. $5.3 \mathrm{ml}$ of this mixture was poured into the $35 \mathrm{~mm}$ glass ring and the remaining $3 \mathrm{ml}$ was poured into the $30 \mathrm{~mm}$ glass ring. After testing the resulting PVC membrane, 1t appeared that using 1,2-dichloroethane fon-exchanger solution as the plasticizer was not effective. The membrane produced had toughness and durability but lacked the plasticity needed to form a good seal in Orion 92-32 liquid membrane electrode body.

PVC membranes using plasticizers, such as di(2-othylhexyl)-2ethylhexylphosphonate or didecyl phthalate, have been developed. 35 A FVC membrane contalning d1-n-decyl phthalate (DDP) was prepared using the following materials. The first attempt used $0.33 \mathrm{~g}$ of 1,2-dichloroethane 1on-exchanger solution, $0.04 \mathrm{~g}$ of FVC and $0.33 \mathrm{~g}$ of DDP, all dissolved in $8.3 \mathrm{ml}$ of THS. $5.3 \mathrm{ml}$ of this mixture was poured Into the $35 \mathrm{~mm}$ glass ring and the remaining $3 \mathrm{ml}$ was poured into the $30 \mathrm{~mm}$ glass ring. These PVC membranes had a soft highly rubbery surface that was easily breakable due to no supportive properties. The second attempt used $0.33 \mathrm{~g}$ of 1,2-d1chloroethane 1on-exchanger solution, $0.20 \mathrm{~g}$ of $\mathrm{PVC}$, and $0.16 \mathrm{~g}$ of DDP all dissolved in $8.3 \mathrm{ml}$ of THF. $5.3 \mathrm{ml}$ of this mixture was poured into the $35 \mathrm{~mm}$ glass ring and the remaining $3 \mathrm{ml}$ was poured into the $30 \mathrm{~mm}$ 
glass ring. These PVC membranes had slight flexibility with good supportive characteristics and the necessary plasticity to make a good seal in the Orion liquid membrane electrode body.

Buffer Solutions. Standard aqueous pH buffers were prepared according to R. G. Bates ${ }^{36}$ to callbrate the pH electrode and pH meter. A pH 4.008 buffer was prepared by making a $0.05 \underline{M}$ potassium hydrogen phthelate solution. The potassium hydrogen phthelete was dried at a temperature of $100^{\circ} \mathrm{C}$ for three hours prior to use. This buffer solution was kept from accidental contamination with strong acld or alkall. A pH 6.865 buffer solution was prepared by making a $0.025 \underline{M}$ potassium dihydrogen phosphate and $a .025 \underline{M}$ disodium hydrogen phosphate solution. Both compounds were dried for at lest three hours at $110^{\circ} \mathrm{C}$ and cooled in a desiccator. A pH 9.180 buffer solution was prepared by making a $0.01 \underline{M}$ borax (sodium borate) solution. This buffer solution was stoppered tightly as the absorption of only 0.27 carbon dioxide by the solution causes the pH to be altered by 0.001 unit.

The aqueous buffer solutions employed for experimental analysis of the different IIquid membrene electrode systems were prepared in a manner similar to the directions in the "United States Pharmacopeis" (USP). 37 The buffer solutions studied had pH values of 4.0,6.0,6.6, and 8.0. According to the USF method, $50 \mathrm{ml}$ of 0.2 M potessium dihydrogen phosphate solutions or $50 \mathrm{ml}$ of $a .2 \underline{M}$ potessium hydrogen phthalate solution with appropriate amounts of $0.2 \mathrm{M}$ sodium hydroxide solution were used in the buffer preparations to make $0.05 \underline{M}$ potessium dihydrogen phosphate solutions or $0.05 \underline{M}$ potessium hydrogen phthalate solutions with various concentrations of sodium hydroxide. These salt 
concentrations were proportionslly increased in order to obtain stronger buffer solutions conteining $0.1 \underline{M}$ potassium dihydrogen phosphate or $0.1 \underline{M}$ potassium hydrogen phthalate with the proportionally Increased concentrations of sodium hydroxide. A pH 4.0 buffer solution was prepared by making a $0.1 \underline{M}$ potassium hydrogen phthalate and a $0.0008 \underline{M}$ sodium hydroxide solution. A pH 6.0 buffer solution was prepered by making a $0.1 \mathrm{M}$ potassium dihydrogen phosphate and a $0.01128 \mathrm{M}$ sodium hydroxtde solution. A pH 6.6 buffer solution was prepared by making a $0.1 \underline{M}$ potassium dihydrogen phosphate and a $0.03548 \underline{\mathrm{M}}$ sodium hydroxide solution. A pH 8.0 buffer solution was prepared by making a $0.1 \underline{M}$ potassium dihydrogen phosphate and a $0.0937 \underline{M}$ sodium hydroxide solution using water that had been bolled and cooled prior to use in order to eliminate any dissolved carbon dioxide that could interfer with this buffer preparation. The potassium dihydrogen phosphate and potassium hydrogen phthalate were dried in an oven at $100^{\circ} \mathrm{C}$ for at least three hours and cooled in a desiccator bofore use in all these buffer preparations.

Thtamine Hydrochloride Solutions. In the preperation of solutions containing thiamine hydrochloride, a problem arose concerning the high hygroscoplc quality of this compound. Two methods were ut1lized to determine the amount of water absorbed by the thiamine hydrochloride in the reagent bottle. In one method a known amount of thlamine hydrochloride from the reagent bottle was heated at $100^{\circ} \mathrm{C}$ for twentyfour hours. It was cooled in a desiccator and reweighed to determine the loss of water upon heating of the sample. It was calculated that 
for 1 mole of thianine hydrochloride, there was 0.8 mole of water. However, this value may not be correct since upon weighing of the thismine hydrochloride after heating the weight of the sample gradually increased, Indicating absorption of ter from the atmosphere by the sample. The other method to analyze the hydrated thiamine hydrochloride was to use a thermobalance (Perkin Elmer, TGS-1) with a differential scanning celorimeter (Perkin Elmer DSC-1B). The sample was heated to aximum temperature of $120^{\circ} \mathrm{C}$. The amount of water detected by this method was approximately 0.6 mole of water for each mole of thiamine hydrochloride. However, In this instrumentational method, hellum is passed through the system, and the thiamine hydrochloride sample showed a weight loss at room temperature even before hesting occurred. Th1s indicated that the thiamine hydrochloride forms a weak complex with water since the water was easily evaporated by the constent helfum flow over the sample. After careful evaluation of both methods employed, it was concluded that reagent thiamine hydrochloride is definitely a monohydrate. Therefore, the thiamine hydrochloride was always kept in a desiccator and stored in the dark unt1l needed.

Because of the hydrogen chloride complexed to the thiamine, all aqueous solutions prepared from thiamine hydrochloride had to be monttored with a pi electrode and meter due to the formation of an acidic solution upon addition of the salt to water. Appropriate steps had to be taken to adjust the pH value of the thiamine hydrochloride solutions to the desired value. 


\section{The Ifquid Membrane Electrode's Internal Reference Solution.}

The Internal reference solution of the liquid membrane electrode consisted of a $0.001 \underline{M}$ thismine and a $0.1 \underline{M}$ sodium chloride solution. The $\mathrm{pH}$ of this solution was adfusted to the same $\mathrm{pH}$ value as that of the sample solution to be analyzed. The following wethod was used to prepare the Internal reference solution. The appropriate amount of thiamine hydrochloride, taken directly from the reagent bottle, was weighed to meke $100 \mathrm{ml}$ of $0.001 \underline{\mathrm{M}}$ solution. Likewlse, the appropriste amount of sodium chloride, dried at $100^{\circ} \mathrm{C}$ for at least three hours and cooled in a desiccator, was welghed to give $100 \mathrm{ml}$ of a $0.1 \mathrm{M}$ solution. These were quantitatively mixed and diluted to about $50 \mathrm{ml}$ with water. The pH electrode was carefully imersed in this solution and the solution was stirred. A $0.01 \underline{M}$ sodium hydroxide solution wes added unt1l the desired pH of the solution was attalned. The amount of sodium hydroxide solution added was recorded, and the thiamine-sodium chloride solution was diluted to $100 \mathrm{ml}$ in a volumetric flask.

Sample Solutions. Preparation of initial sample solutions for analysis by the IIquid membrane electrode system was accomplished by having an initial volume of sample containing $100 \mathrm{ml}$ of a suitable buffer solution by itself or with previously added Interfering substances.

For blank sample solutions containing no interfering substances, $100 \mathrm{ml}$ of a buffer solution was added to the jacketed heat controlled beaker and logarithnic amounts of a thiamine stock solution of about 0.1 concentration or other types of stock solutions were added in milliliter increments using the micropipet or the $10 \mathrm{ml}$ cepecity buret. 
These milliliter additions of stock solution were $0.01,0.01,0.03$, $0.05,0.1,0.3,0.5,1.0,3.0,5.0,10.0$, etc. In which the total logarithmic volumes of stock solution in milliliters present in the semple solution were $0.01,0.02,0.05,0.1,0.2,0.5,1.0,2.0,5.0$, 10.0, 20.0, etc. This method of adding a stock solution to an initial volume of sample gave a practical range of concentrations of the fon of Interest that the liquid membrane electrode could analyze.

A $0.1 \underline{M}$ sodium chloride stock solution was prepared by dissolving $2.92214 \mathrm{~g}$ of oren dried sodium chloride in $500 \mathrm{ml}$ of water and was added to a $\mathrm{pH} 6.0$ buffer solution in the volume increments as given above to make a range of sample solutions with different sodium chloride concentrations.

Sample solutions containing possible interfering substances were made using the type of substances commonly found in commercially avallable vitamin preparations. For reguler vitamin capsules, each capsule usually contalned $15 \mathrm{mg}$ of thiamine mononitrate, $10 \mathrm{mg}$ of riboflavin, $5 \mathrm{mg}$ of pyridoxine monohydrochloride, $50 \mathrm{mg}$ of ntcotinamide, $10 \mathrm{mg}$ of d-calctum pantothenate, and $300 \mathrm{mg}$ of ascorbic acid. These amounts were found in two commercially popular vitamin preparations named Allbee with C (A-H Robins Company) and B-Complex with Vitamin C (Rite-Ald Company). In all cases, four times the amount spectfied in each commercial vitamin capsule preparation were added to $100 \mathrm{ml}$ of sample solution.

An interference sample solution of riboflavin, pyridoxine monohydrochloride, and d-calcium pantothenate was propared by combining these substences and diluting to one $100 \mathrm{ml}$ with $\mathrm{pH} 6.0$ buffer solution. 
Because it was belleved that nicotinamide may interfer with the thiamine response of the liquid membrane electrode as noted by Das Gupta and Cadwallader, ${ }^{29}$ the nicotinamide and ascorbic acid interference semple solution was made separately in pH 6.0 buffer solution. Due to the ascorbic acid, the buffer capacity of the solution was exceeded and neutralization of the interference substances was required before final dilution with the buffer solution. The interference substances were added and diluted to about $25 \mathrm{ml}$ with $\mathrm{pH} 6.0$ buffer solution and neutralized to $\mathrm{pH} 6.0$ with additions of $1.0 \mathrm{M}$ sodium hydroxide solution recording the emount of sodium hydroxide used. The mixture wes then diluted to $100 \mathrm{ml}$ with the $\mathrm{pH} 6.0$ buffer solution.

A separate Interference sample solution was prepared for both the nicotinamide and the ascorbic acid. The nicotinamide sample solution required no noutralization and was mixed directly with $100 \mathrm{ml}$ of $\mathrm{pH}$ 6.0 buffer solution. The ascorbic acid sample solution was neutralized with $1.0 \underline{M}$ sodium hydroxide in the manner as stated above. The amount of sodium hydroxide added was recorded. This interference solution was then diluted to $100 \mathrm{ml}$ with the $\mathrm{pH} 6.0$ buffer solution.

A $0.0420 \underline{M}$ sodium chloride interference sample solution was prepered by adding $0.24780 \mathrm{~g}$ of oven dried sodium chloride to $100 \mathrm{ml}$ of $\mathrm{pH} 6.0$ buffer solution.

All the above interference sample solutions were used fust for the initial sample solution to which a thiamine stock solution of about $0.1 \mathrm{M}$ concentration was added in the volume increments stated previously to make ange of semple solutions with different the mine concentrations that could be analyzed by a liquid membrane electrode. 
The Thtamine Stock Solution. The preparation of a $0.1 \mathrm{M}$ thiemine stock solution wes performed by two mothods.

Method 1 assumed the thiamine hydrochloride to be the hydrated form when taken directly from the reagent bottle and the appropriate amount of thiamine hydrochloride hydrate was weighed to make $0.1 \mathrm{M}$ thiamine solution in a totel volume of elther $100 \mathrm{ml}$ or $200 \mathrm{ml}$ depending upon the amount of stock solution needed for an anslysis. This method did not give precise concentrations of thiamine stock solution but in the preliminary task of finding a liquid membrane electrode that would show good thiamine response this was not critical.

Method 2 used a more precise manner in obtaining a thiamine stock solution. A beaker equipped with a cap was employed. The beaker was heated in an oven to remove all moisture present on its walls, and then cooled in a desiccator for one hour. The beaker was touched only with a pair of tongs or for a short time with tissue paper. After the cap was placed on the empty beaker, both were welghed accurately. The approximate amount of thiamine hydrochloride hydrate needed to make a 0.1 M solution in a total volume of $100 \mathrm{ml}$ or $200 \mathrm{ml}$ was taken fram the reagent bottle, added carefully to the beaker, and then oven heated at $100^{\circ} \mathrm{C}$ for three hours. The beaker and sample were cooled in a desiccator for about one hour, after which the same cap was positioned tightly on the beaker, and the entire assembly accurately weighed. The actusl weight of the unhydrated thiamine hydrochloride was then celculated.

After a thiamine hydrochloride sample had been weighed by olther methods 1 or 2 , the thiamine hydrochloride was then neutralized to the 
pH value of the inftial sample solution to be tested. This sample solution always contalned a buffer and, therefore, the thiamine stock solution had to be neutralized to the appropriate $\mathrm{pH}$ in order not to extend the capecity of the buffer once it was added. The neutralization of the thiamine stock solution was similer to that method used for the thiamine-sodium chloride internal reference solution. The thiamine hydrochloride was quant1tatively diluted to about $50 \mathrm{ml}$ with water. The pH electrode was immersed in this solution. The solution was stirred. $1.0 \mathrm{M}$ sodium hydroxide was added unt1l the desired $\mathrm{pH}$ of the solution was attained. The amount of sodium hydroxide ras recorded. This thiamine solution was quantitatively transferred into an appropriate volumetric flask and diluted to the mark with water.

\section{Methods of Anglysis.}

The liquid membrene electrode systems used in this project consisted of Inftial deta of volume of stock solution added to an initial volume of sample solution and the corresponding measured potentials in millivolts. To use these data effectively, a working curve must be developed in order to deternine the kind of response the liquid membrane electrode has towards the concentration of the lon of interest, which can be thiamine or any other substance. Also, a working curve Indicates how reproducibly the electrode responds to the different concentrations of the 1 on of interest. If the liquid membrane electrode is responding in the desired manner, calibration working curves have to be implemented for a wide range of concentrations of the lon of interest. Working curves have to 
be constructed to determine the effect of interference substances In the sample solution on the response of the liquid membrane electrode towards the fon of interest.

To form these working curves, the measured potential in millivolts versus the corresponding $\log _{10}$ activities of the lon of interest have to be evaluated. The activity of an lonic substance is related to all the Ionic species present in the semple solution. For example, in the addition of a thiamine stock solution to a sample solution, the activity of the thiamine is a function not orly of the added thiamine and sodium chloride fram the stock solution, but also of the salts of the buffer solution and any other lonic interference substances that are present.

Two Fortran IV programs have been developed to easily convert the amounts of stock solution of the 1on of interest added to a sample solution into the $\log$ activities of the ion of interest. Fach log activity value and its corresponding measured potential are used in a Iinear regression method to determine the slope, the intercept, the standard deviation of these values, and the correlation coefficient for the plot of the measured potent1al versus log activity of the ion of interest. These programs are called SALTBI and SALTTV.

Progran SALTBI (Appendix A) is used for sample solutions containing only a buffer, one lon of interest, and only one additional lonic salt.

Program SALTIV (Appendix 3 ) is used for sample solutions containing a buffer and Interference substances numbering no more than five. Similar to program SALTBI, one Ion of interest and one additional fonic salt can be accomodated in this program. 
Both programs ut1lize Devis equation ${ }^{2}$ for determining the activity coefficient, and the lonic strength contributed by each lonized salt in the sample solution is obtained by the factor method described on page 8. Two subroutines, FREE and LINFIT, are used. Program FREE ${ }^{38}$ (Append1x C) allows free input format of data values for the SEL 72 computer system from any control unit and assigns the input value to a variable in the main program. Program LINFIT (Append1x D) is the subrout ine employling the linear regression method using the calculated $\log$ activity of the ion of 1nterest and 1ts corresponding measured potent 1al.

From these Fortran IV programs, the working curve cen be drawn by plotting the measured potential versus the corresponding log activity of the ion of interest. It is these curves that show whether a liquid membrane electrode is responding in suitable manner with or without Interference substances present and whether the electrode response depends upon certain conditions such as pH.

The Generel Procedure for an 5xperiment Employing a Liquid Membrane Electrode Cell.

The general format of performing an experiment with a liquid membrane electrode was as follows:

1. Assemble the Orion liquid membrane electrode according to the Orion Research 92-32 manual and choose the appropriate porous membrane support to contain the 1on-exohanger solution.

2. Position the electrode upright without the top cap and add the desired Ion-exchanger solution through the larger outside hole on top of the electrode leading to the liquid membrane solution reservolr 
in the outside chamber of the electrode. Be sure of proper wicking of the membrane support by the lon-exchanger solution by holding electrode overhead and observing the membrane. As the membrane wloks the 1onexchenger solution fram the reservoir it should becane pertially translucent or wet-looking. Plece the washer over the lon-oxchenger solution filling hole and, using syringe with the special nozzle for this electrode, add the internal reforence solution in the center filling hole on top of the electrode. Since this solution will be emitted out of the electrode from the vent hole, it is necessary to catch this solution with a tissue. This internal reference solution should be sufficlently flushed through the inner electrode chamber to remove any trapped alr bubbles. Replace the top cap containing the lead for the electrical connection between the internal reference electrode in the Inner chamber of the liquid membrane electrode and the voltmeter, and connect the lead to the appropriate voltmeter terminal.

3. Once assembled, the liquid membrane electrode can be used for long periods of time with the same lon-exchanger solutions. However, before each experiment using the eloctrode, a fresh internal reference solution is prepered because of the possible decomposition of the thiamine in the old internel reference solution. This fresh reference solution replaces the old solution in the inner chamber of the electrode by flushing the chamber five to six times.

4. The liquid membrane electrode is conditioned before use.

5. Prepare the externel double junction reference electrode for use by adding the appropriate solutions of saturated potassium chloride 
and $1.0 \mathrm{M}$ sodium chloride and connect the electrode to the proper terminal on the voltmeter. Since the sodium chloride solution contacts the sample solution through a porous ceramic plug, it is replaced with new sodium ehloride solution by suitable flushing of the chamber fust before the reference electrode is used. Store the double function reference electrode in water. Also prepare the pH electrode for use by conditioning it in a buffer solution.

6. Start the constant temperature elroulator and mainta in a temperature of $25^{\circ} \mathrm{C}$.

7. Place the magnetic stirring bar and $100 \mathrm{ml}$ of sample solution Into the jacketed beaker. Rinse the 11quid membrane electrode with water and blot dry with peper tissue. Place the electrode in the sample solution and stir this solution at constant speed throughout the experiment. Check for air bubbles trapped under the bottan electrode cap where the membrane sensor is located. If air bubbles form, tap the electrode to remove them.

8. Rinse with water and blot dry the external double function reference electrode. Place this electrode into the sample solution and turn on the voltmeter to the millivolt mode. If the measured potential is stable, showling 11ttle drift, then continue. If the mesured potential is not stable but fluctuates widely, then check for a1r bubbles under the electrode cap or In the internal reference solution chamber of the liquid membrane electrode.

9. Rinse with water and carefully blot dry the pH olectrode. Place this electrode into the sample solution and turn on the $\mathrm{pH}$ meter. 
10. Cover the jacketed beaker and its sample solution with

a layer of parafilm.

11. Wait for the voltmeter and the $\mathrm{pH}$ meter to $\mathrm{g}$ ive stable readings.

12. Bore a hole in the parafilm and beg in to add the desired volumes of stock solution.

13. Record the amount of stock solution dispensed into the sample solution upon each addition, the total amount of stock solution added to the sample solution, the measured potential (In millivolts) and the pH of the sample solution after each stock solution addition, and the description of the Ilquid membrane electrode response.

14. After the range of concentrations of the fon of interest has been anelyzed by the liquid membrane electrode, shut off the inst rument, clean all glassware and equipment, and properly store all the electrodes.

\section{The Progressive Procedure for Deternining the Most Sultable Liquid} Membrene Electrode for Thiamine Analysis.

The f1rst ion-exchanger solution extensively studied in this investigation was the 1,2-dichloroethene fon-exchanger solution. The liquid membrane electrode employed an Orion Research divalent cation membrane (Model 92-32-044) as the support for the lon-exchenger solution.

To determine the $\mathrm{pH}$ dependence of the liquid membrane electrode's response towards thiamine concentration, the inftisl sample solutions contained no interference substances and three different pH buffer solutions were employed for analysis. The liquid membrane electrode was tested for its response in a range of thiamine concentretions in sample solutions of $\mathrm{pH} 4.0,6.0$, and 8.0 to determine which $\mathrm{pH}$ gave the optimum response. The thiamine-sodium chloride internal reference solution and the thiamine 
stock solution (prepared according to Method 1, page 52) were adjusted to the $\mathrm{pH}$ value of the buffer solution in the initial sample solution. The 1iquid membrane electrode was conditioned in the appropriate buffer solution containing same thiamine stock solution. Two consecutive trials using thiamine stock solution additions were performed for each pH analysis to study electrode reproducibility. The working curves of potentisl (millivolts) versus the $\log _{10}$ activity of thiamine were constructed using program SALTBI and the slope, intercept, standard deviations, and correlation coefficient were calculated. In using this program, it was assumed that thiamine is a divalent ion, which may or may not be true, at the $\mathrm{pH}$ values studied.

All the working curves for each pH studled had gradually increasing slopes, the degree of slope depending on the $\mathrm{pH}$ used. The pH 6.0 sample solutions had a higher slope value than the sample solutions of $\mathrm{pH} 4.0$ and $\mathrm{pH}$ 8.0. A table of the results are given below.

\section{$\underline{\text { Table } 2}$}

pH Dependence of the

1,2-dichloroethane Liquid Membrane Electrode

\begin{tabular}{|c|c|c|c|}
\hline ph Studied & Reproduc1bility & $\begin{array}{l}\text { Slope for } \\
5 \times 10^{-3} \text { to } 3 \times 10^{-2} \mathrm{M} \\
\text { Thiamine (mv/decade) }\end{array}$ & $\begin{array}{l}\text { Mea sured } \\
\text { Potent1al } \\
\end{array}$ \\
\hline $\begin{array}{l}4.0 \\
6.0 \\
8.0\end{array}$ & $\begin{array}{l}2 \mathrm{mv} \\
3 \mathrm{mv} \\
2 \mathrm{mv}\end{array}$ & $\begin{array}{l}13 \\
17 \\
14\end{array}$ & $\begin{array}{l}\text { stable } \\
\text { stable } \\
\text { stable }\end{array}$ \\
\hline
\end{tabular}

In Table 2, slope values were determined for the thimine concentration range of $5 \times 10^{-3}$ to $3 \times 10^{-2} \underline{M}$ because, in this range, the largest potential change per logarithmic addition of stock solution was observed. However, 
small potential change response was observed between the lower thiamine concentrations whlch gradually increased as the thiamine concentration Increased. Highest sensitivity of the liquid membrane electrode towands thiamine was obteined at a pH of 6.0. This pH appeared to be the best condition to study subsequent Ilquid membrane electrodes.

Because thiamine sensitivity was not sufficient for the 1,2-dichloroethane liquid membrane electrode to make it practical, a number of other liquid membrane electrodes were studied using the following lon-exchanger solutions: pure chloroform, pure octanol-1, $1,1,2,1$, and 4:1 chlorof orm-octanol-1, nitrobenzene, trifluoroacetylp-butylbenzene, and two PVC polymertc membrane films using di-n-decyl phthelate as plasticizer. All the liquid membrane electrodes employed the Orion Research divalent cation porous membrane support (Model 9232-04) except, naturally, for the PVC membrane films that are selfcontained Ion-sensitive matrices requiring no additional membrane supports. The initial sample solution was the pH 6.0 buffer solution. The thiamine stock solutions were prepared according to method 1 on page 52. The thiamine-sodium chloride internal reference solutions and thiamine stock solutions were neutralized to $\mathrm{pH} 6.0$. The liquid membrane electrodes were conditioned in fresh pH 6.0 buffer solutions containing same thiamine stock solution for at least two hours before use. During storage, the electrodes were either placed in thiamine buffer solutions as described above or allowed to remain in the atmosphere. Two consecutive trials using thiamine stock solution additions to the sample solution were performed for each electrode to 
study thiemine response and reproductbility. The working curves of the potential (millivolts) versus the $\log _{10}$ activity of thiamine were constructed using program SALTBI. The thiamine was assumed to be a divalent cation at this $\mathrm{pH}$.

A surmary of the results obtained using these different liquid membrane electrodes is given in Table 3, on page 62.

The pure chloroform, pure octanol-1, and chloroform-octanol-1 electrodes showed an increasing potential change between each thiamine stock solution addition. No electrode gave a linear Nernstian response for any thiamine concentration range. As a result, the working curves of potential (millivolts) versus $\log _{10}$ activity of thiamine were Indeed curves and not straight lines. The pure chlorof orm electrode gave good response with different thiamine concentratias but reproduc1bility was extremely poor. The pure octanol-1 electrode responded slightly better towards thiamine if stored in 2 ir but the response was still only fair. The advantage of this electrode was its great stability with no potential drift. The chloroform-octanol-l combination electrodes were devised to capture the best characteristics of the two solvents and to find the combination that would possess the best response towards thiamine concentration, potential stability, and acceptable reproducibility. The 1,1 chloroforn-octanol-1 liquid membrane electrode proved to best suit these requirements.

The nitrobenzene liquid membrane electrode had poor thiamine sensitivity. Incompatibility with the Orion divelent cation membrane support was the probable reason for this. The divalent cation membrane 


\section{Table 3}

Results for Varlous Liquid

Membrene Electrodes Studied at pH 6. 0

Liquid

Membrane

Eloctrode

pure chloroform

Reproduclbility

poor

excellent

excellent

falr

fair

2,1 chloroformoctenol-1

nitrobenzene

trifluoracetylp-butylbenzene

polymeric films with DDP,

thick PVC nembrane

not determined

thin PVC membrane

not determined

(excellent $= \pm \mathrm{m} \mathrm{mV}$, fair $= \pm 3 \mathrm{mV}$, poor $\geq \pm 3 \mathrm{mV}$ )
Thiamine

Conc. Range and Slope (mv/decade)

$5 \times 10^{-3}-2 \times 10^{-2} \approx 34$

$5 \times 10^{-3}-3 \times 10^{-2} \approx 20-27$

$5 \times 10^{-3}-3 \times 10^{-2} \approx 40$

$5 \times 10^{-3}-3 \times 10^{-2} \approx 43$

$5 \times 10^{-3}-3 \times 10^{-2} \approx 42$

not determined

not determined

not determined

not determined

\section{Remarks}

substantial potent ial drift

no potential drift

no potential drift

slight potential drift at low thiamine conc.

slight potential drift at low thia mine cone.

possible membrane incompatibility

no response to thinmine

symptams of high resistance across membrane

symptams of high resistance across membrane 
support used appeared to deteriorate fran contact with nitrobenzene. Another membrane support was prepered from Duralon, a nylon be sed support with a pore size of 1.0 - $\mathrm{m}$, made by Millipore Corporation. A nylon membrane, according to Orion Research reports, is suitable with nitrobenzene but problems developed with this liquid membrane due to leakage of lon-exchanger solution from the electrode body, probably as a result of the poor sealing characteristics of the nylon membrane support. A teflon membrane support with the product name Mitex, made by Millipore Corporation, was also tried with the nitrobenzene 1on-axchanger solution, but wicking of this solution Into the pores of the teflon support was unsuccessful. Finally, a Un1-pore membrane support (B10-Pad Laboratories, 0.03 yn pore size) was prepared, but was completely decomposed by the nitrobenzene solvent.

The trifluoroacetyl-p-butylbenzene lon-exchanger solution was simply not suitable as an lon-exchanger solution and response was poor towards thiamine detection.

The polymeric films were taken fran the preparations using di-n-decyl phthalate as the plasticizer as stated on page 45 . The PVC membranes used were obtained from the products of the second atterupt. These PVC membranes sealed well into the Orion Research 11quid membrane electrode. The PVC membrane from the $35 \mathrm{~mm}$ glass ring appeared to have a higher resistance across the membrane than the PVC membrane from the $30 \mathrm{~mm}$ glass $\mathrm{r}$ ing. Th1s was expected since the former membrane was thicker than the latter. 
Considering all the 1iquid membrane electrodes studied, the best electrode developed appeared to be the $1: 1$ chloroform-octanol-1 liquid membrane electrode. It was this electrode that was extensively studied for pH dependence, response towards thiamine, reproducibility, and Interference fram the substances cannonly found in commercial preparation of vitamin capsules.

\section{The 1:1 Chloroform-Octenol-1 Liquid Membrane Electrode.}

For all experiments desling with the 1,1 ohloroform-octanol-1 liquid membrane electrode, the electrode was exposed to the atmosphere until just prior to use when the electrode was conditioned in a pH 6.0 buffer solution with a small amount of thiamine stock solution that has been neutralized to $\mathrm{pH} 6.0$. All thiamine stock solutions were prepared according to method 2 on page 52 in order to have precise thiamine concentrations for the study of this chosen liquid membrane elect rode.

The $\mathrm{pH}$ dependence of the 1:1 chloroform-octanol-1 liquid membrane electrode towards thiamine response sotermined by varying the $\mathrm{pH}$ of a $0.01 \underline{M}$ thiamine sample solution and observing the measured potential.

This initial sample solution gives a $\mathrm{pH}$ value of approximately three because of the acidic nature of the thiamine hydrochloride, therefore, supplying an initial sample solution that can be directly analyzed without further preparation. The $\mathrm{pH}$ of the sample solution was varied by adding various amounts of $1.0 \mathrm{M}$ sodium hydroxide. The measured potential, the $\mathrm{pH}$, and the amount of sodium hydroxide solution added to the sample solution were recorded. 
Because of the high concentration of the sodium hydroxide, only sull amounts had to be used to vary the pH of the sample solutions. This was beneficial in that, by the end of the pH analysis, a total of approximately one milliliter of sodium hydroxide solution was needed to adjust the entire $\mathrm{pH}$ range of the sample solution studied. This meant that the thiamine concentration was not changed drastically by volume change indicating that the measured potential change was directly due to $\mathrm{pH}$ variation. Due to the small amounts of sodium hydroxide solution used, the Manostat micropipet could be used to dispense the sodium hydroxide solution into the sample. A working curve of potential (millivolts) versus pH was constructed and is shown in Figure 10. Reproducibility is not good for the two consecutive trials made, but for both trials a minimum in the curve is noted that correlates with the $\mathrm{pH}$ value of approximately 6.5, the value Das Gupta and Cadwallader ${ }^{29}$ obtained as the $\mathrm{pH}$ range for best extraction of thiamine into the organic solvent as thiamine-bromothymol blue salt. This minimum of measured potential would be expected at the best solution $\mathrm{pH}$ due to the consideration of the partition coefficient of thiamine between the aqueous sample phase and the active liquid organic phase of the liquid membrane electrode 39 . The best pH range for detection of thlamine by the 1:1 chloroform-octanol-1 liquid membrane electrode was between 5.5 to 7.5 where there is only about a one millivolt difference. This is in pertial agreement with the optimum pH value of 5.2 to 6.6 calculated by Das Gupta, Cadwallader, Herman, and Honigberg ${ }^{30}$ for the extraction method. The 1:1 chloroform-octanol-1 11quid membrane electrode was therefore studled at a $\mathrm{pH}$ of 6.0 . 


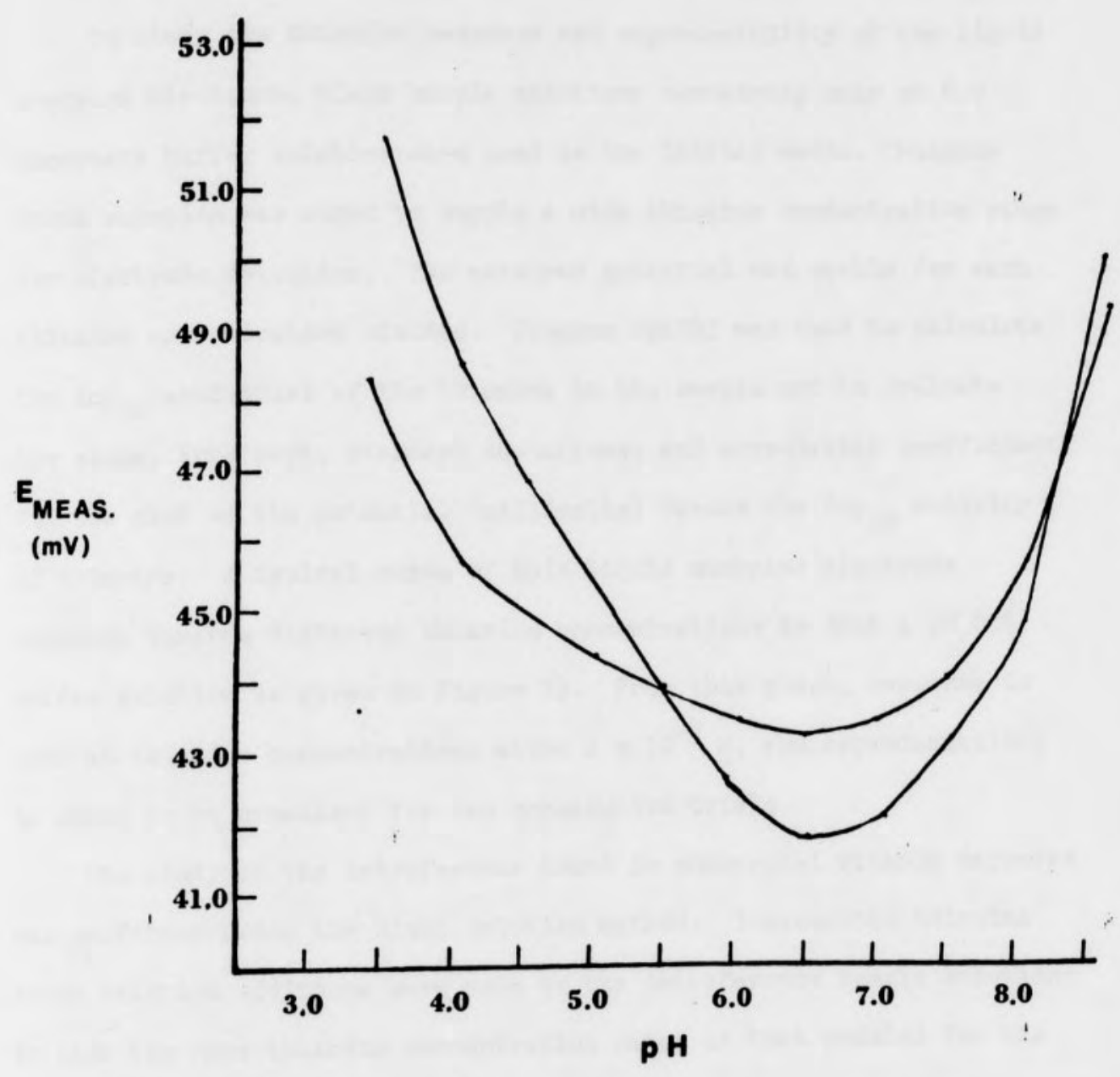

Figure 10. $\mathrm{pH}$ dependence of the 1:1 chloroform-octanol-1 liquid membrane electrode (two separate trials). 
To study the thiamine response and reproducibility of the liquid membrane electrode, blank sample solutions containing only $\mathrm{pH} 6.0$ phosphate buffer solution were used as the initial media. Thiamine stock solution was added to supply a wide thiamine concentration range for electrode detection. The measured potential was stable for each thiemine concentration studied. Program SALTBI was used to calculate the $\log _{10}$ activities of the thiamine in the sample and to evaluate the slope, intercept, standard deviations, and correlation coefficient for the plot of the potential (millivolts) versus the $\log _{10}$ activity of thiamine. A typical curve of this liquid membrane electrode response towards different thiamine concentrations in just a $\mathrm{pH} 6.0$ buffer solution is given in Figure 11. From this graph, response is good at thiamine concentrations above $1 \times 10^{-3} \mathrm{M}$, and reproducibility is shown to be excellent for two consecutive trials.

The study of the interference found in commercial vitamin capsules was performed using the mixed solution method. Incrementel thiamine stock solution additions were made to the interference sample solutions to give the same thiamine concentration range as that studied for the blank buffer sample solutions. The initial interference sample solutions were prepared just prior to use in order to avoid possible decamposition of the interference substances. Thiamine solutions in a pH 6.0 phosphate buffer were analyzed before the solutions with the interference substences in order to construct working curves to calibrate the IIquid membrane electrode. These calibration curves were compared to the curves developed from the interference sample solutions in order to evaluste the extent of interference from the different substances studied. Program SALTIV was used to caleulate 


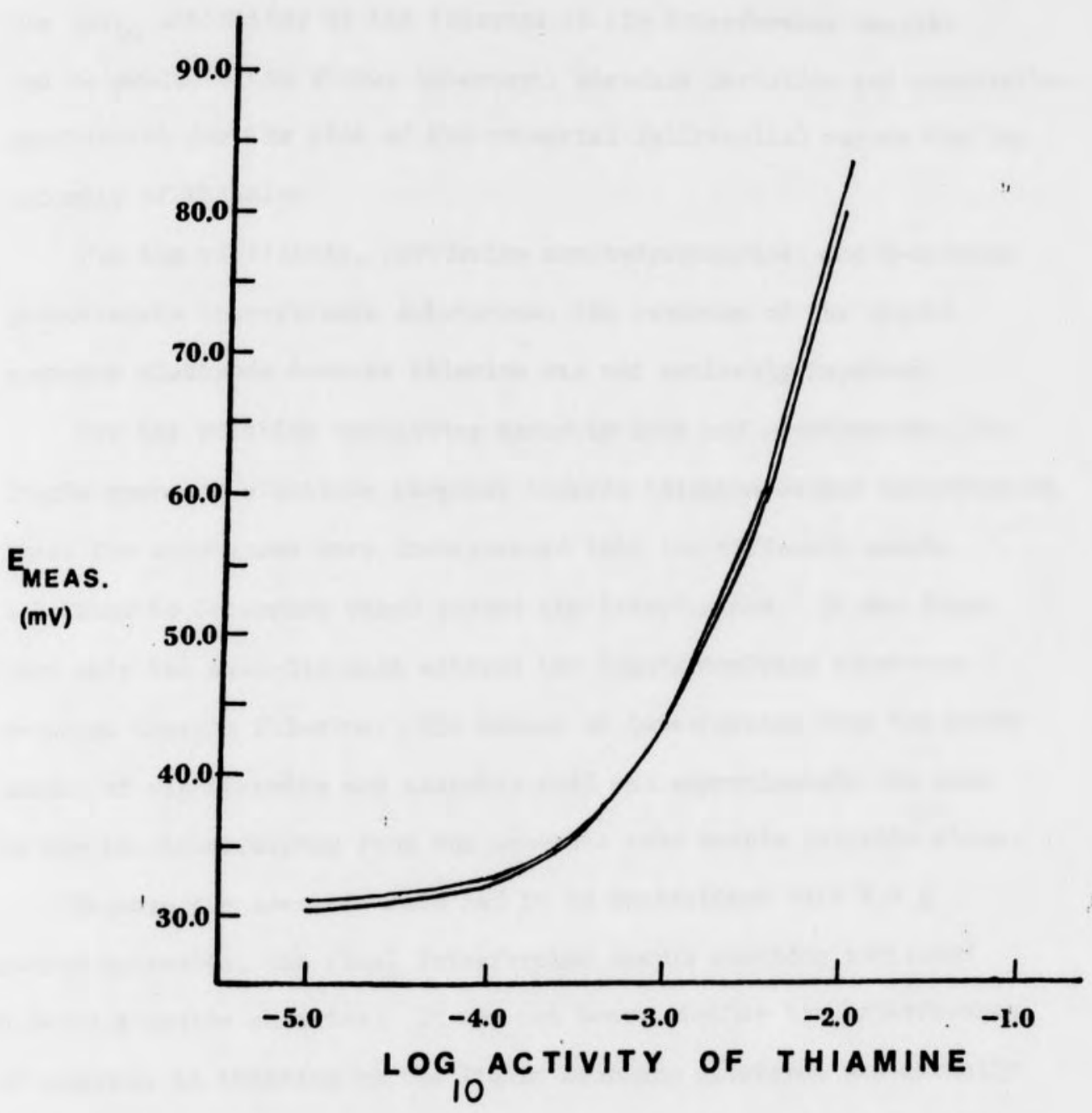

Figure 11. A working curve 1llustrating the response and reproduclbility of the $1: 1$ chloroform-octanol-1 liquid membrane - lectrode towards different thiamine concentrations (two separate trials). 
the $\log _{10}$ activities of the thiamine in the interference samples and to evaluate the slope, intercept, standard deviation and correlation coefficient for the plot of the potential (millivolts) versus the log activity of thiamine.

For the riboflavin, pyridoxine monohydrochloride, and d-calcium pantothenate Interference substances, the response of the 11quid membrane electrode towards thiamine was not noticably impaired.

For the solution containing ascorbic acid and nicotinamide, the I1quid membrane electrode response towards thiamine showed interference. These two substances were incorporated into two different sample solutions to determine which caused the interference. It was found that only the ascorbic acid altered the liquid membrane electrode response towards thiamine. The amount of interference from the mixed sample of nicotinamide and ascorble acid was approximately the same as for the interference from the ascorbic acid sample solution alone.

Because the ascorbic acid had to be neutralized with $1.0 \mathrm{M}$ sodium hydroxide, the final interference sample solution contained $0.04240 \underline{M}$ sodium chloride. It was not known whether the interference of response to thiamine by the liquid membrane electrode was actually due to the ascorble acid or to the sodium chloride produced from the neutralization of the ascorble acid. Another trial was made to determine if Interference wes due to the sodium chloride by prepering a sample solution of $0.04240 \underline{M}$ sodium chloride solution in the $\mathrm{pH}$ 6.0 buffer solution. Using program SALTIV, the working curve for this trial is shown in Figure 12 along with a calibration working 


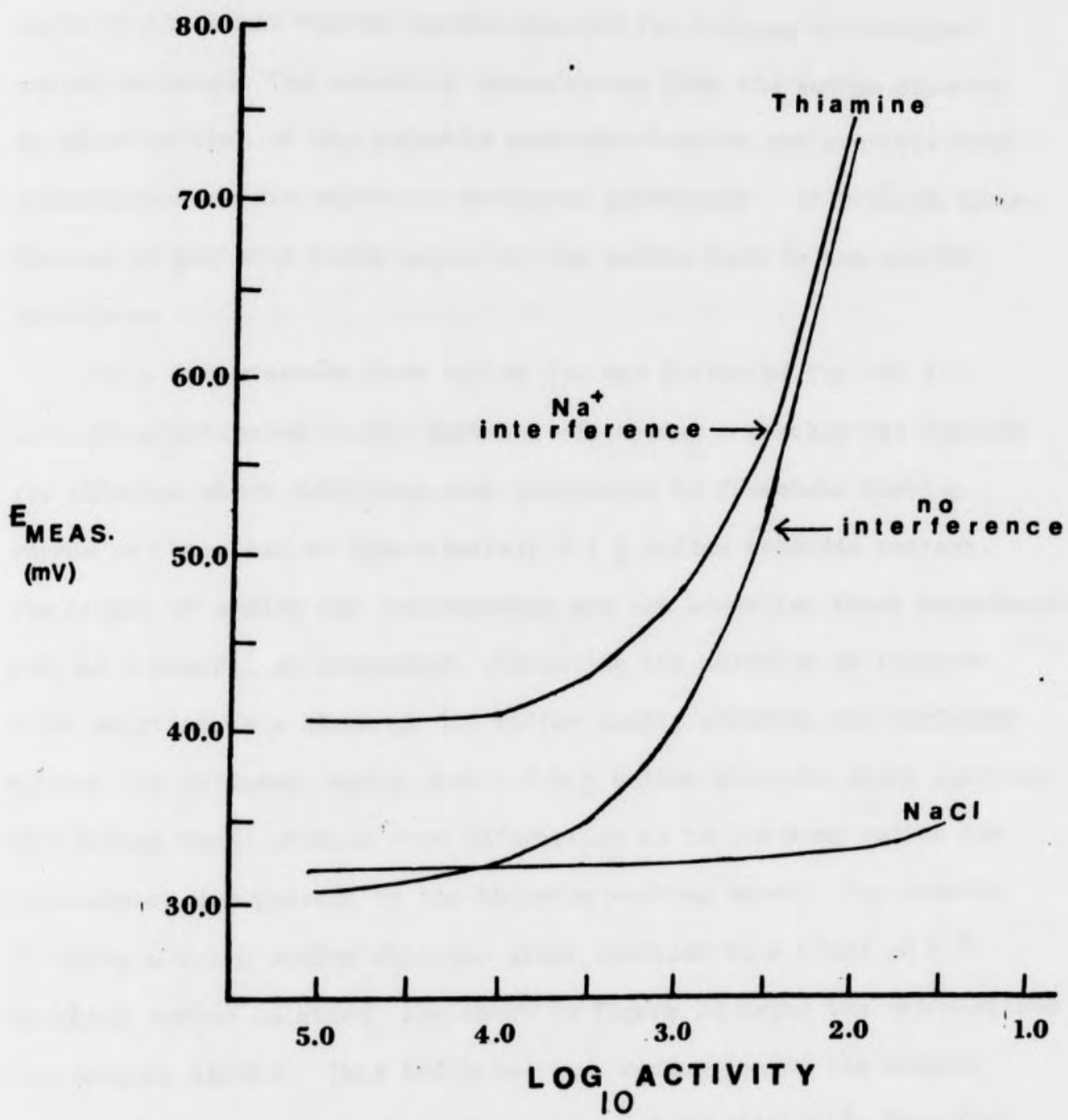

Figure 12. A working curve 1llustrating the response of the $1: 1$ chloroform-octanol-1 liquid membrane electrode towards thiamine with and without sodium lon 'interference and towards sodium ion without thiamine. 
curve of the blank buffer sample solution for a range of thiamine concentrations. The amount of interference from the sodium chloride is close to thet of the ascorbic acid-nicotinamide and ascorblc acid Interference sample solutions evaluated previously. In reality, interference is probably being caused by the sodium fons in the sample solutions.

Since Interference fram sodium Ion was indicated for the 1:1 chloroform-octanol-1 liquid membrane electrode, a problem was implied for thiamine stock solutions used previously to formulate working curves as these had an approximately $0.1 \underline{M}$ sodfum chloride content. The extent of sodium Ion interference was not known for these experiments and, as a result, an experiment simulating the addition of thiamine stock solution to a blank pH 6.0 buffer sample solution was performed without the thiamine, using just a $0.1 \underline{M}$ sodium chloride stock solution. This method would provide sane information as to how much sodium ion interference was present in the thiamine working curve. The results of adding a $0.1 \underline{M}$ sodium chloride stock solution to a blank $\mathrm{pH} 6.0$ phosphate buffer solution are shown in Figure 12 using the calculations from program SALTEI. Th1s indicated that sodium ion in the amounts found in the thiamine stock solutions did not substantially interfere whth this liquid membrane electrode response torrards thiamine, and proved that the electrode is actually responding towards thiamine for the concentration range studied. It was established that the liquid membrane electrode started to be affected by sodium lons at a high concentration level beginning approximately at $0.4 \underline{M}$. This explained why the measured potential shifted when a $0.0424 \underline{M}$ sodium chloride 
In the pH 6.0 buffer sample solution was used. The Initial sodium Ion level from the added interference and from the buffer solution Itself exceeded the sodium Ion concentration where interfering response by the liquid membrene electrode starts. Before addition of any thlamine stock solution, the sodium ion interfering sample solution already has a sodium ion concentration of $0.05 \underline{\text { M. }}$ 
CHAPTER SEVEN

DISCUSSION AND CONCLUSIONS

The lon-exchanger solution using pure chloroform as the solvent produces a Ifquid membrane electrode that gives large measured potential drifting even though in combinations with octanol-1 the measured potential was more stablilized for the different thiamine concentrations analyzed. The probable reason for this potential drift is the partial solubility of chloroform in water. It is known that for liquid membrane electrodes slight potential drifting is caused by leakage of the lon-exchanger solution into the sample solution. Usually these ion-exchanger solvents are highly viscous and leaking is therefore slow. But the chloroform has a very low viscosity and this, in confunction with its solubility in water, makes a poor solvent for the active liquid phase of a liquid membrane electrode. Once the chloroform is cambined with the octanol-1 In any of the amounts Indicated, potential drifting is substantially decreased. Apparently, the octanol-l, a highly viscous solvent, is able to combine with the chloroform to form a solvent with octanol-1's potential stability and chloroform's high thiamine extraction capability as described by Das Gupta and Cadwallader. ${ }^{29}$

When employlng the $1: 1$ chloroform-octanol-1 liquid membrane electrode, the $\mathrm{pH}$ of the sample solutions must be controlled by a buffer solution, common treatment for clinical analysis. The best pH is $5.5-7.5$. The graph showing the pH dependence of the electrode 
was not syumetrical, probably due to the probable decamposition of thiamine in alkaline solutions. Alkalinity could also explain the irreproducibility found for two consecutive trials. Immersion of the electrode in an alkaline solution could be destructive to the 11quid membrane making the electrode response for the second trial different than the first. The 1,1 chloroform-octanol-1 liquid membrane electrode has the capability of being utilized for at least five hours without recalibration. Within this time, the electrode showed a relative precision of about 2.04 . Also, the response time is relatively fast, taking up to one minute for low thiamine concentrations and about thirty seconds for high thismine concentrations. The quick response Indicates that the thiamine-bramothymol blue ion-exchanger site in the active liquid phase has the necessary mobility in the solvent used In this electrode. A feature of the electrode that should be noted is its non-ideal Nernstian response towards thiamine. The thiamine seems to behave neither as a univalent or a divalent species. According to Ishibashi, Kina, and Maekawa? their Ilquid membrane electrode responded to thiamine as a bivalent species. This does not necessarily prove thiamine to be a bivalent species at the pH range studied. Nevertheless, in practical usage it is more important for the liquid membrane electrode to respond reproducibly and selectively than to respond in a Nernstian manner even though it is advantageous to possess both in an electrode system.

For practical application in determining thismine concentration In camercially available vitam in capsules, one capsule per 20-25 ml 
of $\mathrm{pH} 6.0$ buffer solution would be necessary for analysis by the $1: 1$ chloroform-octanol-1 liquid membrane electrode. For convenience in these experiments, the amount of Interference substances analyzed in the sample solutions in the project have been increased proportionally to equal the amount found in four capsules dissolved in $100 \mathrm{ml}$ of pH 6.0 buffer solution which would contain a thiamine concentration of approximately $1 \times 10^{-3} \mathrm{M}$. The sodium ion concentration in the sample solutions must be known if the thiamine is to be analyzed properly due to sodium ion interference above $0.04 \underline{M}$. To assure no substantial interference fram sodium ion in the sample solutions, sodium ion should be less then $0.04 \underline{M}$ if possible. Potessium ion interference is expected to be similar to sodium ion interference based on the same degree of sodium and potassium interference found in the liquid membrane electrode developed by Ishibash1, KIna, and Naekawa. ${ }^{27}$ The selectivity constant for thiamine in the presence of sodium and potassium lons was calculated to be bout $1 \times 10^{-1}$. The great advantage of this $1: 1$ chloroform-octanol-1 liquid membrane electrode compared to the one developed by Ishibash1, Kina, and Maekawa is the high selectivity for thiamine over pyridoxine monohydrochloride ( $\nabla$ itamin $\mathrm{B}_{6}$ ), making 1 t a more practical electrode for realistic clinical analysis. No interference is expected from any substances found in commercial vitamin capsules with the possible exception of chemical binders which were not tested.

For further studies with the 1:1 chloroform-octanol-1 liquid membrane electrode, thiemine mononitrate stock solutions could be used to calibrate the electrode. Three important features of using thiamine mononitrate are 
that it would not require as much preparation for weighing because of 1ts low hygroscopicity, the thiamine mononitrate stock solution would not have the initial acidity of its thiamine hydrochloride counterpart, possibly oliminating the neutralization stop with sodium hydroxide, and, finally, this species is used more extensively in pharmaceutical preparations than thiamine hydrochloride because of 1ts better time stability so that calibration of the liquid membrane electrode would be attained using the same thiamine form as used in these pharmaceutical preparations. Further analyses of different pharmaceutical preparations containing thiamine may be examined with the corresponding interference study of other substances found in these preperations. Also, in the future, it may be possible to analyze blood samples after proper study of the IIquid membrane electrode for this type of analysis.

A new area that requires investigation is the finding of a better solvent for the lon-exchanger solution that will increase electrode response at an even lower thiamine concentration while at the same time maintain response and reproducibility, making it a more practical electrode to use for further clinical analysis. 
PART II

AUTOMATION OF THE ION-SELECTIVE ELECTRODE APPARATUS 


\section{CHAPTER ONE}

\section{INTRODUCTION}

In the development and utilization of lon-selective electrodes for analytical studies, it is necessary that a large number of routine samples be analyzed. There are usually two methods used for determining the potential response of lan-selective electrodes for the various concentration ranges of the ion of interest. One is to prepare the solutions of the fon before analysis and the other is to systematically add a stock solution of the Ion to an Initial volume of solvent to obtain the range of concentrations desired. This latter method is probably the better of the two, since the electrode is continously irmersed in the solution for all the concentration ranges and any error due to the removal and cleaning of the electrode as performed in the first method is eliminated. For this reason, the second method has been choosen for our current research in the analysis of Ion-selective electrodes. In this procedure, the manual addition of a stock solution Into a reaction cell and manual recording of the potential would be tedious and time consuming. To solve this difficulty, a hard-wire autconatic pump unit for solution addition has been developed which handles addition of a stock solution of desired volumes either by a manual control or by an automatic control. In confunction with this unit, ata recording system was developed to store the potential reading of the electrode cell for the different concentrations studied.

Same of the advantages of this particular system are the easy 
control of the volumes of solution being delivered to the reaction cell and the reproducibility of these volumes for each different test trial. The system gives accurate data which are stored for later evaluation and, when in autcmatic control, stops when all desired solution concentrations have been analyzed. Th1s automatic control allows the analyst to perform other duties while the pump is operating In this mode because no supervision is required. 
Figure 13 shows the block diagram of the autcomatic pump system. Eech unit's function and implementation are as follows. The pump delivery system was tested with two types of pump: syringe and peristaltic. During a solution addition, the pump delivery system emits a certain volume of stock solution each time a pulse is sent to it from the auto pump unit. The amount of solution displaced into the reaction cell depends on the length of this pulse. The voltmeter is used to measure the potential difference between a reference electrode and the appropriate lon-selective electrode for the different solution concentration ranges being determined. The automatic pump unit consists of two sections, the decision unit and the pulse generator. The decision unit determines the mament to add stock solution, while the pulse generator responds to the information provided by the decision unit by sending pulses of the appropriate length and timing required by the pump delivery system. The timer unit consists of a quartz oscillator and scaler. The rate of the output time pulses are programable by a series of switches which select the scale to be utilized. The amplifier and filter unit is designed to amplify the output signal of the voltmeter and to simultaneously filter out noise that could Interfer with the decision section of the auto prmp unit. The amplifier and filter unit contains several amplification selections and a separate control for several filter selections. The advantage of this unit is the compectness of its structure and conventence of signal 


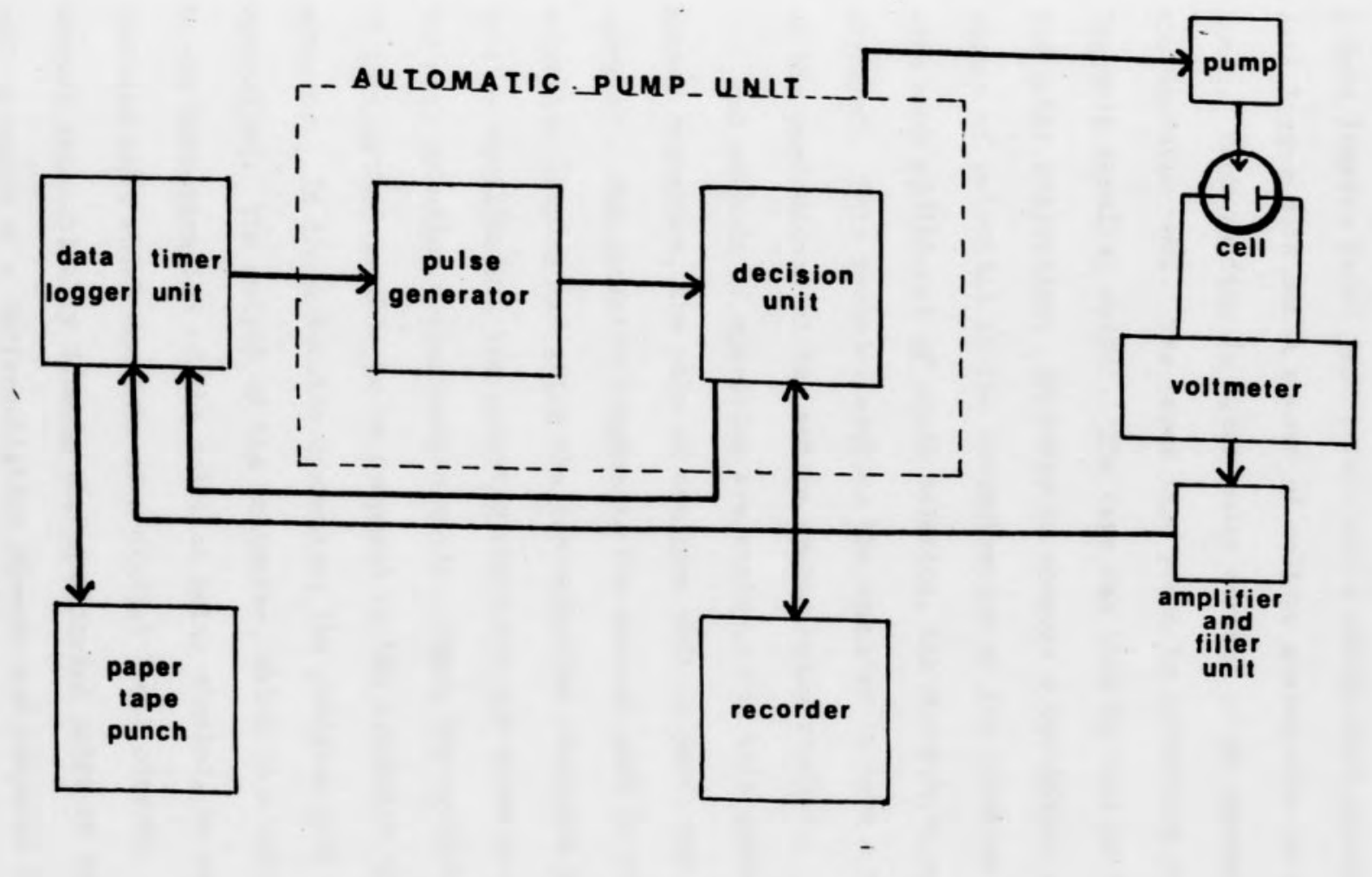

Figure 13. Block Diagram of the Automatic Pump System 
regulation in one package. The data recording system incorporates a data logger, paper tape punch, and a strip-chart recorder. The data logger puts out a record of voltage analog data to a peper tape punch. Each reading is taken under control of an external pulse from the decision unit. The paper tape punch is interfaced for the data logger's parallel output. The tape can then be used as data storage for later evaluation. In order to observe a continuous scan of the change of potential as the concentration of the solution is changed with each additional of stock solution, the stripchart recorder is employed. This recorder enables the operator to have a visual account of the performance of the entire system being studied.

Two methods of operation are employed for this system. In the mamul operation, the role of decision unit is performed by a human operator. The operator behaves as the control unit by viewing the voltmeter display and after the ion-selective electrode potential attains equilibrium, the operator activates the pulse generator for the next solution concentration study. Thus, the equilibrium detection by this method is able to be compered to the automatic operation for accuracy. In the automatic operation, the decision unit is hardwarecontrolled. The output of the voltmeter, which is a voltage related to the concentration of the solution being studied, is sent to the decision unit which consists of a digital logic circuit. This $\log 1 \mathrm{c}$ circuit autcomatically detects the equilibrium point of the reaction cell by means of a differentiation circuit and compares the differentiator output to a reference voltage. When equilibrium is attained, the pulse generator is activated for the next solution addition. 
A schematic diagram of the digital logic circuit comprising both the pulse generator and decision unit used in the auto pump unit 1s shown in Figure 14 and Figure 15. Table 4 gives the symbol designations for these figures.

In the pulse generator, each Gl gate acts as a divide-by-two gate for the clock input pulse to each gate. As a result, each gate Gl doubles the length of the pulse of the preceding gate Gl, thus, giving the different pulse lengths. The reason for this pulse-doubling operation is related to the Nernst equation where the solution concentration factor is logarithmic. The output of each of these seven GI gates is placed in a data selector/multiplexer integrated elrcuit controlled by a decade counting unit. This binary coded count selects which pulse length of a particular Gl gate output is to be sent to the pump delivery system. The combination of the decade counting unit and dats selector/multiplexer allows each different length pulse to be associated with a binary count number from the decade counting unit. This decade counting unit has a count range fram zero to nine, and every time an output pulse from the multiplexer ends, a monostable multivibrator connected to the clock input of the decade counting unit cammands the decade counting unit to increase one count. If one particular pulse length is desired for every solution addition, the count associated with that pulse length can be selected, and a multiplexer pulse control switch can be thrown to "on" position to keep the decade counting unit at that desired count.

Contained within the decision unit is a manusl reset push button 
PULSE GENERATOR

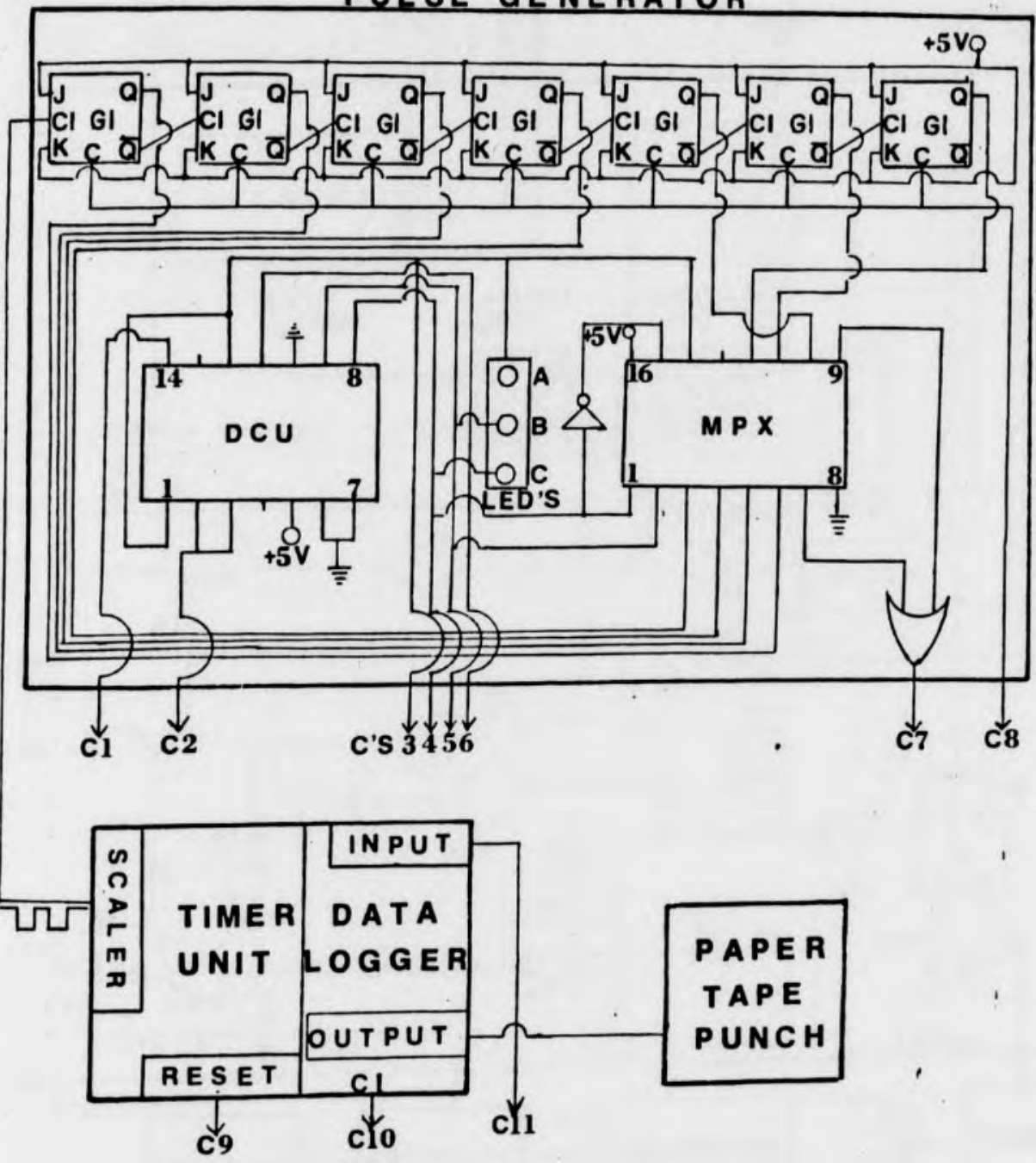

Figure 14. Schematic Diagram of the Circuit Design for the Puilse Generator of the Automatic Pump Unit 


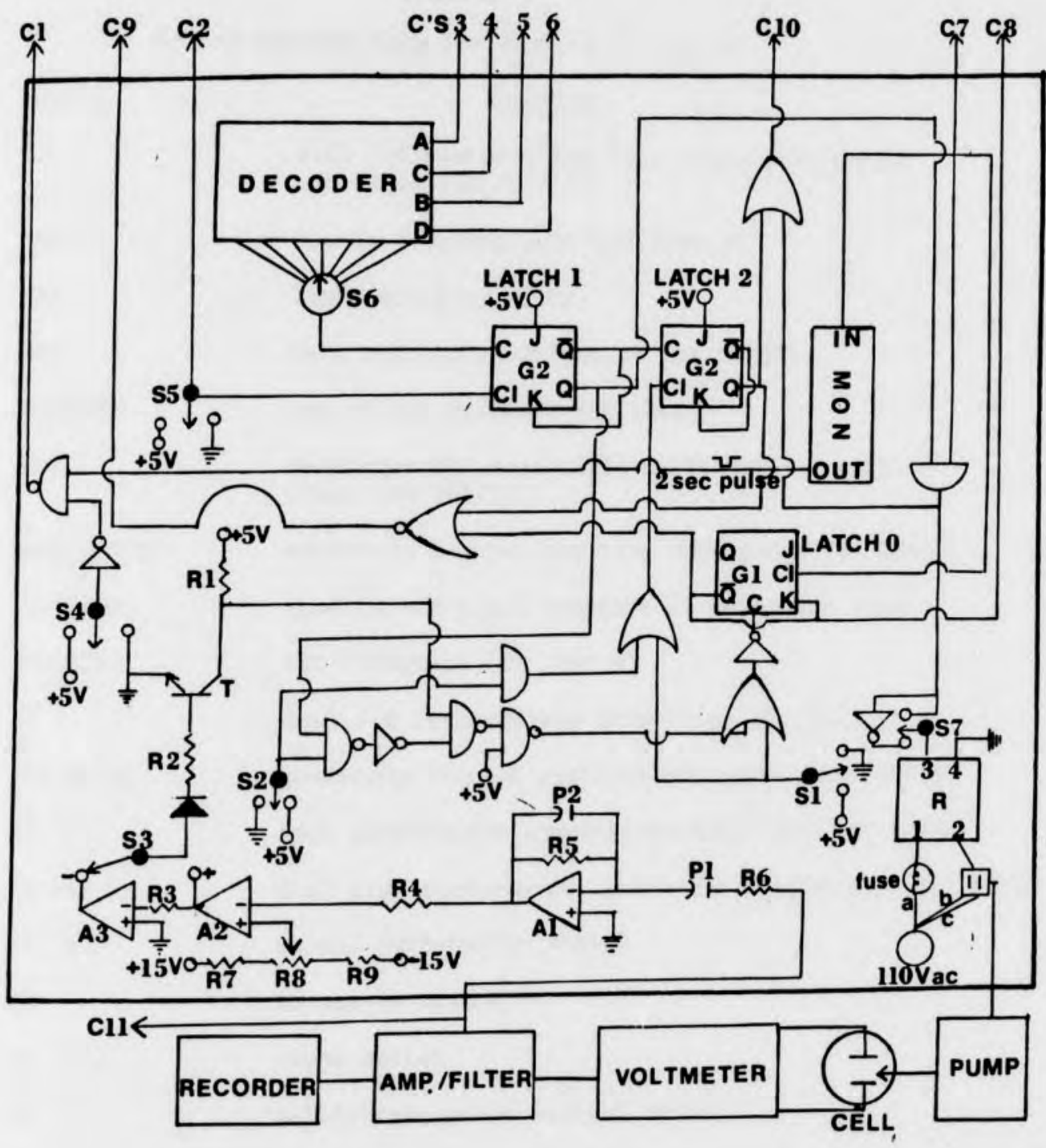

Figure 15. Schematic Diagram of the Circult Design for the Decision Onit of the Autcomatic Pump Unit 


\section{Table 4}

Symbol Desiganations for Figures 13 and 14

Symbol

GI

DCU

LED

MPX

DECODER

MON

NAND GATES

OR GATES

INVERTER

G2

NOR GATES

Al

$A 2$ and $A 3$

S1

s2

S3

S4

S5

s6

S?

RI

R2

\section{Function}

dual J-K master-slave flip flops with preset and clear (SN $7476 \mathrm{~N}$ )

decade counting unit (SN $7490 \mathrm{~N}$ )

light emitting diode

deta selector/mult1plexer (SN 74153)

one of ten decoders (SN 7442)

retriggerable monostable mult1vibrator with clear (SN 74123)

quadruple 2-input positive NAND gates (M $74 \mathrm{HOOJ}$ )

quadruple 2-input positive OR gates (DM 7432)

hex inverters (SN $7404 \mathrm{~N}$ )

dual J-K master-slave flip flops (SN $7473 \mathrm{~N}$ )

quadruple 2-input positive NOR gates (SN $7402 \mathrm{~N}$ )

high performance operational amplifier (SN 72307)

dual high performance operational amplifier (SN 72747)

manual push-butt on switch

autconatic switch

slope switch

mult1plexer pulse control switch

manual reset push-button switch

termination selector switch

relay switch

$2.2 \mathrm{k}$ ohm resistor

$1 \mathrm{k}$ ohm resistor 
Table 4 (con't.)

Symbol

Function

R3 and R4

R5

$\mathrm{R} 6$ and $\mathrm{R} 8$

$R 7$ and $R 9$

P1

P2

T

R

2

b

c

C

cI

$J$ and $K$

$Q$ and $\bar{Q}$

Cl to Cll
$20 \mathrm{k}$ ohm resistor

$10 \mathrm{k}$ ohm resistor

$100 \mathrm{k}$ ohm resistor

$500 \mathrm{k}$ ohm resistor

$10 \mu \mathrm{F}$ capactior

0.1 rF capacitor

trans1st or ( $\mathrm{T}-336-2 \mathrm{~T}-1811)$

Teledyne relay ( $P / N$ 611-1)

hot line

ground

neutral

clear

clock

Inputs

outputs

connection leads 
swltch used to reset the decade counting unit back to the zero count. Th1s swltch not only resets the decade counting unit, but it also prepares the latch 1 circuit used in confunction with the termination selector for operation. The selector allows the operator to set the count, representing a certain length pulse, that will automatically stop the operation of the auto pump unit after that count pulse is finished. The selector originates from a "one of ten" decoder eircuit which transfers the binary code of the decade counting unit, from zero to nine, into ten separate pulses. When the reset switch is engaged, the $Q$ of the latch $I$ eireuit is one $(+5 \mathrm{~V})$ as long as the termination selector is not in the shut-off state after the last count pulse. When this shut-off state does occur, the $Q$ of latch 1 chenges to $O$ (ground), disabling with an AND gate any further count pulses from the multiplexer output to the pump delivery system gate. This enables the pump to respond to only the desired pulses. The recycling of the pulse count can only be started again when the reset swltch is engaged once more.

The data logger takes a voltage reading only if its clock is triggered from 0 to 1 . This triggering is accomplished whenever the pump is switched on because it is understood that the pump will only add the stock solution when potential equilibrium in the cell is attained. Unfortunately, this works well for all the pulse counts except when the last pulse count is finished at which time the pump, as explained above, is shut-off permanently due to the latch 1 eircuit. To compensate for this circult limitation, the latch 2 circult was 
devised especially to trigger the data logger clock at the end of the last pulse count. When the $\bar{Q}$ of the latch 1 elreuit goes from 0 to 1 with the completion of the last pulse count as decided by the termination selector, the $Q$ of latch 2 remains 0 until the latch 2 clock is triggered from 0 to 1 when the cell potential reaches equilibrium, $Q$ goes to 1 and the last date point $1 \mathrm{~s}$ recorded. It should be noted that the latch $2 Q$ can only be triggered this one time because no matter how many times the latch 2 clock is triggered the $Q$ still remains in the 1 state unt1l the reset switch is engaged and the $Q$ roturns to 0 .

The starting owitch to enable and disable the pulse generator Is actually a dual system, with both manual and automatic control. Both are connected to latch 0 where the clear is initially in a 1 state and the clock in a 0 state. When the manus 1 or auto control switch goes from 1 to 0 , the clear of latch 0 goes from 1 to 0 and back to 1 again, but the $\bar{Q}$ of latch 0 , which is Initially at 0 , is set to 1. The NOR gate is connected not only to the $\bar{Q}$ of latch 0 but also to the $Q$ of latch 2 which is initially at 0 until the end of the last pulse count when potent1al equilibrium is reached as described above. When the $\bar{Q}$ of latch 0 goes fram 0 to 1 . The reset of the timer unit, Initisily at $1,1 s$ grounded and the elock starts. Simultaneously, the clear of the G1 gates in the pulse generator goes to 1 which starts the divide-by-two timers. The $\bar{Q}$ of latch 0 goes beck to Its original state when the end of the pulse from the multiplexer is $\mathrm{fin} 1 \mathrm{shed}$. It is then necessery to have the aut cmatic or manual switch turn on agein in order to have the next pulse start 
the pump delivery system. When the lest pulse count is finished, the $Q$ of latch 2 (as explained above) goes from 0 to 1 wh1ch starts the timer unit by bringing the reset to 0 through the NOR gate but it does not start the pulse generator G1 gates as these depend on the $\bar{Q}$ of latch 0 . Because the data logger clock is established around the ame timer unit, the $Q$ of latch 2 starts the timer unit only for the purpose of allowing the last potential to be recorded by the data logger, since this timer unit has to be off reset to be in the recording mode.

The manual control is merely a push button switch, which the operator depresses when a pulse is needed to start the pump. The automatic control, however, is basically a differentiator circult with two comparators and an interfacing transistor awitch for conversion of voltage into proper logic voltage. The output of the voltmeter is amplified and filtered and is connected to the differentiator circuit camposed of two resistors and two capacitors and a 307 integrated circult operational amplifier, A1. The gain of this differential circult is dependent on the $10 \mu \mathrm{F}$ capecitor and the $10 \mathrm{~m} \Omega$ resistor. The $0.1 \mu \mathrm{F}$ capecitor and the $100 \mathrm{k} \Omega$ resistor are connected only for additional filter purposes necessary for an operational amplifier differentiator circult. When the output of the Al operational amplifier reaches the reference level of comperator A2, a 747 operation amplifier 11ke A3, the comparator output has been adjusted to go to $-15 \mathrm{~V}$ from $+15 \mathrm{~V}$ for reasons that will be explained later. In the study of ionselective electrode systems, it is known that the change of potential increases for cations or decreases for antons as solution concentration 
increases. Because of this principle, two operational amplifiers, A2 and A3, are utilized for the comparator switch. A2 is used for an increasing potential signal with an increase of solution concentration and $A$, serving as an inverter, is used for a decreasing potential signal with an increase of solution concentration. Elther one can be enabled by employing the slope switch indicating + for the A2 and - for the A3. When a certain volume of solution is added to the reaction vessel, the amplified and filtered output voltage of the voltmeter changes to a large positive or negative voltage depending on the direction of the potential change, and the comparator changes to a $+15 \mathrm{~V}$ since the reference voltage of the comparator has been adfusted to be approximately $0 \mathrm{~V}$. The comparator is usually not set exactly on zero because the nolse In the entire system has to be accounted for and, therefore, the comparator has to be adjusted to respond to a voltage fust outside that level of noise. When the voltmeter responds to the equilibrium potential of the reaction cell, the change of amplified voltage to the differentiator circuit is zero, making the output of the differentiator clrcuit likewise zero, which is detected by the comparator with a reference voltage of approximately zero. This zero differentiator circult output triggers the comparator from $+15 \mathrm{~V}$, the state of the comparator at non-equilibrium potential, into a $-15 \mathrm{~V}$, the state of the comparator at equilibrium potential. The comparators $A 2$ and $A 3$ are connected to the transistor switch, which allows the comparator signels to be converted into digital logic voltage of ground and $+5 \mathrm{v}$. The diode installed before the transistor allows only the positive voltage through to the transistor switch. 
For either $A 2$ or $A 3$, when the output is $+15 \mathrm{~V}$, indicating non-equilibrium potent1al, the $+15 \mathrm{~V}$ is passed to the base of the transistor, giving it a low resistance which allows the current from the $+5 \mathrm{~V}$ power supply to flow through the transistor. Therefore, the output at the collector going into the $\log 1 \mathrm{c}$ eireuit is at ground. This ground signal does not allow the pulse generator to be activated. However, when the comparator output is $-15 \mathrm{~V}$, indicating equilibrium potential, the $-15 \mathrm{~V}$ is not allowed through the diode, making the transistor posses a high resistance. Thus, the output of the collector going into the logic circuit is $+5 \mathrm{~V}$, which activates the pulse generator under the following conditons. The $\log 1 \mathrm{c}$ circuit of the automatic control is constructed so that the $+5 \mathrm{~V}$ transistor trigger pulse cannot activate the pulse generator unless the autcomatic switch is thrown on and unless the $Q$ of latch 1 is 1, which is 1ts state before the end of the desired last pulse count. When this last pulse finishes, the transistors trigger pulse is unable to pass into latch 0 , which sets off the pulse generator, beceuse the $Q$ of latch 1 is switched to 0 . However, the transistor trigger pulse can clock into the latch 2 circuit which triggers the data logger to record the last amplified potential reading of the voltmeter when potentiel equilibrium is reached. The advantage of the latch 2 circult can be seen in that no matter how frequently the transistor trigger pulse attempts to reclock the latch after the last recording. Its $Q$ never changes state unt 11 the reset button is ongaged bringing the entire system beck to its initial state.

All the pulses that lead out to the pump delivery system pass through a relay switch which allows the operator to switch the pump manually to the opposite voltage signal being given off by the pulse 
generator, or it allows the pump to receive the voltage signal exactly as it comes out of the pulse generator. A relay unit is connected before the pump to convert the $+5 \mathrm{~V}$ output pulse directed to the pump from the auto pump system into a $110 \mathrm{v} A C$ power source to start the pump which operates only on this AC voltage. 


\section{CHAPTER THREE}

RESULTS AND DISCUSSION

As mentioned previously, two types of pump delivery systems were employed, one syringe pump and the other a peristaltic pump. Both of these were calibrated by using the mamal control mode of the automatic pump unit. This calibration determined that the syringe pump used in this particular test is capable of 0.64 precision while the peristaltic pump used in the test is capable of $1.0 \%$ precision. The advantage of the syringe pump is its greater precision and its ability to deliver the sample volumes of stock solution in a shorter time, which makes the differential eircuit in the decision unit of the automatic pump system more sensitive due to the large change of potential being detected. The disadvantage is the necessity of refilling the syringe mamally for each set of different volumes and the problem of mounting the syringe pump properly. On the other hand, the advantage of the peristaltic pump is that there is one stock solution reservolr which supplies the pump continously with stock solution without the need for frequent filling. and there is the conventence of having the pump ready instantaneously for actual testing purposes. However, the disadvantage is that even at 1ts maximum speed, the pump still delivers solution more slowly than the syringe pump, making the change of potential detected by the differentiator circuit smaller and, thus, reducing the sensitivity of the automatic pump unit. 
A typical strip-chart recorder plot of an actual test with the syringe pump delivery system is shown in Figure 16. This plot displays the potential scan of the reaction cell containing a fluoride lonsolective electrode and an appropriate reference electrode for five different fluoride ion concentrations at a temperature of $25^{\circ} \mathrm{C}$. Table 5 lists the concentrations of fluoride lon being analyzed and the corresponding potential for each plateau indicated on the plot in Figure 15. The potential is the recorded voltage output from the voltmeter amplified through the amplifier-filter unit.

\section{Table 5}

Analysis of Strip-Chart Recorder Plot of Potentisl versus Fluoride Ion Concentration

$\begin{array}{clc}\text { Plateau } & \frac{F^{-} \text {Conc. }(M)}{1} & \text { Potent181 (volts) } \\ 1 & 9.80 \times 10^{-4} & +0.532 \\ 2 & 2.63 \times 10^{-3} & +0.048 \\ 3 & 5.61 \times 10^{-3} & -0.315 \\ 4 & 1.12 \times 10^{-2} & -0.641 \\ 5 & 2.16 \times 10^{-2} & -0.943\end{array}$

It must be stated that these concentrations are not the limit that can be evaluated by this automatic pump system; they are merely used to 1llustrate the capability of this system. When the lon-selective electrode responds completely to the concentration of the solution in the resction cell, a plateau is recorded on the plot indicating the equilibrium response of the electrode. As demonstrated in the plot, the equilibrium plateau is followed by another stock solution addition, indicated by a change 
96

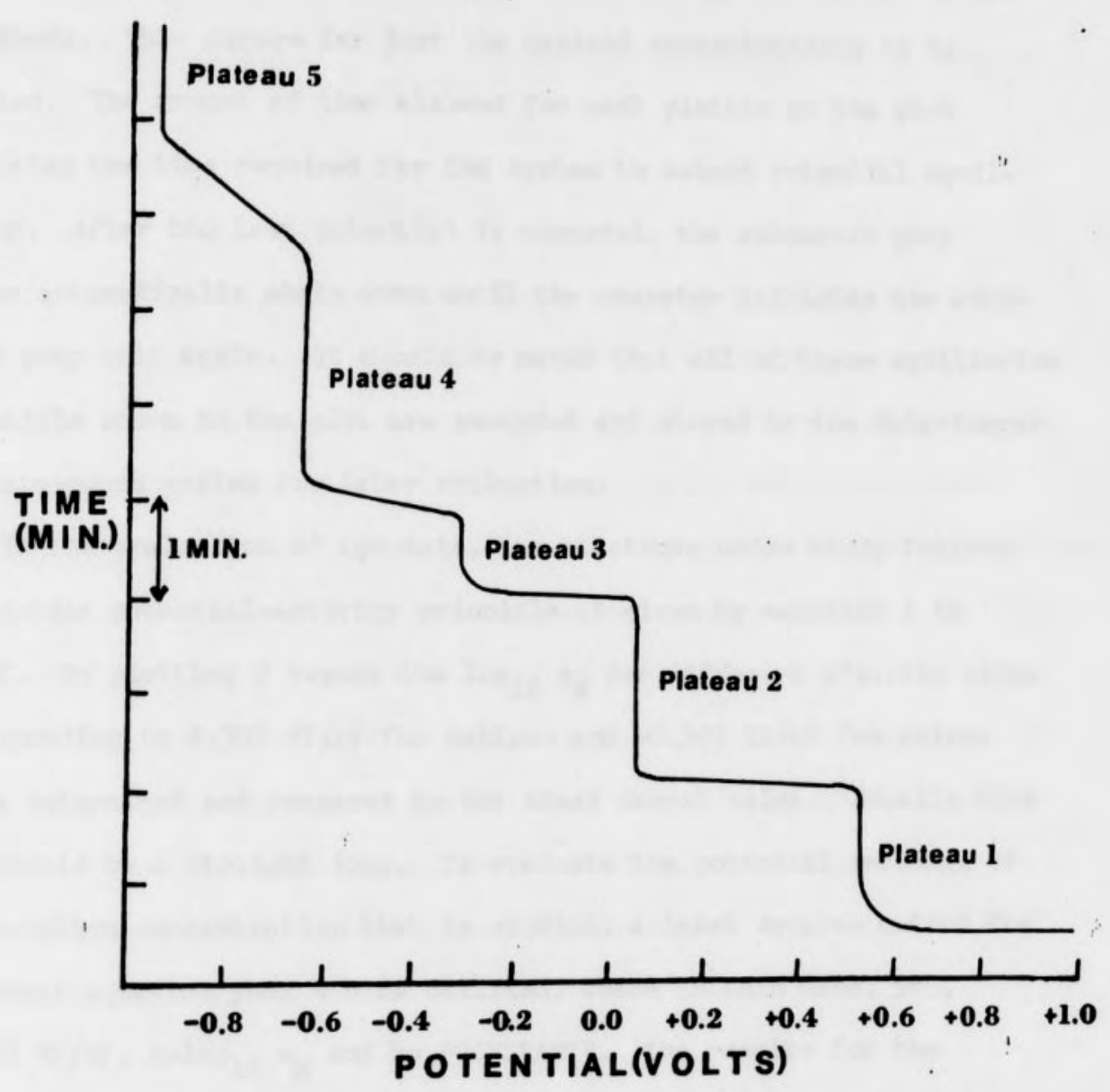

FIgure 16. lustration of a strip-chart recorder scan of fluoride electrode response towards five different fluoride concernrations using the automatic pump unit working with a syringe pump delivery system. 
In slope, until en equilibrium response is once again detected by the electrode. This occurs for fust the desired concentrations to be studied. The amount of time elapsed for each plateru on the plot Indicates the time required for the system to detect potential equil1brium. After the last potentiel is recorded, the automatic pump system automatically shuts down unt 11 the operator initiates the automat1c pump unit again. It should be noted that all of these equilibrium potent 1s is shown in the plot are recorded and stored by the data-logger and tape-punch system for later evaluation.

In the evaluation of the data, the electrode under study follows a Nernstian potentisl-sctivity principle as given by equation 1 in Part I. By plotting E versus the $\log _{10} 2 \mathrm{M}$ for different $a^{\prime} s$, the slope corresponding to $2.303 \mathrm{RT} / \mathrm{nF}$ for cations and $-2.303 \mathrm{RT} / \mathrm{nF}$ for anions can be determined and compared to the 1deal Nernst value. Ideally this plot should be straight line. To evaluate the potential readings of each solution concentration that is studied, a least squares method for the Iinear equation $y=m x+b$ is utilized, where in this case, $y=E$, $m=2.303 \mathrm{RT} / \mathrm{nF}, x=\log _{10} \mathrm{~m}$ and $\mathrm{b}=$ "CONSTANT". The results for the fluoride electrode using both the syringe and peristaltic pump showed good reproductbility and the Individual data points correlated well with the slope of the $E$ versus $\log _{10} a_{M}$ plot. Also, when the results of the automatic control mode were compared to those of the manual control with the peristaltic pump delivery system, which has a higher relative standard deviation of 1.04 compared to the syringe pump with only a relative standard deviation of $0.6 \%$, very good agreement was obtalned. 
In general, the entire aut cmatic pump system has proven to be effictent and reliable for the study of electrode response in solution analysis.

\section{Summary}

In conclusion, the thiamine liquid membrane electrode employing the thiamine-bromothymol blue salt in the $1: 1$ chloroform-octanol-1 ionexchanger solution is suitable and convenient for limited clinical use of thiamine determination in certain camercially available vitamin preperations with no interference problems except for high concentrations of sodium Ion (above $0.04 \underline{\mathrm{M}}$ ). This electrode is $\mathrm{pH}$ dependent with fair response starting at $1 \times 10^{-3} \underline{\mathrm{M}}$ thiamine concentration in a $\mathrm{pH} 6.0$ buffer sample solution and has a high degree of reproducibility.

An automatic system for use with ion-selective electrode analysis has been successfully developed for controlling the addition of known Incremental volumes of solutions and for recording the potential of the fon-selective electrode cell after solution addition. 


\section{BIBLIOGRAPHY}

(1) G. A. Rechnitz, Chem. Eng. News, 53(4), 29(1975).

(2) C. W. Davles, J. Chem. Soc., 2093(1938).

(3) G. J. Moody and J. D. R. Thomas, "Selective Ion Sensitive Electrodes", Merrow Publishing Co. Itd., Watford Herts, England, 1971, pp 2-24.

(4) G. J. Moody and J. D. R. Thomas, 1bid., p 10.

(5) G. J. Moody and J. D. R. Thomas, 1bid., p 12.

(6) G. J. Moody and J. D. R. Thomas, 1b1d., p 13.

(7) G. J. Moody and J. D. R. Thomas, 1bid., p 16.

(8) K. Srinivasan and G. A. Rechnitz, Anal. Chem., 41, 1203(1969).

(9) H. D. Portnoy, E. S. Gurdjian, and B. Henry, Am. J. Clin. Pathol., 45. 283(1966).

(10) H. D. Portnoy and E. S. Gurdjian, Clin. Chim. Acta., 12, 249(1965).

(II) J. W. Ross in "Ion-Selective Electrodes", R. A. Durst, Ed., National Bureau of Standards Special Publication 314, U. S. Government Printing office, Washington, D. C., 1969, pp 77-80.

(12) M. S. Frant and J. W. Ross, Sctence, 154, 3756(1966).

(13) D. R. Tares, Nature, 217, 1050(1968).

(14) L. Singer and W. D. Armstrong, Anal. Chem., 40, 613(1968).

(15) D. Ammann, E. Protsh, and W. Simon, Anal. Lott., 7, 23(1974).

(16) M. S. Frant and J. W. Ross, Science, 167, 987(1970).

(17) H. B. Herman and G. A. Rechnitz, Science, 184, 1074(1974).

(18) H. B. Herman and G. A. Rechnitz, Anal. Chin. Acta., 76, 155(1975).

(19) J. Koryta, "Ion-Selective Electrodes", Cambridge University Press, Cambridge, England, 1975, pp 52-54. 
(20) F. A. Ibbott, T. S. Is Ganga, J. B. Gin, and J. A. Inkpen In "Clinical Chemistry: Principles and Techniques", 2 nd ed, R. J. Henry, D. C. Cannon, and J. W. Winkelman, Ed., Harper and Row Publishers, Inc.. Hagerstown, Md., 1974, p 790.

(21) H. B. Herman and G. A. Rechnitz, Anal. Lett., 8, 147(1975).

(22) "Merck Index", 8th ed, P. G. Stecher, Dd., Merck and Co., Inc., Rahway, N.J., 1968, pp 1036-1037.

(23) A. Cantarow and M. Trumper, "Clinical Blochemistry", 6th ed, W. B. Saunders Co., Philadelphis, Penn., 1962, pp 668-670.

(24) "Methods of Vitamin Assay", 3rd ed, the Association of Vitamin Chemists, Inc., Ed., Inter Science Publishers Inc., New York, N.Y., 1966, pp 123-124.

(25) J. A. Demetriou in "Clinical Chemistry: Principles and Techniques", 2nd ed, R. J. Henry, D. C. Cannon, and J. W. Winkelman, Ed.. Harper and Row Publishers, Inc., Hagerstown, Md., 1974, pp 1381-1382.

(26) K. A. Valselan, M. S. Thesis, The University of North Carolina, Greensboro, N. C., 1976.

(27) N. Ishibash1, K. Kina, and N. Maekawa, Chem. Lett., 119(1973).

(28) N. Ish1bash1, K. Kina, and N. Maekawa, Bull. Chem. Soc. Japan, 46. $2772(1973)$.

(29) V. Das Gupta and D. E. Cadwallader, J. Pharm. Se1, 57, $112(1968)$.

(30) V. Das Gupta, D. E. Cadwallader, H. B. Herman, and I. L. Honigberg, J. Pharm. Se1., 57, $1199(1968)$.

(31) V. Des Gupta and H. B. Herman, J. Pharm. Se1., 62, 311(1973).

(32) G. J. Moody, R. B. Oke, and J. D. R. Thomas, Anslyst, 95, 910(1970).

(33) G. H. Griffiths, G. J. Moody, and J. D. R. Thomas, Analyst, 97. $420(1972)$.

(34) J. E. W. Davies, G. J. Moody, and J. D. R. Thomas, Analyst, 97. $87(1972)$.

(35) R. W. Cattral1 and S. Tribuzio, Anal. Cham., 46, 2223(1974).

(36) R. G. Bates, "Determination of $\mathrm{pH}$, Theory and Practice", Wiley and Sons Inc., New York, N.Y., pp 73, 94-98.

(37) "United States Pharmacopeia", 15th rev., Mack Publishing Co.. Eeston, Pa.. 1955, pp 930-932. 
(38) D. Perkins, The University of North Carolina at Greensboro, personal communication, 1975.

(39) G. Elserman in "Ion-Selective Electrodes", R. A. Durst, Ed., National Bureau of Standards Special Publication 314, U.S. Governent Printing office, Washington, D. C., 1969, pp 5-6. 
APPENDIX A

Fortran IV Program SALTBI

C PROGRAM SALTBI

OIMENSION ALMLC50),P(50),SALTEC50),IC50),ACTCOF(50), ACTIVESO),LAC -TIV TSO)

DIMENSION DATA 9 )

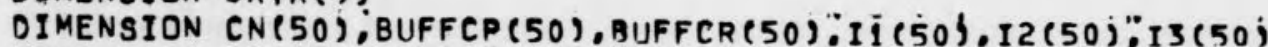

REAL I,I1,I2,I3,LACTIV,INVOL:INT

INPUT $=5$

SOUT 96

JINPUTET

READEINPUT,5;Z,F,FI,F2,F3

5 FORMAT (5E13.4)

READCINPUT, 5 ) CS,BCP,BCR,INVOL, STKCON

3 WRITE (SOUT.6)

6 FORMATE/I ENTER " DATA VALUESI/I

CALL FREE CDATA.1)

NEDATA (1)

WRI TE S JOUT;8;Z,F,FI ,F2;F3

8 FORMAT (/1 Z,F,F1,F2 \& F3 ARE \&!/5E13.4)

WRITE ( JOUT, 9) CS, BCP,BCR, INVDL,STKCON

9 FORMATE/ STK SALT CONC, INVOL BUFF PROD,INVOL BUFF REAGT'INVOL \& \STKCONC ARE:1/5E13:4)

WRITE ( JOUT, 10 ) N

10 PORMATII N ISII/IS)

WRITE (JOUT, 12) 
12 FORMATC/8X, ITOTML'.13X,IPI/1j

DO $13 K=1 . N$

READ (INPUT,15)ALML (K),P(K)

15 FORMAT (2E 15,4 )

13 WRITE (JOUT, 15) ALML (K),P(K)

WRITE ( JOUT.25)

25 FORMAT ( $17 X$, 'SALTCI,16X,II',18X,'ACTCOFI;

WRITE (JOUT.26)

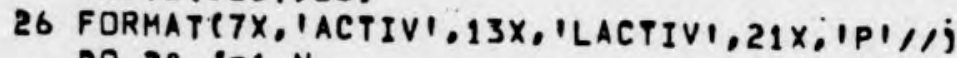

DO $20 \quad J=1, N$

$S A L T C(J)=A L M L(J) * S T K C O N /(I N V O L+A L M L(J) j$

$C N(J)=(A L M L(J) * C S) /(I N V O L+A L M L(J))$

BUFFCP $(J)=(I N V Q L * B C P) /(A L M L(j)+I N V D L)$

BUFFCR $(J)=(I N V O L * B C R) /(A L M L(J)+$ INVOL

$11(\mathrm{~J})=\mathrm{P} 1 * \mathrm{CN}(\mathrm{S})$

$15(J)=F 2 \star B U F F C P(J)$

I3 $3(\mathrm{~J})=\mathrm{F} 3 * \mathrm{BUFFCR}(\mathrm{J})$

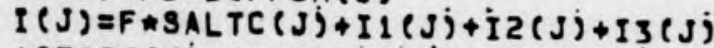

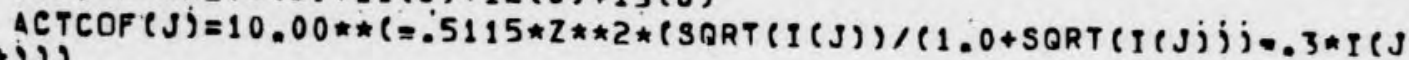

1) 29

ACTIV Jj=SALTC $(J) * A C T C O F(J)$

LACTIVCJ) $=A L O G I O$ (ACTIVCJS)

WRITE (JOUT, 35) SALTC (J):I (J),ACTCOF (J)

35 FORMAT (E15.4.E18.4.E25,4)

20 WRITE (JOUT.36) ACTIVES):LACTIVES):P(J)

36 FORMAT(E15,4,E18,4:E25,4/1)

CALL LINFIT (LACTIV,P,N, INT,SINT,SLOPE,SSLOPE,R) WRITE (SOUT, 904 )

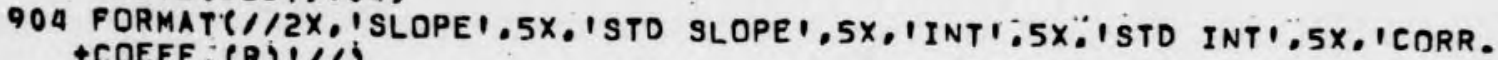
+ COEFF: $(R) 1 / 1)$

WRITE ( SOUT, 905 ) SLOPE,SSLOPE, INT, SINT,R

905 FORMATCF8.2,F11.2.F13.2.F7.2.F15.7j

WRITE ( JOUT.50)

50 FORMATEI DONE? YES 1 , NOCOS $1, j$

CALL FREE CDATA.1; $L=D A T A(1)$ 
IF CL,EQ:1) 160 TO 70

70 CONTINUE

STOP

ต

END 
APPENDIX B

Fortran IV Program SALTIV

C PROGRAM SALTIV

DIMENSION ALML $(50)$,P $(50), S A L T C(50)$, I $(50)$, ACTCOF $(50)$, ACTIV (50),LAC -TIV(50)

DIMENSION DATAC9)

DIMENSION CN $(50)$, BUFFCP $(50)$, BUFFCR $(50)$, I I $(50), 12(50), 13(50)$

DIMENSION CS4 $(50) . C S 5(50), \operatorname{Cs6}(50), C S 7(50), C S B(50)$

DIMENSION I $4(50), 15(50), 16(50), I 7(50), 18(50)$

REAL I,I1,I2,I3,LAETIV, INVOL, INT

REAL I $14,15,16,17,18$

INPUT $=5$

JOUT $=6$

JINPUT $=7$

READ(INPUT,5)Z,F,F I,F2,F3

5 FORMAT (5E13,4)

READCINPUT, S)FA,F5,FG,FT,FB

READ (INPUT, 5)CS,BCP,BCR, INVOL, STKCON

READ (INPUT. 5) S4, $55,36,37,58$

3 WRITE ( JOUT, 6)

6 FORMATE/I ENTER DATA VALUESI//j

CALL FREE (DATA;1)

$N=D A T A(1)$

WRI TE ( JOUT, , 8 ) Z,F, F1,F2,F3

8 FORMATC/I Z,F,F1;F2 \& F3 ARE:1/5E13,4)

WRITE (JOUT, T) PA,PS,FG,FT, FB 
7 FORMATC/, F4,F5,F6,FT \& F8 ARE:1/5E13:4) WRITE ( JOUT, 9 ) CS.BCP.BCR, INVOL, STKCON

9 FORMATCI STK SALT CONC, INVOL BUFF PROD, INVOL BUFF REAGT.INVIL +STKCONC ARE:1/5E13:4j

WRITE ( JOUT.11) 144.55 .36 .37 .98

11 FORMATC/I S4,S5,S6,S7 \& S8 ARE\&I/5E13:4)

WRITE ( JOUT. 10 ) N

IO FORMATEI N IS:1/I5)

WRITE ( JOUT, 12)

12 FORMAT (I8X,ITOTMLI,13X:1PI/1)

DO $13 \mathrm{~K}=1, \mathrm{~N}$

READ (INPUT, 15) ALML (K),P(K)

15 FORMAT (2E15,4)

13 WRITE (JOUT.15) ALML (K).P(K)

WRITE ( JOUT, 25)

25 FORMATC/7X.ISALTCI;16X;'I';18X.'ACTCOFI; WRITE (JOUT, 26 )

26 FORMAT $17 \times$, 'ACTIV', I3X, 'LACTIVI: $21 \times, 1 P 1 / 1$; DO 20 J $201, \mathrm{~N}$

SALTC $(J)=A L M L(J) \neq S T K C O N /(I N V O L+A L M L(J)$

$C N(J)=(A L M L(J) * C S) /(I N V O L+A L M L(j))$

BUFFCP $(J)=(I N V O L * B C P) / C A L M L(J)+I N V O L)$

BUFFCR $(J)=($ INVQL $\star B C R) /(A L M L(J)+I N V O L)$

CSA $(J)=($ INVOL SA) $/(A L M L(J)+I N V O L)$

CS5 (J) $=$ (INVOL $* S 5) /($ ALML $(S)+I N V O L)$

CS6 $(J)=($ INVOL $\$ 6) /($ ALML $(J)+I N V O L)$

C37 $(J)=($ INVOL $\star S 7$ ) $/($ ALML $(S)+I N V O L)$

CSB (J) a (INVOL $* S B) /($ ALML $(J)+I N V O L)$

I $1(\mathrm{~J})=\mathrm{F} 1 * \mathrm{CN}(\mathrm{J})$

$15(J)=F 2 \star B U F F C P(s)$

I3 $3(\mathrm{~J})=\mathrm{F} 3 \star \mathrm{BU}$ UFCR $(\mathrm{J})$

$I 4(J)=F 4 * C S 4(J)$

$I S(\mathrm{~J})=F 5 * C S 5(\mathrm{~J})$

$16(\mathrm{~J})=\mathrm{F} 6 * \mathrm{CS} 6(\mathrm{~J})$

$17(\mathrm{~J})=\mathrm{FT} * \mathrm{CST}(\mathrm{J})$ 


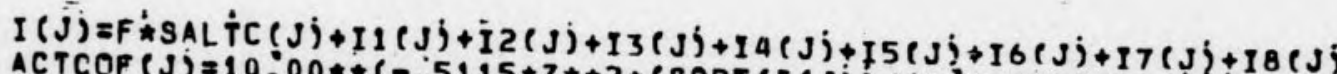

$+j)$,

$\operatorname{ACTIV}(J)=S A L T C(J) * A C T C O F(J)$

LACTIVES) =ALOGIOCACTIV(J)S

WRITE (JOUT, 35 ) SALTC (J), I (J),ACTCOF (J)

35 FORMAT (E15:4,E18,4,E25,4)

20 WRITE (JOUT : 36) ACTIVCJ),LACTIVEJj,PCJ)

36 FORMATCE15:4,EI0:4,E25:411)

CALL LINFITCLACTIV:P,N,INT,SINT,SLDPE, SSLOPE,̈R广

WRITE (JOUT,904)

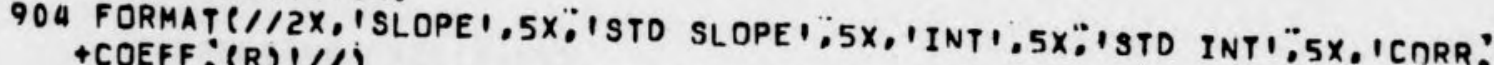
(COEFF, (R) 1/1')

WRITE (JOUT,905) SLOPE,"SSLOPE, INT ISINT, R

905 FORMATCFB:2,F11,2,F13,2,F7:2,F15:7

WRITE (JOUT.50)

50 FORMAT(I DONE? YES(1), NO(O)1/;

CALL FREE (DATA,1)

$L=O A T A(1)$

IF (L;EQ. 1$) G 0$ TO 70

GD TO 3

70 CONTINUE

STOP

n

END 
APPENDIX C

Fortran IV Subroutine Program FREE

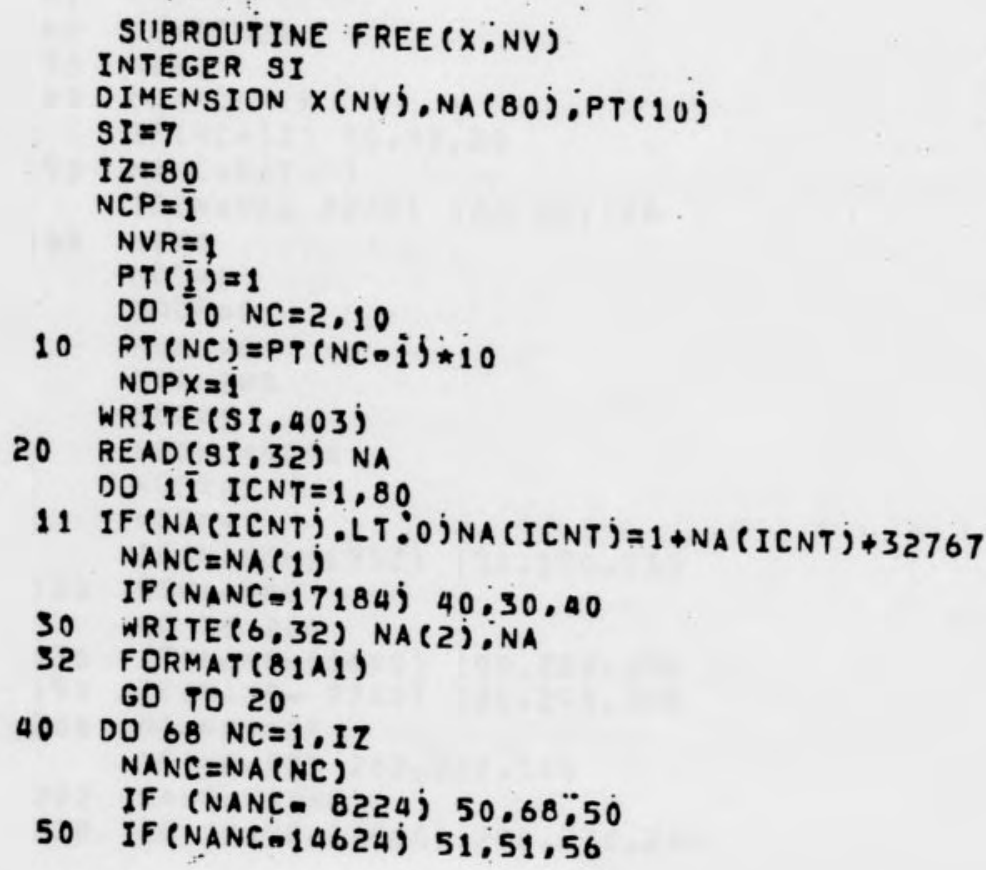




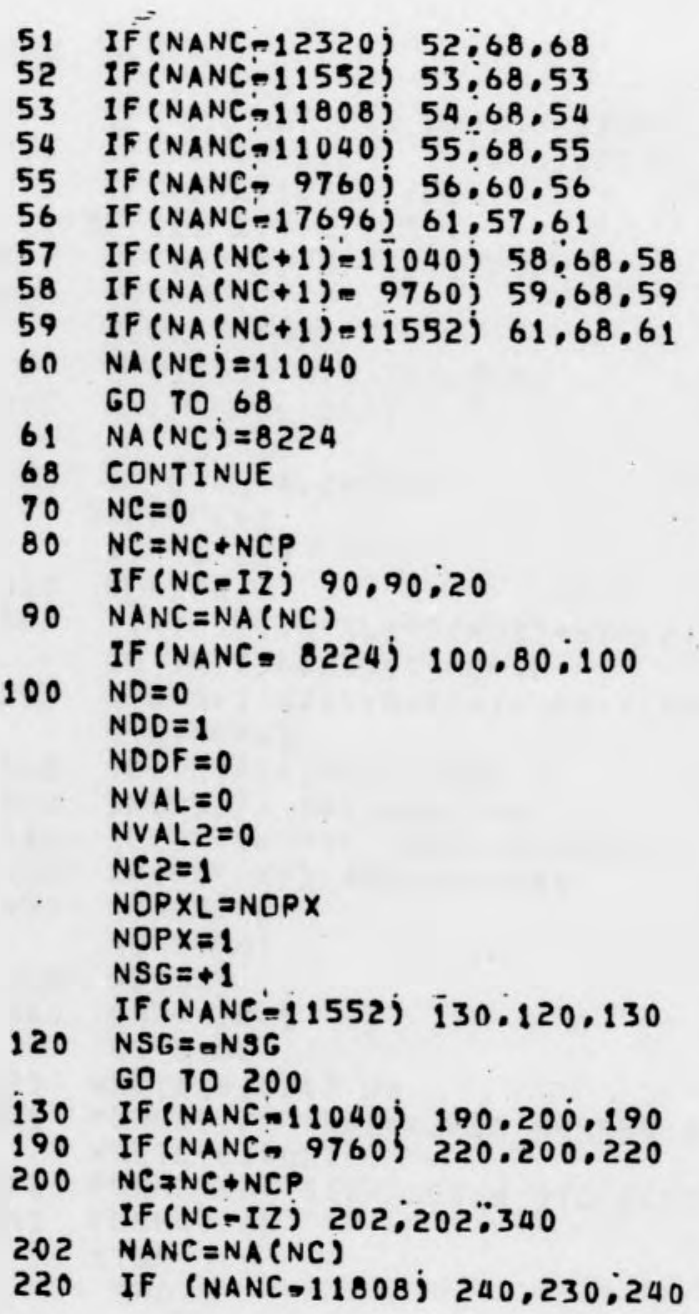

220 If (NANC $=11808$; 240,$230 ; 240$ 


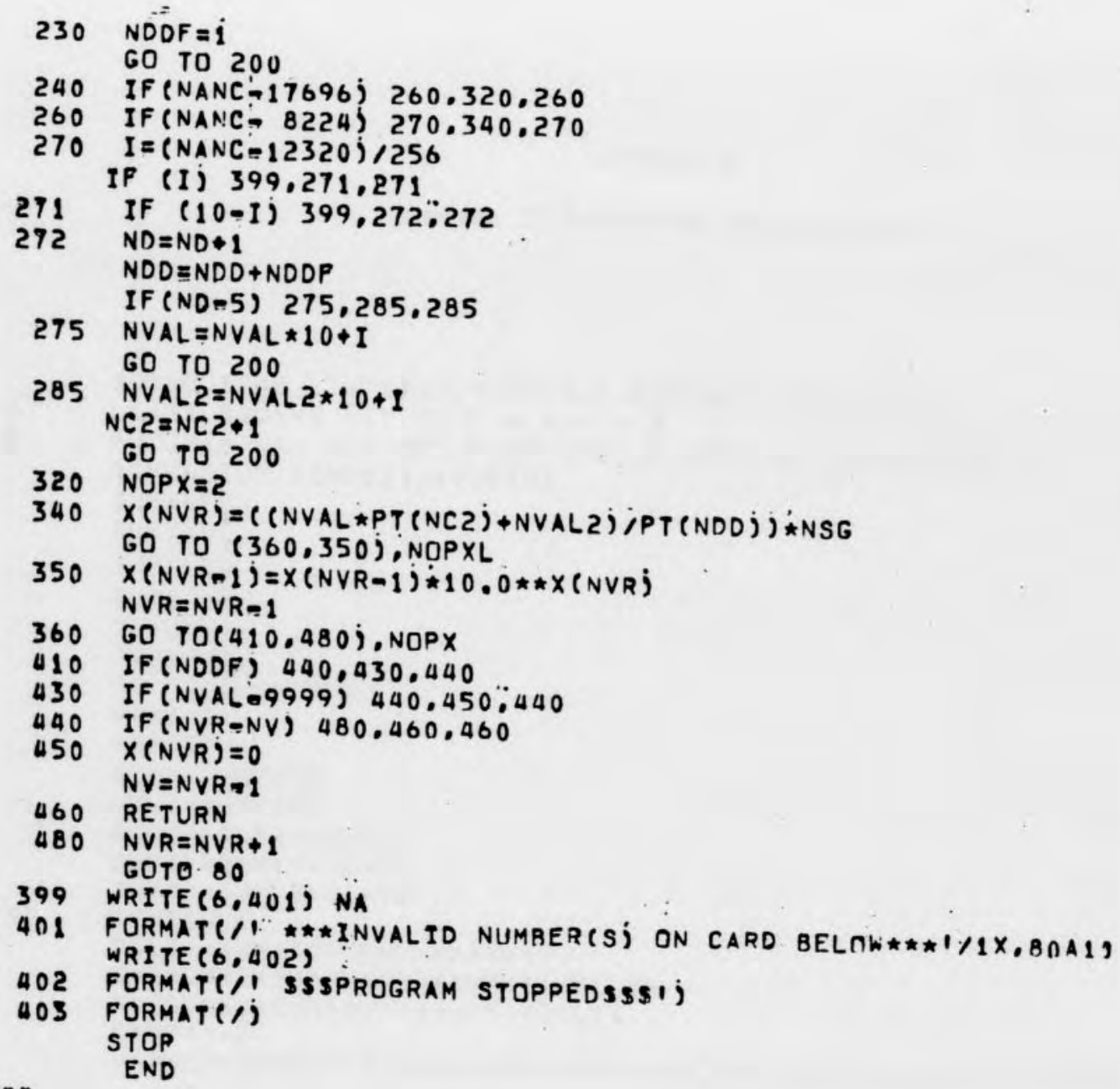


APPENDIX D

Fortran IV Subroutine Program IINFIT

C SUBROUTINE LINFIT $(X, Y, N P T S$; $B$,SIGMAB,A,SIGMAA,R)

C DRT SQUARE FIT TO $Y=A \# X+B$

PRDGRAM WAS ADAPTED FORM ONE IN TEXT BY BEVINGTON SIMMENSION $X$ (NPTS),Y (NPTS)

SUM $=$ NPTS

SUMX $=0$;

SUMY $=0$ ?

SUMX2 =0:

SUMXY $=0$,

SUMYZ =0

DO $50 \quad I=1$, NPTS

$X I=X(I)$

$Y I=Y(I)$

SUMX $=S U M X+X I$

$S U M Y=S U M Y+Y I$

SUMXZ $=$ SUM $X 2 \pitchfork X I * X I$

SUMXY $=S U M X Y+X I * Y I$

SUMYZ $=S U M Y Z * Y I * Y I$

50 CONTINUE

$D E L T A=S U M * S U M X 2-S U M X * S U M X$

$B=($ SUMX $2 *$ SUMY $-S U M X * S U M X Y) / D E L T A$

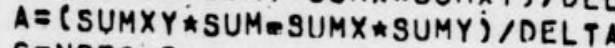

$C=N P T S-2$

VARNCE $=(S U M Y Z+B \star B \star S U M+A \star A \star S U M \times 2-2: \star(B \star S U M Y * A \star S U M \times Y-B \star A \star S U M X) ; / C$ 
SIGMAB $=$ SART $(V A R N C E \star S I J M \times 2 / O E L T A)$

SIGMAAISORT (VARNCE $\$$ SUM/DELTA)

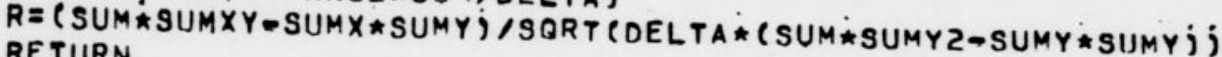

RETURN

n

END 